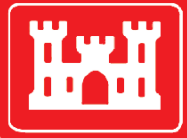

US Army Corps of Engineers ${ }_{\circledast}$ Engineer Research and Development Center

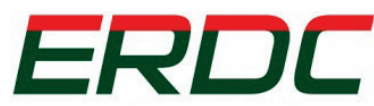

INNOVATIVE SOLUTIONS for a safer, better world

\title{
Bonneville First Powerhouse ERDC Turbine Operating Range Investigation
}

Robert A. Davidson

May 2017

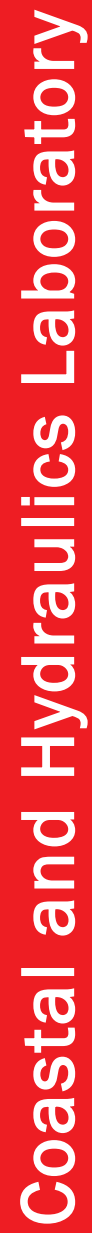

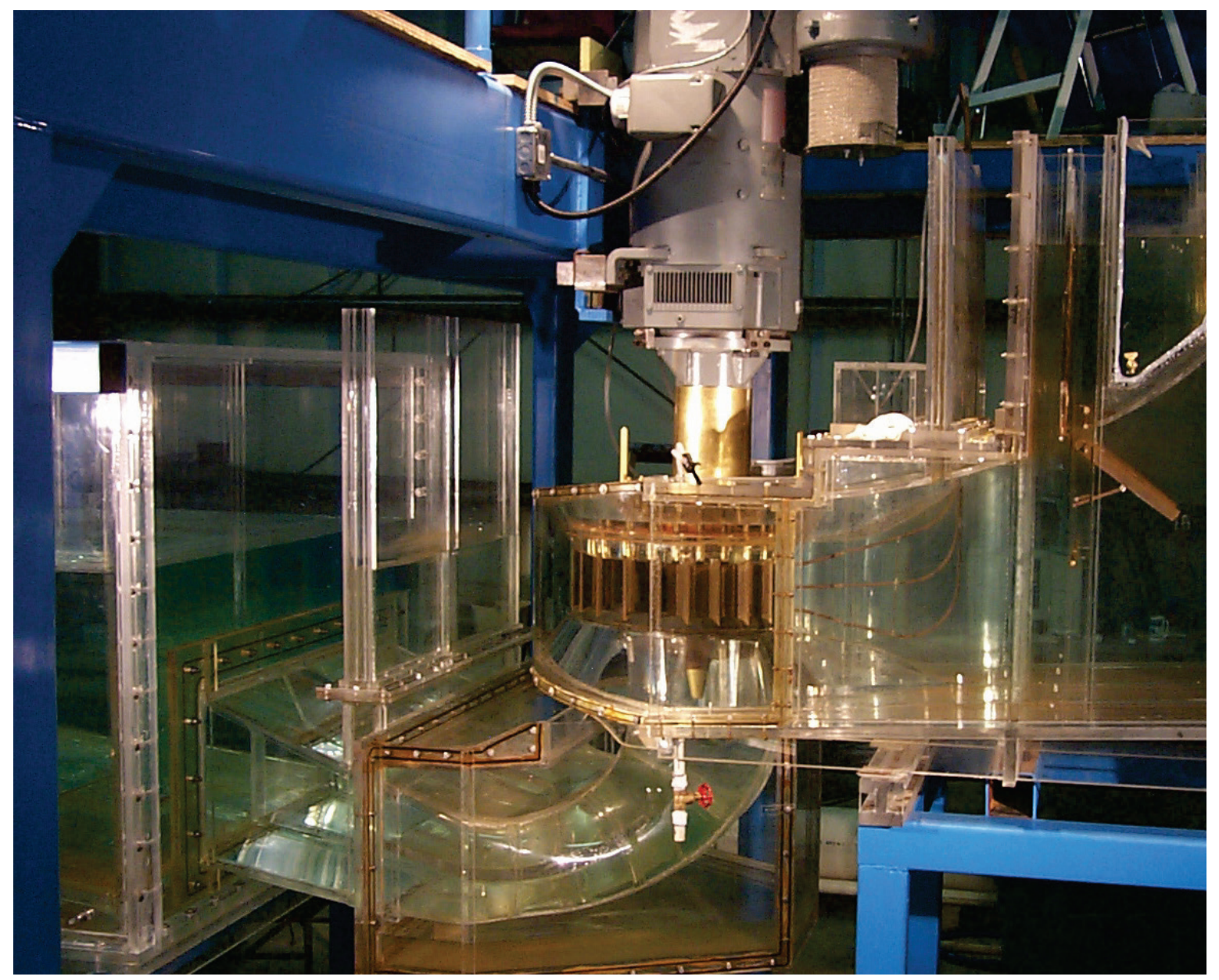


The U.S. Army Engineer Research and Development Center (ERDC) solves the nation's toughest engineering and environmental challenges. ERDC develops innovative solutions in civil and military engineering, geospatial sciences, water resources, and environmental sciences for the Army, the Department of Defense, civilian agencies, and our nation's public good. Find out more at www.erdc.usace.army.mil.

To search for other technical reports published by ERDC, visit the ERDC online library at http://acwc.sdp.sirsi.net/client/default. 
May 2017

\title{
Bonneville First Powerhouse ERDC Turbine Operating Range Investigation
}

\author{
Robert A. Davidson \\ Coastal and Hydraulics Laboratory \\ U.S. Army Engineer Research and Development Center \\ 3909 Halls Ferry Road \\ Vicksburg, MS 39180-6199
}

Final report

Approved for public release; distribution is unlimited.

Prepared for U.S. Army Corps of Engineers, Portland District 333 SW First Ave.

Portland, OR 97204-3440

Under Project Number 26480A, "CRFM-SYS TURB BIO INDEX TEST” 


\section{Abstract}

As part of the Turbine Survival Program implemented by U.S. Army Corps of Engineers, Portland and Walla Walla Districts in the Northwestern Division, this study investigates all potential fish passage routes through the Bonneville First Powerhouse (B1), minimum gap runner (MGR), and draft tube using a 1:25 physical turbine model. Fish passage at on-cam turbine operations is investigated throughout the complete operating range of the B1 MGR to help determine the target operating range for minimizing turbine effects on fish passing through the B1 powerhouse. Relative effects of blade contact, shear, stay vane and wicket passage, draft tube conditions, and effects on egress were determined across the entire turbine operational range at $55 \mathrm{ft}$ head. This includes operation within and beyond the current $1 \%$ operating zone. Results from these model investigations indicate that that steeper blade angles (BAs) (if operated at peak efficiency for that subject blade angle) provide for better passage conditions for fish. Fewer severe contacts with the turbine runner and less severe change in direction occur at steeper BAs. The draft tube elbow performs better at steeper BAs, and the quality of flow exiting the draft tube is better at steeper BAs. In addition, there are indications that egress conditions may be better at steeper BAs.

DISCLAIMER: The contents of this report are not to be used for advertising, publication, or promotional purposes. Citation of trade names does not constitute an official endorsement or approval of the use of such commercial products. All product names and trademarks cited are the property of their respective owners. The findings of this report are not to be construed as an official Department of the Army position unless so designated by other authorized documents. 


\section{Contents}

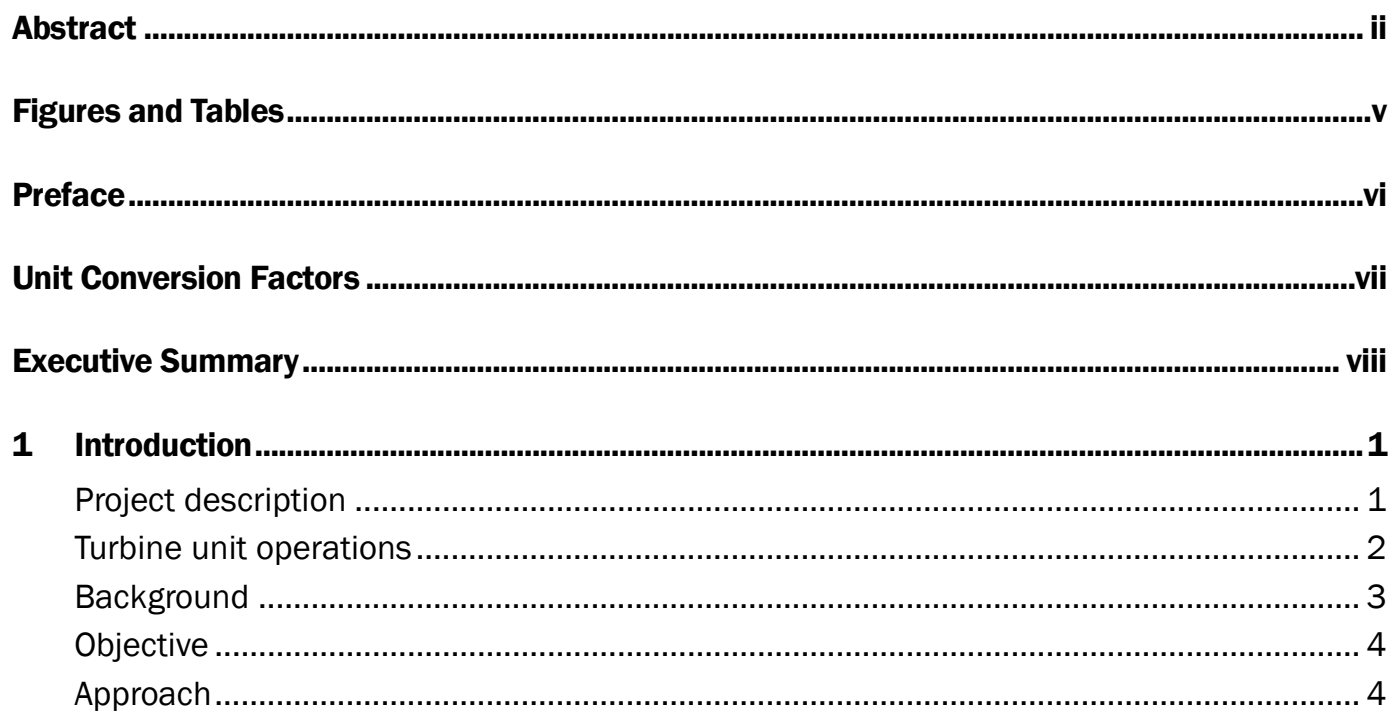

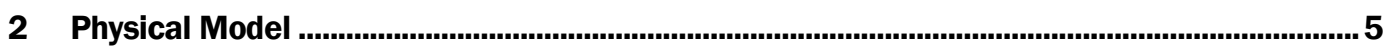

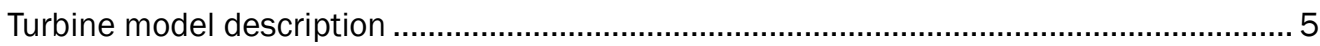

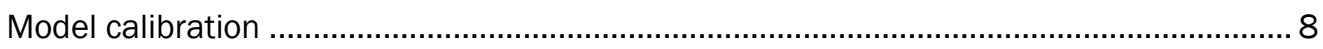

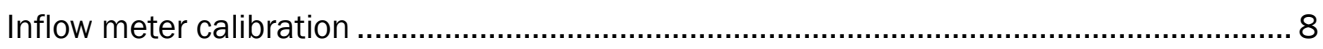

Wicket gate calibration ....................................................................................... 9

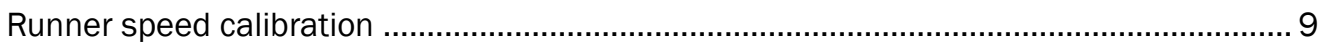

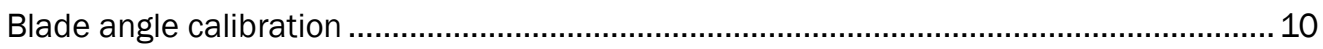

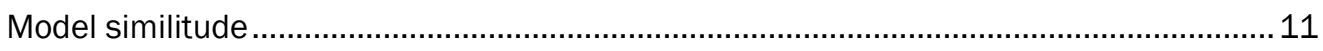

Model operation procedure ......................................................................................... 11

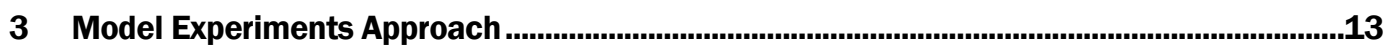

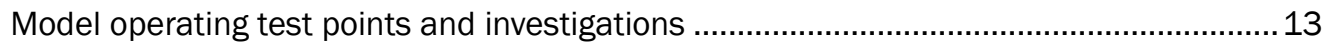

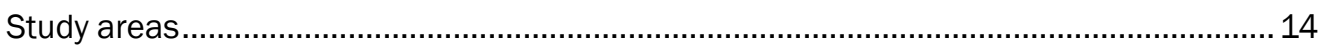

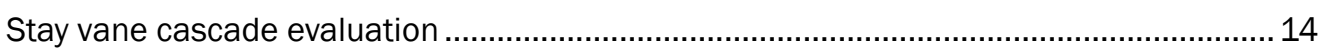

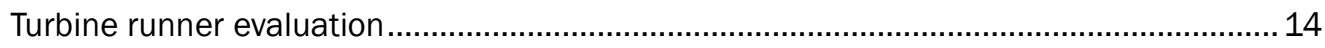

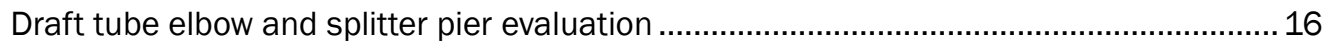

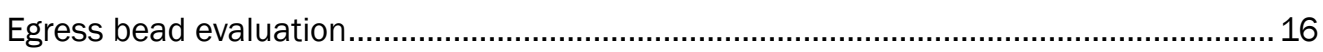

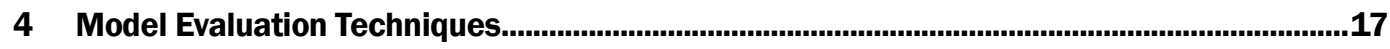

Data acquisition with Laser Doppler Velocity (LDV) meter.................................................. 17

Data acquisition and analysis with neutrally buoyant beads .......................................... 18

Test bead sample size ............................................................................................ 20

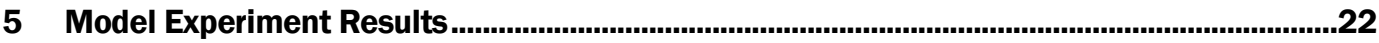

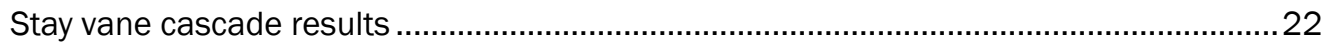

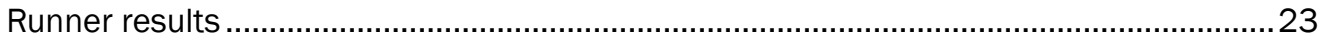

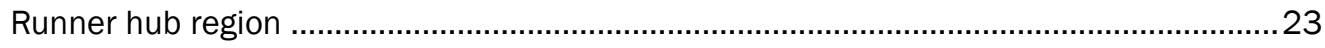

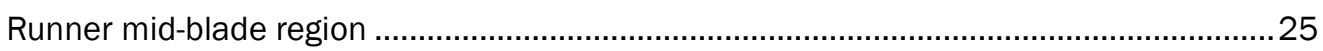




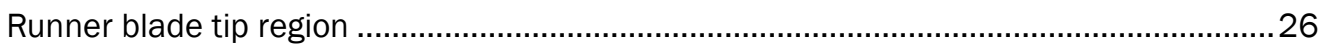

Runner all regions combined...................................................................................... 28

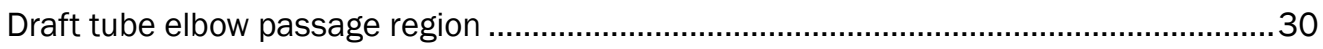

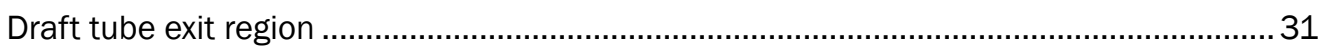

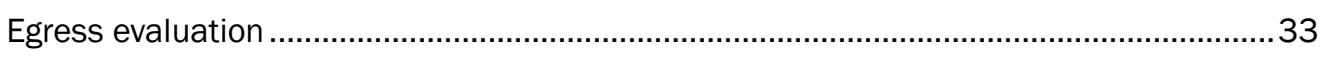

6 Conclusions and Recommendations ......................................................................................35

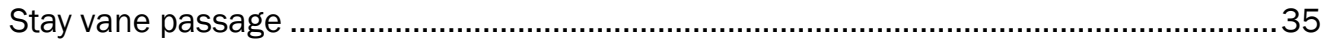

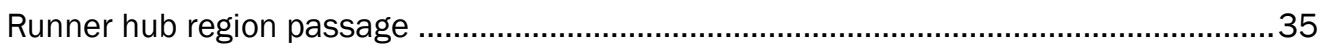

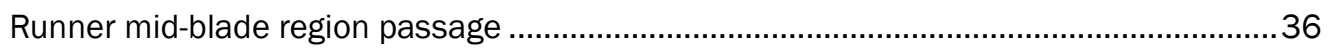

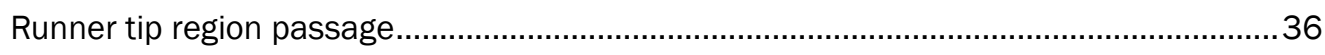

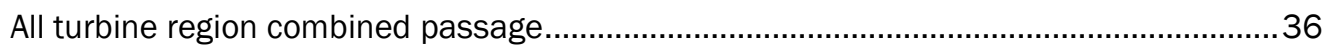

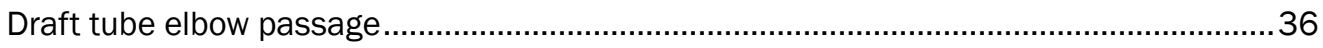

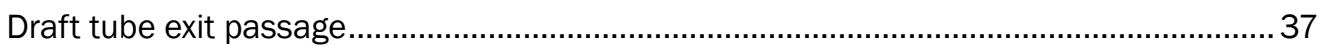

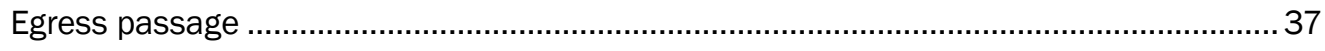

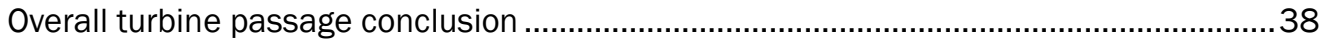

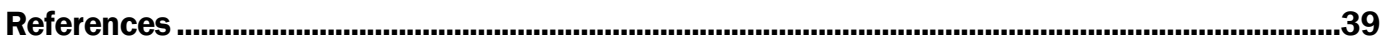

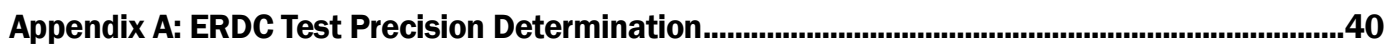

Report Documentation Page 


\section{Figures and Tables}

\section{Figures}

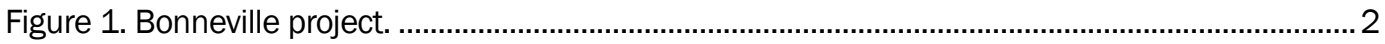

Figure 2. Project location map.................................................................................................. 2

Figure 3. Overall view of model, looking upstream........................................................................ 5

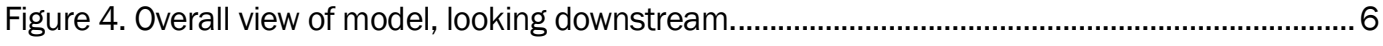

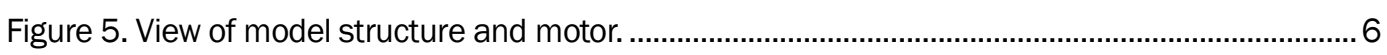

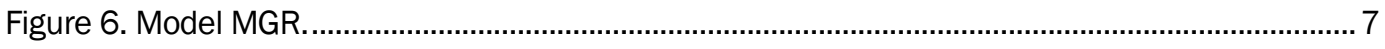

Figure 7. Scribed marking of blade calibration. .............................................................................10

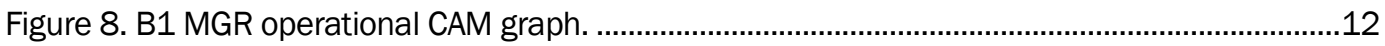

Figure 9. Wicket-gate to stay-vane gap definition..........................................................................15

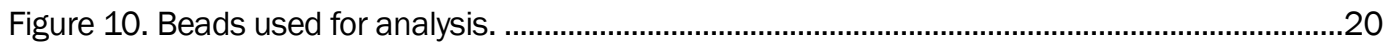

\section{Tables}

Table 1. Equations of hydraulic similitude. .................................................................................1

Table 2. Operational test points. .......................................................................................................... 


\section{Preface}

This study was conducted for the U.S. Army Corps of Engineers, Portland District, under Turbine Survival Program, Project Number 26480A, "CRFM-SYS TURB BIO INDEX TEST." The technical monitor was Mr. Martin L. Ahmann (CENWW-EC-H).

The work was performed by the Navigation Branch, Fish Passage Group of the Navigation Division (CEERD-HNN-F), U.S. Army Engineer Research and Development Center, Coastal and Hydraulics Laboratory (ERDCCHL). At the time of publication, Mr. Timothy W. Shelton was Chief, CEERD-HNN; Dr. Jackie S. Pettway was Chief, CEERD-HN; and Mr. W. Jeff Lillycrop, CEERD-HZT, was the Technical Director for Civil Works.

Mr. Jeffrey R. Eckstein was the Deputy Director of ERDC-CHL, and the Director was Mr. José E. Sánchez.

The experimental program was led by Ms. D. M. Guimbolot-Polk, Ms. P. Van Norman, and Mr. M. P. Thomas under the direct supervision of Mr. R. A. Davidson, Leader Fish Passage Group. Mr. Jon Renholds, U.S. Army Engineer District, Walla Walla (NWW); Ms. Laurie Ebner, U.S. Army Engineer District, Portland (NWP); Mr. Jon Rerecich, U.S. Army Engineer District, Portland (NWP); and Mr. Dan Patla U.S. Army Engineer District, Portland, Hydroelectric Design Center (HDC) performed technical peer review of the report.

During the course of the model study, Mr. M. Ahmann, Mr. J. Renholds, Mr. R. Johnson, and Mr. A. Schuff of U.S Army Engineer District, Walla Walla (NWW); Mr. D. Schwartz and Mr. K. Lightner, U.S. Army Engineer District, Portland (NWP); Mr. R. Wittinger and Mr. J. Kiel, U.S. Army Engineer District, Portland, Hydroelectric Design Center (HDC); Mr. G. Fredricks and Mr. E. Myers, National Marine Fisheries Service (NOAA); and Mr. E. Volkman, Bonneville Power Administration (BPA), visited ERDC to observe model operation, review experimental results, and discuss model results.

The Commander of ERDC was COL Bryan S. Green, and the Director was Dr. David W. Pittman. 


\section{Unit Conversion Factors}

\begin{tabular}{|l|l|l|}
\hline Multiply & By & To Obtain \\
\hline cubic feet & 0.02831685 & cubic meters \\
\hline degrees (angle) & 0.01745329 & radians \\
\hline feet & 0.3048 & meters \\
\hline inches & 0.0254 & meters \\
\hline
\end{tabular}




\section{Executive Summary}

As part of the Turbine Survival Program (TSP) implemented by U.S. Army Corps of Engineers (USACE), Portland and Walla Walla Districts in the Northwestern Division, this study investigates all potential fish passage routes through the Bonneville First Powerhouse (B1), minimum gap runner (MGR), and draft tube using a 1:25 physical turbine model. Fish passage at on-cam turbine operations is investigated throughout the complete operating range of the B1 MGR to help determine the target operating range for minimizing turbine effects on fish passing through the B1 powerhouse. Relative effects of blade contact, shear, stay vane and wicket passage, draft tube conditions, and effects on egress were determined across the entire turbine operational range at $55 \mathrm{ft}$ head. This includes operation within and beyond the current $1 \%$ operating zone. Information from this study was used to develop the B1 portion of the TSP Phase II report.

TSP was developed to evaluate juvenile fish passage through turbines with emphasis on identifying turbine structures and operations responsible for fish injury. The first phase (Phase I) of TSP included four main objectives.

- Evaluate and recommend operational criteria to improve the survival of fish passing through Kaplan turbine units.

- Identify the biological design criteria for design of new modifications to the existing turbines.

- Investigate modifications to existing designs that have a potential to increase survival of fish passing through Kaplan turbine units.

- Recommend a course of action for turbine rehabilitation or replacement that incorporates improvements for fish passage survival.

The 2004 TSP Phase I Report identifies turbine passage conditions that may improve juvenile fish survival and suggests the best turbine operating range (TOR) may not coincide with peak efficiency as previously assumed but may better correlate to open turbine geometry.

This Phase II TSP Report provides discussion regarding the best turbine operating conditions for juvenile salmonids passing through turbines of Lower Snake and Lower Columbia River dams. This report also provides recommended guidelines for the operation of turbines at specific projects where adequate data is available. 


\section{Model investigations}

The model investigations were divided into study areas identified by region. These regions were stay vane and wicket gate cascade region, runner region, draft tube elbow region, tailrace region (egress), and the draft tube exit region.

The model investigations were primarily performed for five operating points at $55 \mathrm{ft}$ of head. These operating points corresponded to the lower $1 \%$, peak efficiency and the upper $1 \%$, the turbine operating limit (TOL) and a point between TOL and the upper $1 \%$ at $55 \mathrm{ft}$ of head.

Neutrally buoyant beads were released within the intake at numerous locations, and their trek was documented through the stay vane and wicket gate cascade, runner, draft tube elbow, and tailrace region using highspeed cameras. Frames rates between 120 and 1000 frames/sec were utilized depending on the region being studied. Beads were evaluated for surface contact and sudden changes in direction (shear) as well as resident time durations in the tailrace. In addition, laser Doppler velocity measurements were obtained within the draft tube near its exit.

Results from this model investigations indicate that that steeper blade angles (BAs) (if operated at peak efficiency for that subject blade angle) provide for better passage conditions for fish. Fewer severe contacts with the turbine runner and less severe change in direction occur at steeper BAs. The draft tube elbow performs better at steeper BAs, and the quality of flow exiting the draft tube is better at steeper BAs. In addition, there are indications that egress conditions may be better at steeper BAs.

The flatter BAs of $16.5^{\circ}$ and $17.5^{\circ}$ should be avoided during juvenile fish passage season if possible. From this model evaluation, the TOR for fish would be from $22.4^{\circ}$ to $31^{\circ}$ BA with the best operating point being at $22.4^{\circ}$. The $22.4^{\circ}$ blade is at the upper limit on the $1 \%$ operating zone. This TOR is also supported by some field studies. However, additional pressure information is needed to fine tune the upper end of the recommended TOR.

Turbine passage pressure effects and project operations are important factors for a full determination of TOR for fish passage but could not be directly addressed in this study. To fully refine the TOR, these two factors should be explored and combined with the results of this model study. 


\section{Introduction}

In 1995, the U.S. Army Corps of Engineers (USACE) Portland and Walla Walla Districts of the Northwest Division implemented the joint district Turbine Survival Program (TSP). The TSP was established to assess the survival of juvenile salmonids passing through the hydro turbines of the Lower Snake and Columbia Rivers and to evaluate the operations and potential modifications to the turbine units for improved fish passage survival (USACE 2004, 2013). In 1997, the Portland District contracted to Voith Siemens Hydro Power Generation Inc. (Voith Siemens) for the design and installation of a replacement turbine at the Bonneville First Powerhouse (B1) on the Lower Columbia River. The new turbine runner was designed to minimize the gap between the runner blade and hub and between the blades' tips and discharge ring for most of its operating range. This turbine runner design is referred to as a minimum gap runner (MGR). All 10 units at B1 were replaced from 1998 to 2010. Between November 1999 and January 2000, direct survival tests were conducted at the project comparing one new MGR unit with one original Kaplan runner.

\section{Project description}

Bonneville Dam (Figure 1) is located on the Columbia River at river mile (RM) 146.1, approximately 40 miles east of Portland, OR (Figure 2).

The dam is a multipurpose project that consists of the first and second powerhouses, the old and new navigation locks, and a spillway with a design capacity of 1.6 million $\mathrm{ft} 3 / \mathrm{sec}$. Construction of the first powerhouse, the old navigation lock, and the spillway began in 1933. President Franklin D. Roosevelt dedicated the lock and dam on 28 September 28 1937. The construction of the first powerhouse was completed in 1943. The first powerhouse has 10 units and a flow capacity of approximately 128,000 $\mathrm{ft} 3 / \mathrm{sec}$ and a rated power output of $526,700 \mathrm{~kW}$. The original $\mathrm{B} 1$ runners were designed and manufactured by S. Morgan Smith. Both the original runners and the new MGR units are 280 in. in diameter and rotate at $75 \mathrm{rpm}$. 
Figure 1. Bonneville project.

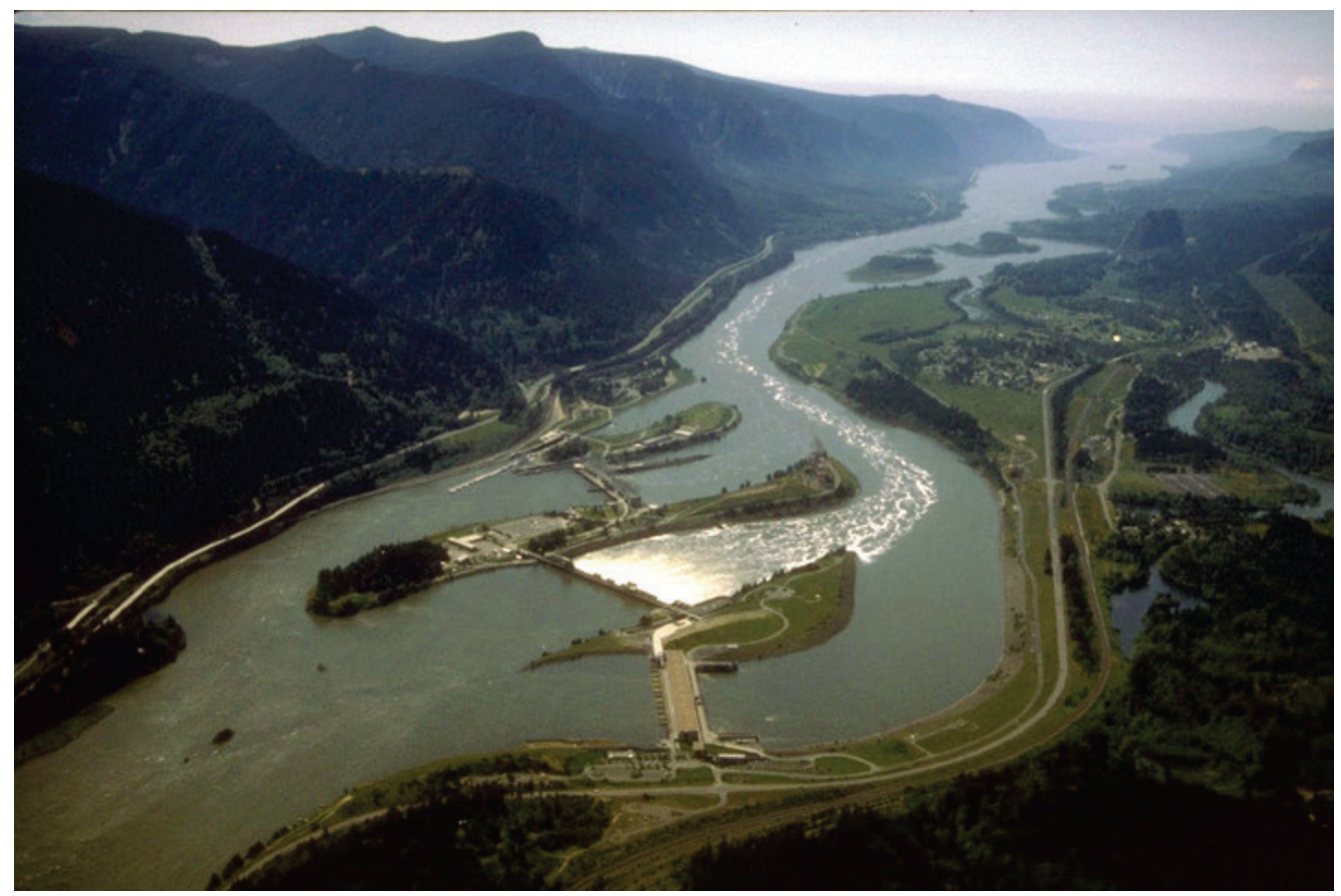

Figure 2. Project location map.

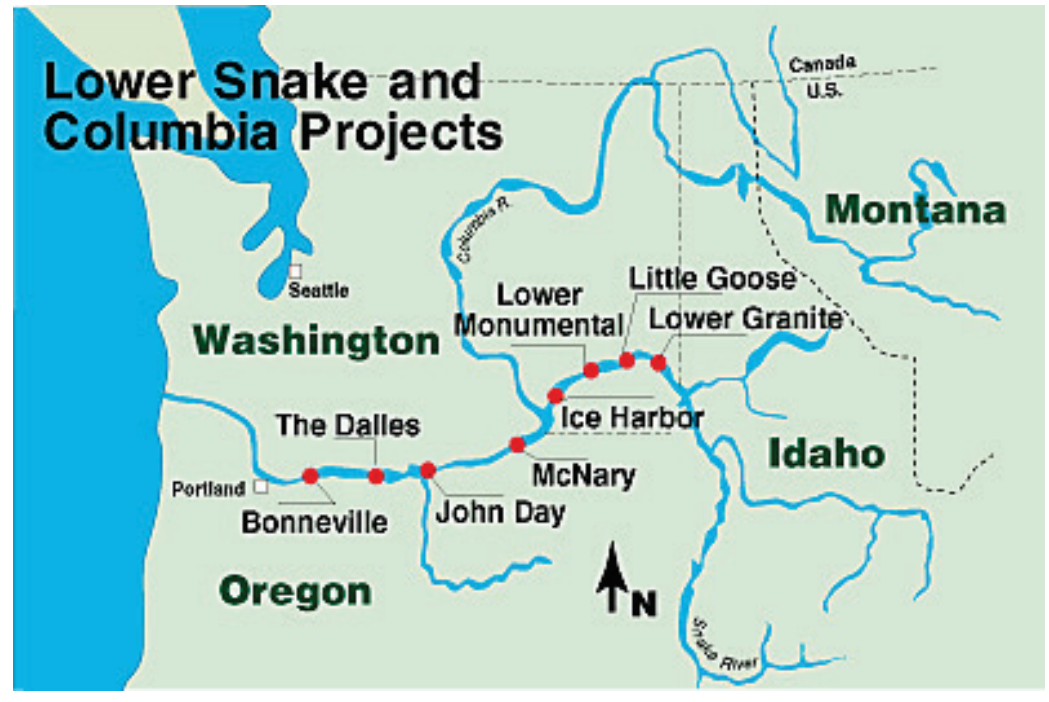

Construction of the second powerhouse began in 1974 and was completed in 1981. The second powerhouse has a flow capacity of approximately $160,000 \mathrm{ft} 3 / \mathrm{sec}$ and a rated power output of $558,200 \mathrm{~kW}$.

\section{Turbine unit operations}

The prototype turbines on the Lower Columbia River USACE projects are presently operated within $1 \%$ of the overall peak efficiency for any head while juvenile salmon are migrating. This is a requirement of National 
Oceanic and Atmospheric Administration (NOAA) Fisheries Biological Opinion (BiOp) (NOAA 2007). This requirement was set in the $2000 \mathrm{BiOp}$ based on research conducted by Bell and Eicher Associates (Bell et al. 1967; Bell 1981, 1986).

\section{Background}

Direct survival tests were conducted at B1 from 1999 to 2000 to compare the existing Kaplan turbine units to the new MGR units. These direct tests consisted of releasing balloon-tagged fish at three specific locations at the stay vane to pass fish through the turbine near the hub, mid-blade, and near the blade tip. The release locations were chosen using an existing 1:25 scale model of the B1 structure that was built in 1995 to investigate improvements to the fish guidance passage system. The model included the intake structure, including the scroll case, stay vane, and wicket gates. The wicket gates were set to a $38.7^{\circ}$ opening for all tests. The model did not include the discharge ring, turbine runner, or draft tube. A new model with operational wicket gates, runner, and draft tube was built to verify the actual path of the fish through the runner. During this determination, poor conditions through the runner for hub passage were observed at low $1 \%$ and peak operating points.

Presently, all turbines are required to operate within $1 \%$ of peak efficiency at any operating head. Based on direct survival tests conducted at the project and model observations, this is probably not the best operating range to minimize the effect of turbines on fish at all projects. Each project should be studied to determine a TOR for minimizing turbine effects on fish and thereby maximizing fish survival. In addition, operating points that should be avoided should be identified as well. There are several things to consider in determining the TOR. Turbine survival is largely dependent on the passage conditions through the powerhouse, overall project operations, and predator abundance downstream of the powerhouse. For turbine passage, direct severe contact with the turbine runner, passing through gaps, passing through high shear zones, and low pressures contribute to direct mortality. Indirect mortality is influenced by the same mechanisms, but in addition, fish experience reduced levels of exposure that result in fish entering the tailrace in a more stressed and disoriented condition. Disoriented and stressed fish in the tailrace may be more susceptible to higher levels of predation as the fish may have greater difficulty in avoiding predators. 
A physical model with an operational runner is an excellent tool to investigate the conditions a fish might experience passing through the powerhouse into the tailrace region. This can be conducted in a controlled environment without disruption to project operations or invasive biological evaluations requiring numerous fish. The investigations can be performed throughout the entire operational range of the runner. This includes operational zones outside the current $1 \%$ operating range. These investigations are used to give a relative comparison of different operating points, hydraulic conditions, and their potential impact on direct and indirect mortality. Every path that a fish may take through the intake, wicket gates, turbine runner, draft tube, and the influence of the passage environment on egress can be evaluated.

\section{Objective}

The purpose of this study was to thoroughly investigate all potential passage routes through the powerhouse main units to assist in determining the TOR for improving fish passage conditions at the Bonneville First Powerhouse. Relative effects of blade contact, shear, stay vane and wicket passage, draft tube conditions, and effects on egress were determined across the entire turbine operational range at $55 \mathrm{ft}$ head. This included operation within and beyond the current operational 1\% zone. Turbine passage pressure effects and project operations are important factors for a full determination of TOR for fish passage but cannot be directly addressed in this study.

\section{Approach}

A physical model was used to fully investigate passage routes through the areas of the powerhouse intake structure where direct fish injury or mortality might occur. This included the stay vane cascade, the turbine runner, and draft tube elbow and draft tube passageway. In addition, the effect of turbine passage on egress conditions in the tailrace was also investigated.

These investigations were conducted throughout the turbine operating range utilizing turbine investigation techniques and methods developed at ERDC. Analysis of results from these investigations allowed for a recommendation of a TOR based on mechanisms contributing to direct injury as well as indirect injury and mortality occurring downstream of powerhouse related to turbine passage. 


\section{Physical Model}

\section{Turbine model description}

The Portland District supplied as-built drawings of the B1 structure and screens. Pertinent information needed for model design and construction were taken from these drawings and transferred into a CAD program.

A new 1:25 scale model of a B1 turbine was constructed at the U.S. Army Engineer Research and Development Center (ERDC) in 2000 and 2001. This model is a geometric replicate of a single powerhouse unit including three intake flow bays, scroll case, stay vane and wicket gate cascade, draft tube, trashracks, screening devices, and vertical barrier screens. The model also replicates approximately $800 \mathrm{ft}$ of approach topography and $300 \mathrm{ft}$ of downstream topography. The model was constructed of acrylic to allow visual observations, turbine evaluation for fish, and hydraulic investigations through the entire structure. Photographs of the new model are provided in Figures $3-5$.

Figure 3. Overall view of model, looking upstream.

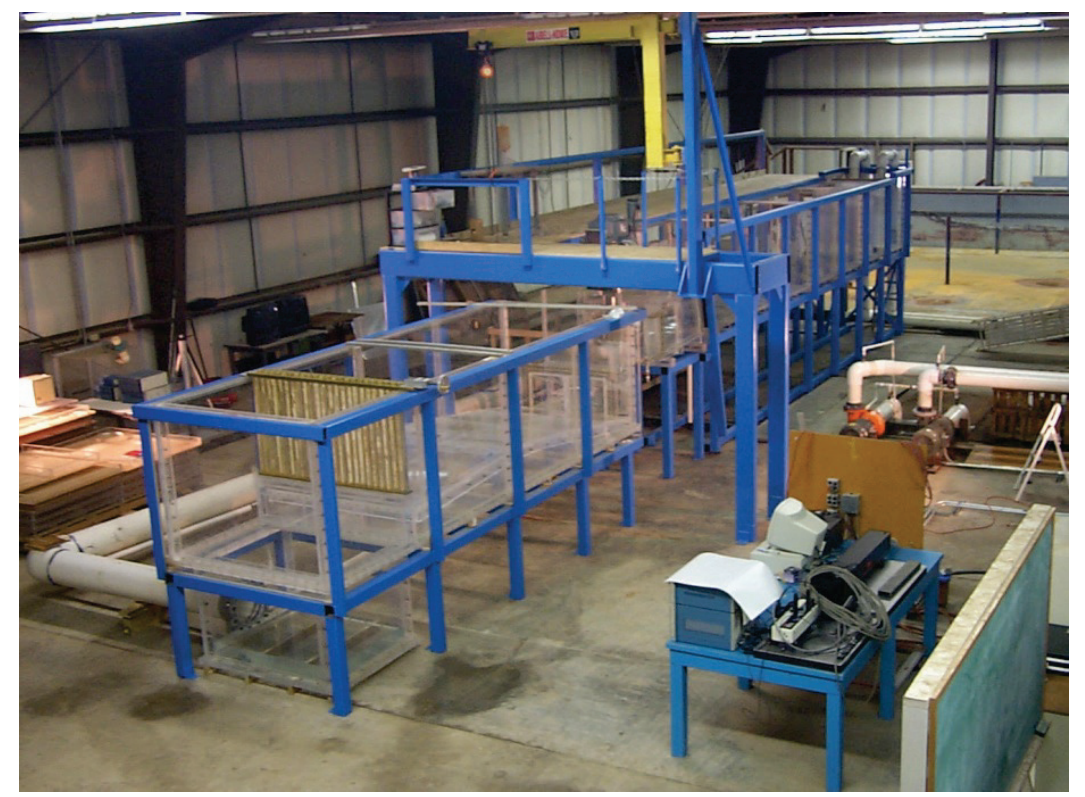


Figure 4. Overall view of model, looking downstream.

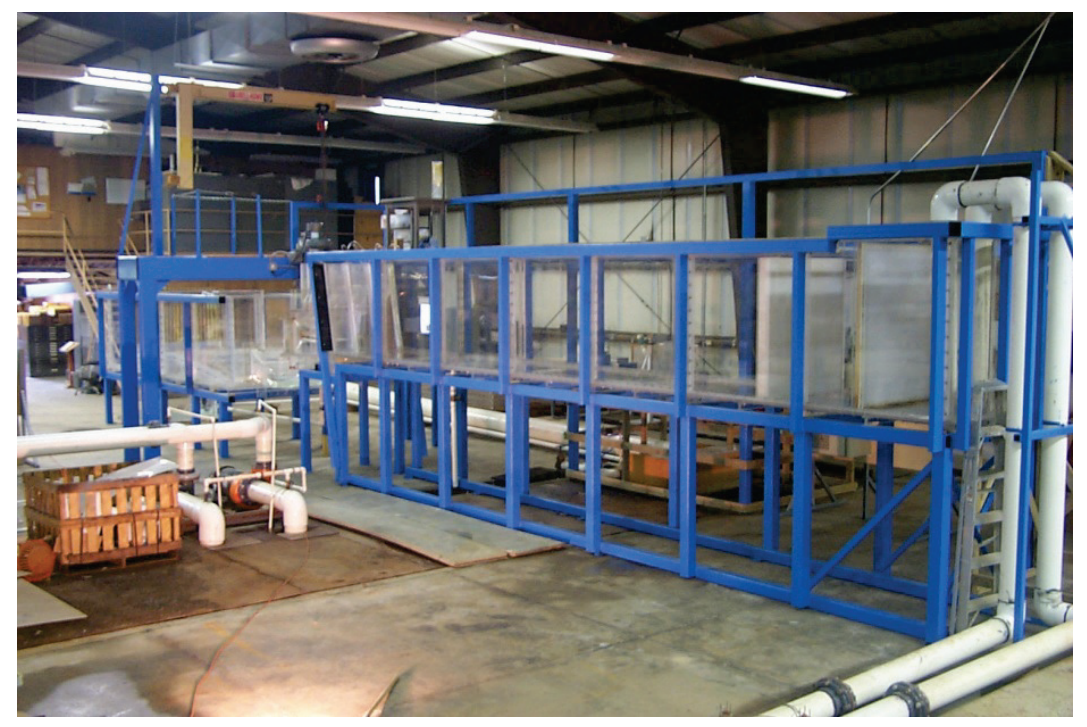

Figure 5. View of model structure and motor.

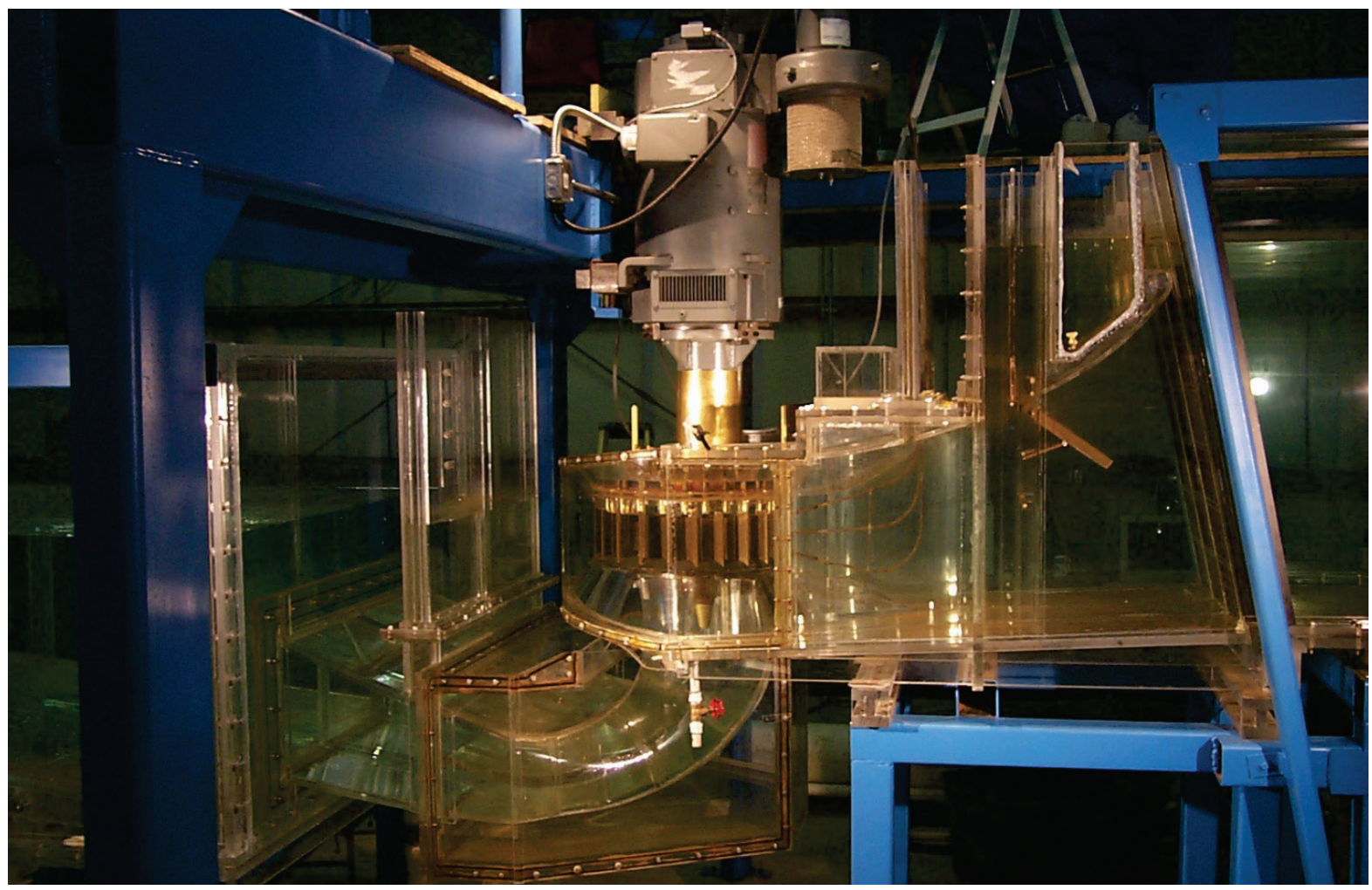

Two five-bladed turbine runners (original and MGR) were constructed by Voith Siemens and delivered to ERDC. Only the MGR was used for this study. The ERDC model was constructed to accommodate either of these turbine runners. A motor and instrumentation to control the speed of the turbine were included with the runners. Figure 6 shows the MGR model runner. 
Figure 6. Model MGR.

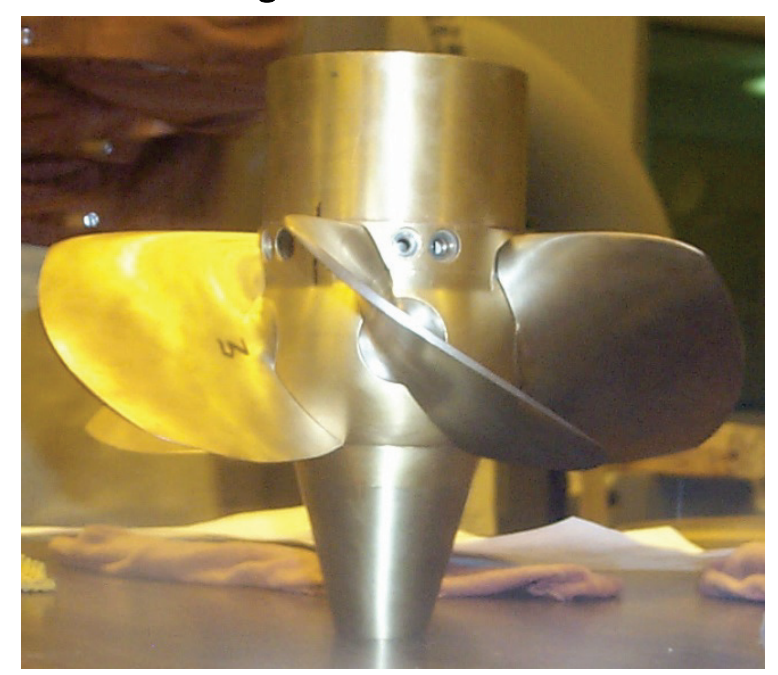

The designs of the standard runner and the MGR were developed from high-head turbine performance models. These models are normally constructed of steel and have very limited visual access to the intake structure, turbine runner area, draft tube, and the tailrace area. In addition, the experiments in the performance model are conducted at high heads, normally $50 \%$ to $70 \%$ of prototype head. This is done to increase the model Reynolds number to allow more accurate head, discharge, and torque measurements. These measurements are required to accurately determine model turbine efficiency. Performance models are constructed of metal (except for the acrylic discharge ring), which does not allow for hydraulic and observational investigations of the entire flow field.

The experiments in the ERDC model were conducted at Froude head. This allows for the entire model to be constructed from acrylic. Accurate hydraulic investigations can be performed anywhere in the flow field. This includes the forebay, intake structure (approach to turbine), stay vane cascade, turbine environment, draft tube, and downstream of the draft exit. Torque is not measured in ERDC turbine models. This is due to the high friction between the runner shaft and runner seals. The operational parameters utilized for the ERDC cam curves are developed in the performance model combined with information obtained from the prototype turbine during field index testing.

Froude modeling more accurately scales screening devices that are used for fish diversion within the intake structure as well as conditions in the draft tube into the tailrace. 


\section{Model calibration}

Calibration of the B1 turbine model requires calibration of the water supply system and the turbine runner control system including control of the wicket gate angle, the runner blade angle, and runner speed. Operation and setting of the model blade angle, gate position, and runner speed are most critical. They are the most well defined and primary operating parameters of the prototype. Because discharge is the least accurate prototype measurement, once the model blade angle, gate position, and runner speed are set, the model discharge can be adjusted as needed to maintain any given project head. An accurate measurement of model discharge can be helpful in assuring that the model turbine runner is operating properly and that the proper prototype cam curves are used in establishing the model test conditions. Discharge information supplied to ERDC for model operation is a calculated value from other measured prototype values such as power and head. Once the model blade angle and wicket gate are set according to the prototype cam curve and the desired project head is reached, the model discharge (which is accurately measured and controlled in the model) should agree with the prototype predicted discharge within $5 \%$. Historically, they normally are within $3 \%$ of each other. Note that often the calculated discharge value supplied to ERDC has error associated with it, requiring extended periods of investigations by Hydroelectric Design Center (HDC) and ERDC to determine more accurate prototype target discharges.

\section{Inflow meter calibration}

Water is supplied to the model by two pumps. Each pump is capable of supplying $9,375 \mathrm{ft} 3 / \mathrm{sec}$ prototype or $3 \mathrm{ft} 3 / \mathrm{sec}$ model scale. This provides a total inflow capacity of approximately $18,750 \mathrm{ft} 3 / \mathrm{sec}$ (prototype), which exceeds the maximum discharge expected at $\mathrm{B} 1$ of $14,000 \mathrm{ft} 3 / \mathrm{sec}$. A Data Industrial flow meter was placed in each inflow supply line to measure the inflow rate. Each flow meter was calibrated in the Coastal and Hydraulic Laboratory (CHL) Volumetric Calibration Flume before it was installed.

Calibration is accomplished by introducing a desired flow into the calibration flume and recording the amount of time needed to fill a known volume. The flow rate is calculated by dividing the flume volume by the time required to fill the flume. This procedure is repeated and the two values are averaged. The resulting value becomes the established flow rate. During the above procedure, the flow is measured by a Data Industrial 
flow meter and this value is recorded. This procedure is repeated for several different inflows. The established flow rates are then plotted against the corresponding Data Industrial-measured values, and a correction factor is applied to the Data Industrial flow meter to give the correct discharge value. Flow calibration curves for the two flow meters are provided in Plates 1 and 2.

The final calibration curves allow for setting the desired model discharge with an accuracy of $1.0 \%$. The r-squared values for each calibration curve varied between 0.9991 and 0.9986 , which proves a very good fit for the calibration data. Calibrations are checked yearly or before a new testing program begins.

\section{Wicket gate calibration}

A regulating ring with graduated marks controls the wicket gate opening. The regulating ring setting-to-wicket gate opening is calibrated by setting the regulating ring to a specified mark and then measuring the channel opening between each pair of wicket gates. The wicket gate channel openings for all channels are averaged and plotted against the regulating ring mark number. This process is repeated incrementally until the full operating range is covered. This information is used to develop a calibration curve for wicket openings versus regulating mark numbers. This calibration curve is provided in Plate 3 .

The final calibration allows for setting the wicket gate opening within $1.1 \%$ of the desired opening. The r-squared value for the calibration curve was 0.999, which proves a very good correlation for the calibration data. The sensitivity of the model regulating ring allows for setting the wicket gate opening to within 0.33 in. prototype or 0.013 in. model scale. The wicket gate angle range for the $\mathrm{B} 1$ model is $\mathrm{O}^{\circ}$ to $61.8^{\circ}$. The accuracy permitted by the regulating ring is $+/-0.5^{\circ}$, which is a maximum error of $1.5 \%$ over the expected operating range.

\section{Runner speed calibration}

The rotational speed of the turbine runner is controlled by a direct current motor/generator. The speed of the runner is verified by a strobe light to ensure the motor speed output is correct. The strobe light emits a pulse of light at a wide range of frequencies, which encompasses the runner speed, with a precision of $0.1 \%$. 


\section{Blade angle calibration}

Voith Siemens supplied the model runner. The B1 model runner can vary between BAs of $16.5^{\circ}$ and $31^{\circ}$. Changing the displacement rod connected to lever arms within the model hub of each runner sets the blade angle. The method Voith Siemens uses for setting the blade angle in their performance model is based on measurements made on the pressure side of the blade in a calibration cradle. Since the runner would have to be removed to perform this calibration, it is not a usable method for the runners in the ERDC model.

Voith Siemens scribed two marks on the runner hub and runner blade trunnions (Figure 7). The marks corresponded to two known BAs. The rod displacement was measured for each of the BAs. To check calibration of the blades in the ERDC model, the marks on the trunnion and the runner hub are matched, and the rod displacement is measured and compared to the Voith Siemens-calibrated measurements. If the marks match, then the runner blades are still calibrated. They have matched each time they have been checked. Voith Siemens calibrated each runner and supplied ERDC with the curves.

Figure 7. Scribed marking of blade calibration.

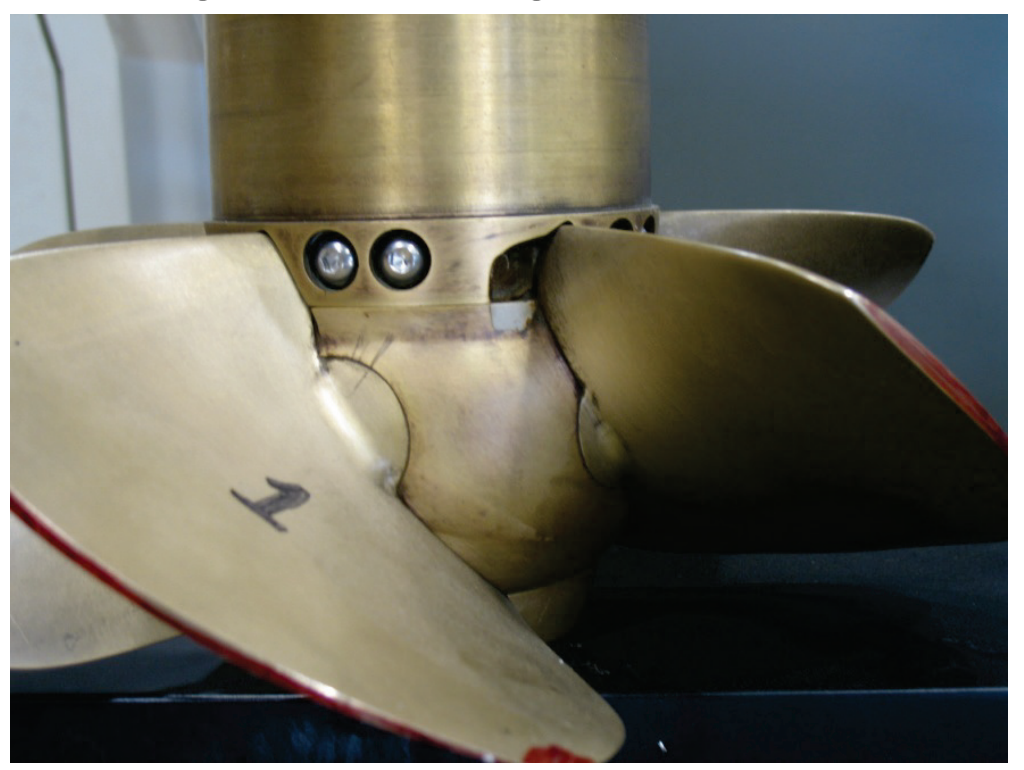

ERDC added additional scribe marks to the hub to allow for calibration points between marks provided by Voith Siemens. The final calibration allows for setting the blade angle within $0.3 \%$ of the desired angle. The rsquared value for the calibration curve was 0.999 , which is a very good fit 
for the calibration data. The calibration curve used during ERDC model experiments is provided in Plate 4.

\section{Model similitude}

Equations of hydraulic similitude, based on the Froudian relations, are used to express mathematical relations between the dimensions and hydraulic quantities of the model and the prototype. General relations for the transfer of model data to prototype equivalents, or vice versa, are presented in Table 1.

Table 1. Equations of hydraulic similitude.

\begin{tabular}{|l|l|l|}
\hline Dimension & Ratio & $\begin{array}{l}\text { Model:Prototype } \\
\text { Scale Relations }\end{array}$ \\
\hline Head & $\mathrm{Lr}=\mathrm{L}$ & $1: 25$ \\
\hline Length & $\mathrm{Lr}=\mathrm{L}$ & $1: 25$ \\
\hline Area & $\mathrm{Ar}=\mathrm{Lr}^{2}$ & $1: 625$ \\
\hline Velocity & $\mathrm{Vr}=\mathrm{Lr}^{1 / 2}$ & $1: 5$ \\
\hline Time & $\mathrm{Tr}=\mathrm{Lr}^{1 / 2}$ & $1: 5$ \\
\hline Discharge & $\mathrm{Qr}=\mathrm{Lr}^{21 / 2}$ & $1: 3125$ \\
\hline Runner speed & $\mathrm{Nr}=1 / \mathrm{Lr}^{1 / 2}$ & $1: 0.2$ \\
\hline
\end{tabular}

Even through the ERDC model is operated according to Froude similitude, Reynolds number similitude is also maintained in the ERDC model within the intake structure, turbine environment, and draft tube. The difference between performance models (Reynolds similitude) and ERDC turbine models is that the Reynolds number is higher in the performance model to minimize frictional resistance. This allows for more accurate determination of model efficiency. Since friction resistance is a very small component for turbine passage hydraulics (with the exception of the power produced), operating the ERDC model at lower Reynolds numbers (still fully turbulent flow) has little effect on the accuracy of the modeling.

\section{Model operation procedure}

The ERDC B1 turbine model is set up by the following procedure. A desired blade angle and wicket gate angle are set, and the inflow discharge is controlled to a desired value. The water elevation in the flume downstream of the draft tube is controlled by a number of vertical wicket gates operated in parallel. When the desired tailrace elevation is set, the discharge is changed until the upstream water surface reaches its desired elevation. The 
discharge, blade angle, headwater elevation, and tailwater elevation will match prototype values. The model discharge is the only variable that does not exactly match the prototype. Note that measurement of discharge through the prototype unit is very difficult. The discharge provided to ERDC for setting the model is a calculated value and thus is not a highly accurate value that is based on both performance model and field-test data. This value has the most uncertainty of any input variable. During the testing of the B1 model, all measured discharges were within $5 \%$, and most were within $3 \%$ of predicted prototype discharge. Also, it is not possible to match every variable because of differences in Reynolds number and roughness between the model and the prototype structures. The blade to wicket gate relationship is the same for a given head for the ERDC model and prototype turbines. Therefore, the difference in discharge for an on-cam point should not affect ERDC model results. This should be true as long as the turbines are operated using a correct cam.

Operational information such as the blade angle, discharge, and wicket opening for 55 and $60 \mathrm{ft}$ of head was supplied by HDC and is based on prototype index tests and high-head model tests (Figure 8).

Figure 8. B1 MGR operational CAM graph.

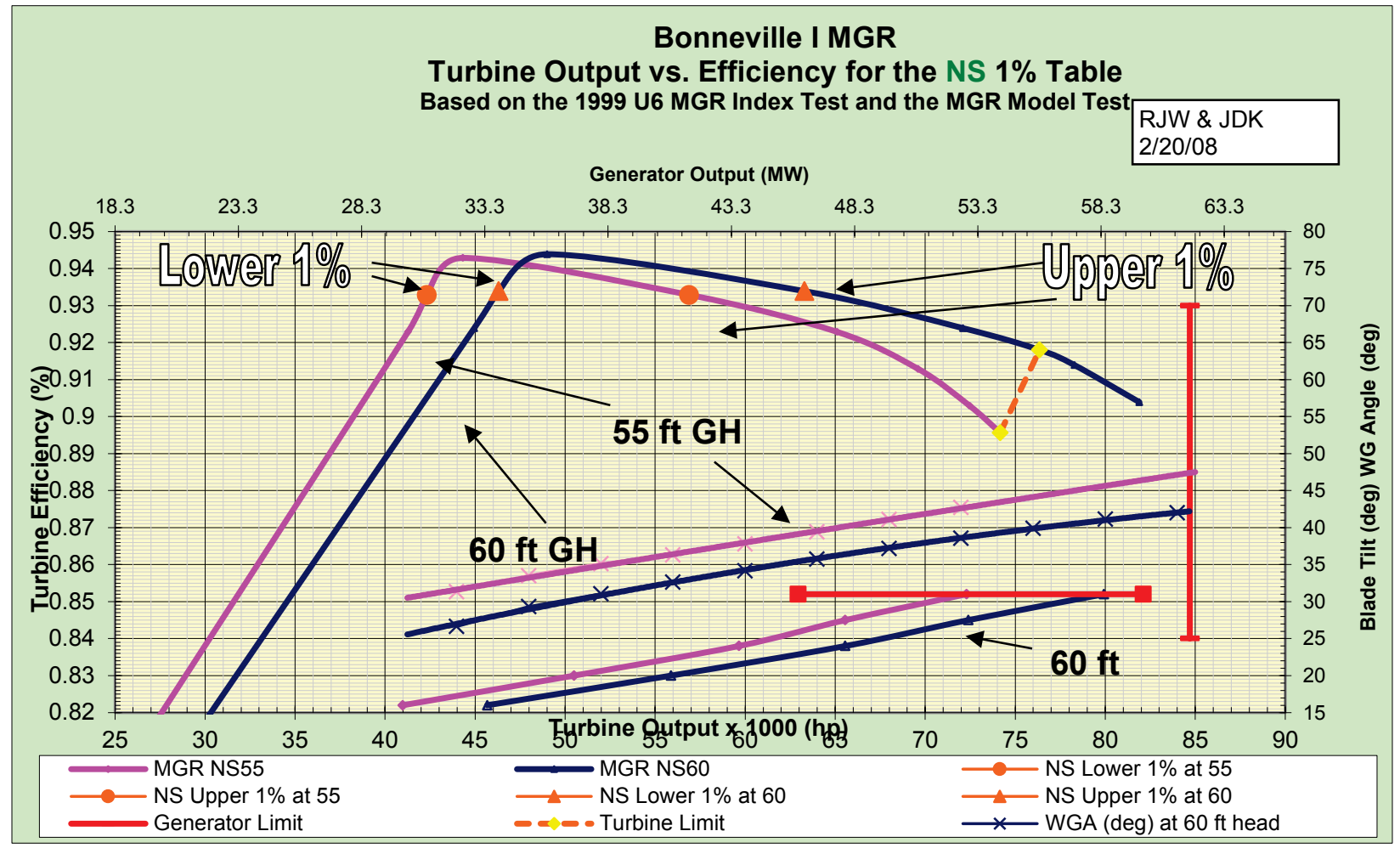




\section{Model Experiments Approach}

\section{Model operating test points and investigations}

Initially, the model investigations were to be performed for three operating points. These operating points corresponded to the lower $1 \%$, peak efficiency, and the upper $1 \%$ at $55 \mathrm{ft}$ of head. At the time of this study, the units were required to operate within $1 \%$ efficiency (off of peak efficiency) During the testing process the testing points were extended to include the TOL and a point between TOL and the upper $1 \%$ while maintaining $55 \mathrm{ft}$ of head. General observations were conducted at $60 \mathrm{ft}$ of head, but no bead data was collected at this head. For $55 \mathrm{ft}$ of head, the forebay was at $72.5 \mathrm{ft}$ at mean sea level (fmsl), and tailwater was at $17.5 \mathrm{fmsl}$ (prototype). For $60 \mathrm{ft}$ of head, the forebay was a $72.5 \mathrm{fmsl}$, and tailwater was at $12.5 \mathrm{fmsl}$ (prototype).The operating parameters supplied by HDC for the model tests are provided in Table 2.

Table 2. Operational test points.

\begin{tabular}{|l|c|c|c|c|}
\hline \multicolumn{1}{|c|}{ Operating Point } & $\begin{array}{c}\text { Blade Angle } \\
\text { (deg) }\end{array}$ & $\begin{array}{c}\text { WG Rotation } \\
\text { (deg) }\end{array}$ & Head (ft) & $\begin{array}{c}\text { Target Discharge } \\
\text { (ft } 3 / \mathbf{s e c})\end{array}$ \\
\hline Lower 1\% (L1\%) & 16.5 & 30.5 & 55 & 7,266 \\
\hline Peak & 17.5 & 31.9 & 55 & 7,529 \\
\hline Upper 1\% (UP1\%) & 22.4 & 36.5 & 55 & 9,768 \\
\hline Above 1\% (AB1\%) & 27.5 & 40.5 & 55 & 11,465 \\
\hline $\begin{array}{l}\text { Turbine operating } \\
\text { limit (TOL) }\end{array}$ & 31 & 43.5 & 55 & 13,248 \\
\hline Lower 1\% (L1\%) & 16.5 & 27.8 & 60 & 7,279 \\
\hline Peak & 17 & 29.5 & 60 & 7,622 \\
\hline Turbine TOL & 29.5 & 40 & 60 & 12,206 \\
\hline
\end{tabular}

All physical hydraulic model investigations were conducted with the $20 \mathrm{ft}$ submerged traveling screens (STS) removed. At the time of this study, the STSs had been removed from the project. The investigations included bead analysis and draft tube velocity measurements. The model was also qualitatively examined with dye. The bead analysis consisted of analyzing high-speed digital imaging of small, neutrally buoyant plastic beads released into the flow path. The digital video was evaluated to determine the exposure of those beads to high shears zones as well as the potential for those beads to impact structure. Laser Doppler Velocimeter (LDV) 
measurements were obtained to define the characteristics of flow within the turbine draft tube barrels.

\section{Study areas}

The model experiments were divided into five parts or study areas identified by region in Plate 5. Part I was to release beads in each intake bay at the screen slot (Plate 6) and to capture their passage trek though the stay vane and wicket gate cascade with high-speed video and then document and analyze each bead for surface contact and sudden changes in direction. Part II was to release beads between stay vane pairs to pass beads through the three zones of the runner (near hub, mid-blade, and near blade tip) for each operating point. The beads paths were imaged with high-speed digital cameras to determine the rate at which beads impact structure and/or experience sudden changes in direction. Part III was to assess passage through the draft tube elbow. Beads were released into the intake (upstream of the turbine) and imaged as they passed through the draft tube elbow. Part IV was to assess turbine operation effect on egress utilizing beads released in the intake and imaging the beads as they exited the draft tube. Part $\mathrm{V}$ was to obtain velocities in the draft tube (near its exit) to determine the quality of draft tube flow.

\section{Stay vane cascade evaluation}

Beads were released in each of the intake bays at various elevations and lateral locations (Plates 6-8). Their passage through the stay vane cascade was imaged with three high-speed digital cameras at a frame rate of 500 frames/sec. A schematic of the stay vane cascade arrangement is shown in Plate 9. Numerous release locations within each intake bay were required to pass beads through the entire stay vane cascade. Each bead was graded for surface contact, sudden change in direction, and for stay vane-towicket gate gap passage (Figure 9). This analysis was performed for three operating points. Stay vane testing was completed before the scope of the ERDC evaluation was changed to include two additional operating points.

\section{Turbine runner evaluation}

Beads were released at the stay vanes to evaluate the impact of the runner. Specific release locations were chosen such that groups of beads would pass through three defined runner zones: near the runner hub, the midblade region, and near the blade tip. Release tubes were secured to the stay 
vanes (as example, near top of the stay vane for hub passage) to ensure consistent release point during bead analysis. Between 350 and 691 beads were released for each of the three runner zones. Beads passing through the runner were videoed using three high-speed cameras at frame rate 1000 frames/sec. One camera was set to image the leading edge of the blade, a second camera to image the pressure and suction side of the blade profile, and the third camera to image the bottom of the blades. All three cameras were time sequenced to each other to ensure that during analysis each individual bead could be identified and evaluated from each camera.

Figure 9. Wicket-gate to stay-vane gap definition.

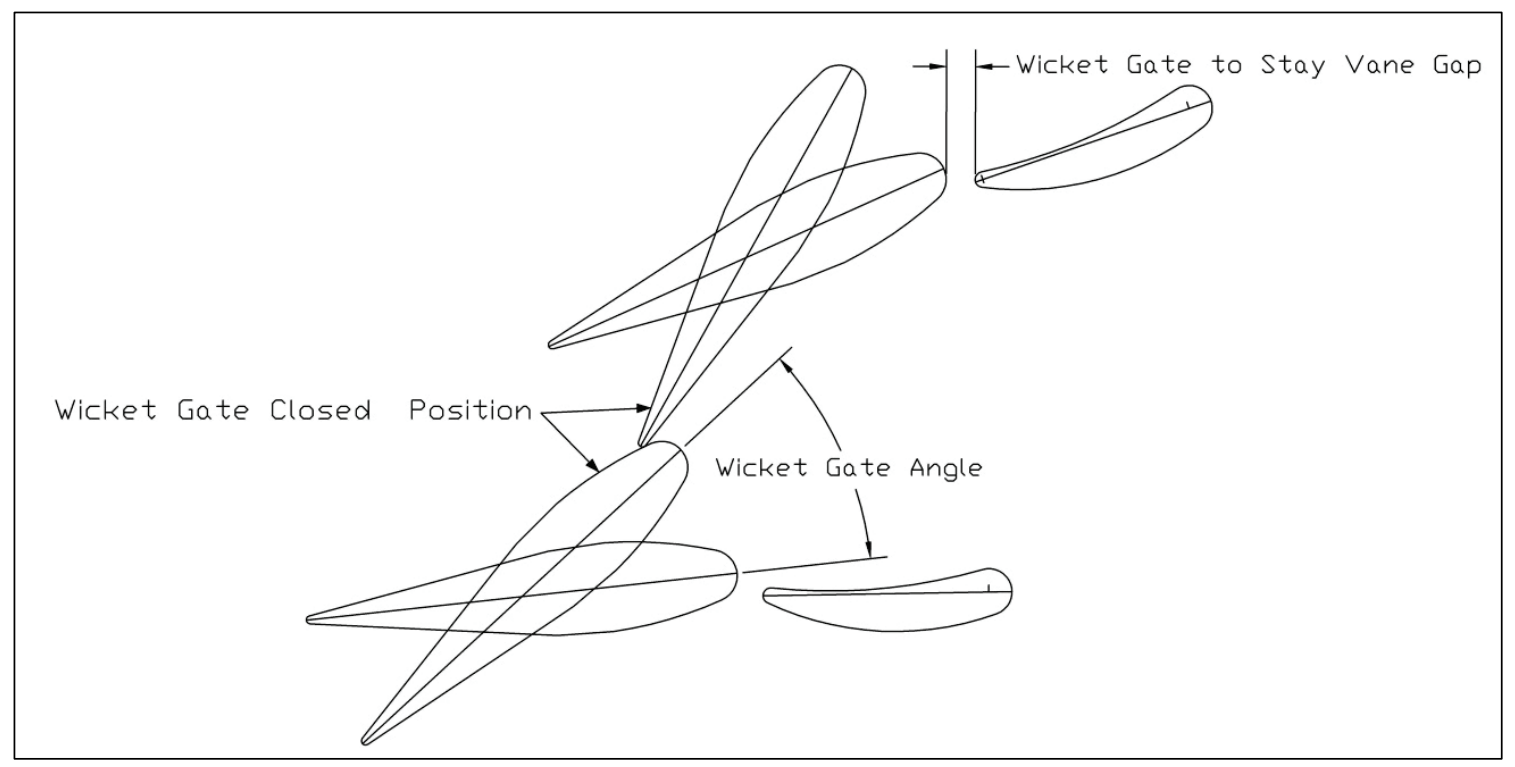

The distribution of fish passing through the prototype runner is unknown, especially when considering the differences in seasonal and diel patterns. Therefore, each passage zone is analyzed independently so that the risk in each passage route is known. Then all passage routes are combined into one data set (at each operating point) and an analysis of all passage routes together is performed. This treats all areas of the turbine equally as potential passage routes.

Assumptions could be made that without screens, more fish would pass near hub to mid-blade zones than the tip passage zone. This is because fish passing through the top to middle of the intake would pass near the top to middle of the distributor if they followed flow lines. However, since fish behavior within the intake and the distribution of fish entering the intake is unknown, the tip passage zone cannot be excluded from the potential fish passage route. 


\section{Draft tube elbow and splitter pier evaluation}

The draft tube elbow is the area below the runner exit where the flow is turned from vertical to horizontal with a $90^{\circ}$ bend along with a flow expansion. At the exit of the draft tube elbow, the Bonneville draft tube has a horizontal splitter pier along with one main vertical splitter pier and several small vertical piers. This draft tube evaluation includes the leading edges of these piers. Neutrally buoyant beads were released at the same locations as used for stay vane evaluation. Multiple release locations were used to give a broad distribution of beads passing through the draft tube elbow. This would be representative of fish having a wide vertical and lateral distribution as they pass through the intake structure, turbine runner, and draft tube elbow. The beads were imaged with three high-speed digital cameras with a rate of 500 frames/sec, and three digital cameras were used for this evaluation. Each bead was graded for surface contact and change in direction in the same manner as the runner bead analysis.

\section{Egress bead evaluation}

Neutrally buoyant beads were released into each turbine intake bay at the same locations as used for stay vane evaluation. Multiple release locations were used to give a broad distribution of beads that would be representative of fish having a wide vertical and lateral distribution as they pass through the intake structure. The beads were filmed with three cameras (120 frames/sec rate) as they exited the draft tube barrels and traveled to location downstream of the influence of the turbine boil (175 prototype $\mathrm{ft}$ ). The general flow path and time of passage was documented. Other parameters, such as entrainment within the backroll and exposure to near surface elevations, were also documented. 


\section{Model Evaluation Techniques}

\section{Data acquisition with Laser Doppler Velocity (LDV) meter}

A four-beam, two-color LDV was used to measure draft tube velocities. This system consisted of a 4-watt Argon laser, optics to split and color separate the laser beam according to precise frequencies of light, fiber optics to carry the light to the model, a fiber probe with a $23.6 \mathrm{in}$. focal length, and signal processors for analyzing the signal from the fiber probe. A computer-controlled traversing system precisely controlled the position of the fiber probe for each velocity measurement. This system measured two components of the flow field within a plane perpendicular to the light beam. The LDV system is a critical non-invasive tool for defining flow distributions, velocity magnitudes and direction, turbulence, and investigations of hydraulic shear.

Velocities were measured at two cross sections in each draft tube barrel. Only the most downstream section is reported. The upstream cross section is used as a quality control for the reported cross section. The reported cross section is 12.6 prototype $\mathrm{ft}$ upstream of the draft tube exit. Plate 10 details the measurement locations. This cross section is in the draft tube as physically close to the draft tube exit where a complete cross section of velocities can be obtained. This is so that the effects of the draft tube exit flow characteristics on egress conditions can be determined.

The velocity data was used to document the flow split between the two draft tube barrels as well as provide a barrel turbulence intensity value for each barrel and the uniformity of flow within and exiting each draft tube barrel. They are defined as

$$
\begin{gathered}
\text { Draft Tube Turbulence Intensity }=\frac{\text { Average Section Standard Deviation of Velocities }}{\text { Average Section MeanVelocity }} * 100 \\
\text { DraftUniformity }=\frac{\text { Standard Deviation of SectionVelocities }}{\text { Average Section MeanVelocity }} * 100
\end{gathered}
$$

This information is used to indicate where it would better to operate the turbine to provide better quality of flow within the draft tube. A higher level of turbulence and shear in the draft tube increases the potential for fish to become disoriented and is likely to increase stress levels in the fish. 
Both of these metrics potentially have a negative effect on indirect survival rates. In addition, the more uniform the flow exiting the draft tube, the more turbulence is reduced and the better the chance the fish will be released into the tailrace with an overall positive downstream movement. In addition, reverse flow (upstream direction) in the draft tube is undesirable and not optimal for the most benign passage experience.

\section{Data acquisition and analysis with neutrally buoyant beads}

A high-speed digital camera system was used to film neutrally buoyant beads as they passed through the stay-vanes, wicket gate cascade, runner region, and draft tube elbow. This system consists of four monochrome cameras set up to capture images of bead passage at a frame rate of up to 1000 frames/sec with a resolution of 1024 pixels. Because of file size, the maximum film duration is limited to $6 \mathrm{sec}$. Each $6 \mathrm{sec}$ segment will capture the passage of 25 to 50 beads depending on passage route, visible access, and the analysis to be conducted. The film segments are stored in an audio video interleaved (AVI) format.

The passage of beads through the stay vane, wicket gates, runner, and draft tube elbow were captured using the high-speed digital cameras. The beads were individually evaluated in order to identify rate and severity of contacts with surfaces in the flow field. A surface contact grading system was established as follows:

- 1 = Very Severe (direct, hard contact causing a severe change in direction)

- $2=$ Severe (direct contact with change in direction)

- $3=$ Moderate Strike (contact with moderate change in direction)

- 4 = Glancing Strike (makes light contact with surface with little change in direction)

- 5 = Touching (bead travels with slight bump of surface or sliding along surface)

- $6=$ No contact with any surface.

The beads were also individually evaluated for abrupt changes in direction, which might indicate areas of high shear. The grading system for bead change in direction was as follows:

- $1=$ Severe sudden change in direction

- 2 = Moderate sudden change in direction 
- $3=$ Small change in direction

- $4=$ No significant change in direction.

After grading each bead, the contact scores and change-in-direction scores were averaged to obtain an overall score. The percentage of severe contacts (those with a score of 1 and 2) and severe direction changes (those with a score of 1 and 2) were also calculated. The grading of the beads was performed manually by the same technician.

In addition to the contact and change-in-direction score, a product score is also calculated for each bead. The product score is obtained by multiplying the contact score by the change-in-direction score. The product score gives an overall grade for comparing different passage routes as well as different turbine operation points. Once the product score has been obtained for each test bead, all the product scores are summed, and the average of the sum is the overall product score for a particular release.

Beads are not fish and do not behave or react to a stimulus in the flow field. However, fish passing through the stay vane cascade entrance would experience velocities that exceed sustained swim speeds of juvenile salmon (Bell 1986). They would have little control to no control when passing into the runner region where velocities are so high that fish would have no choice but to go with the flow. Beads are excellent tools to indicate and predict contact and/or shear impacts fish might experience passing through these areas. Also, beads are excellent tools to compare one turbine operation to another (relative comparison). The beads are approximately cylindrical in shape, which allows bead rotation to be observed. The length of the beads is $4 \mathrm{in}$. in prototype scale, which is close to the length of a juvenile salmon. Figure 10 show beads used in the analysis.

Fish mortality for turbine-passed fish is comprised of two parts: direct mortality and indirect mortality. Direct mortality is attributed to several mechanisms.

Direct morality is mainly the result of fish contact with the turbine runner, passing through gaps in the stay vane cascade, runner blade gap passage, high area of shear, and low pressure areas within the turbine environment. 
Figure 10. Beads used for analysis.

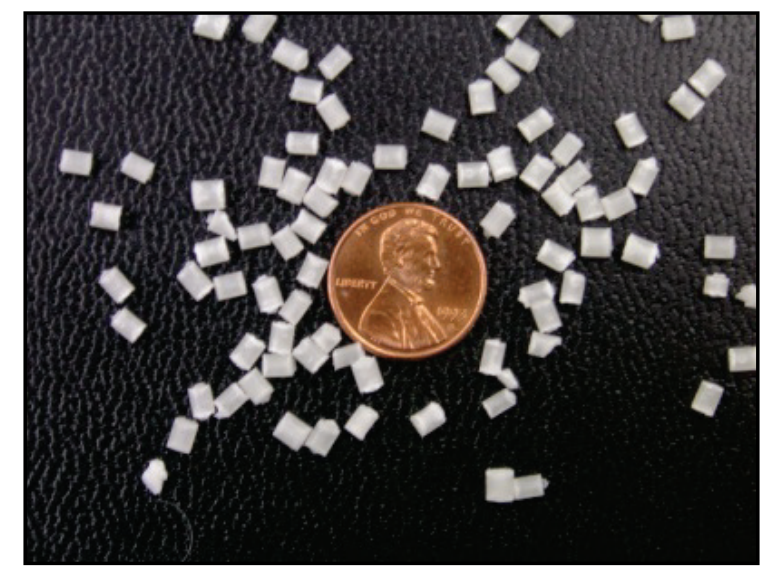

Indirect mortality results mainly from predation downstream of the powerhouse. It is directly influenced by passage through the stay vane cascade, runner passage, draft tube conditions, and where and how the fish are introduced into the tailrace area. It is also influenced by predator abundance, environmental conditions, and project operations.

Bead experiments that evaluate stay vane passage, runner passage, draft quality of flow, and egress investigations allow for the comparison of all passage areas across the entire turbine operational zone. It relatively compares severe contacts and severe changes in direction (high shear), which indicates where it should be better to operate the turbine to minimize risk of direct mortality. However, it also indicates where it is better to operate the turbine to reduce potential stress, disorientation of fish, nonlethal impacts and changes in direction so that the fish are delivered into the tailrace with a better ability to avoid predation. This is not to say that this will eliminate downstream predation, but it should be possible to reduce the downstream predation by operating the turbines as described above. It should be possible to identify the optimal operation range and hydraulic conditions to minimize the potential for strike, shear, and downstream predation applicable to both direct and indirect mortality.

\section{Test bead sample size}

Pre-test determination of bead sample size is determined with the same method as by Normandeau Associates Inc. (2000) for their direct survival tests.

A report entitled Characterization of Sampling Precision and Sample Size Requirements for Bead Strike Trials was prepared for ERDC by 
Dr. John R. Skalski in 2006 (Skalski 2006). This report details the methods used by ERDC to determine sample sizes for all bead evaluations. This method is similar to the methods used in direct-survival balloon tag studies for determining sample size. This report is included in Appendix A.

During ERDC beads experiments, all beads are accounted for, and a control release of beads is not required. The target precision level is between precision level $(\varepsilon)$ of $\leq \pm 0.03 \%$ and $\leq \pm 0.02 \%, 95 \%$ of the time. For the runner evaluation, ERDC uses an expected probability of $12 \%$ (based on previous bead studies). A precision level of $2.5 \%$ would require approximately 650 beads.

For stay vane passage evaluation, an expected event of $12 \%$ was used to determine a bead sample size of 317 beads to obtain $\varepsilon$ of $\leq \pm 0.03 \%, 95 \%$ of the time. The stay vane evaluation requires beads to be released in each of the three intake bays. ERDC released 300 beads in each of the intake bays for a total sample size of 900 beads. 


\section{Model Experiment Results}

\section{Stay vane cascade results}

Approximately 300 beads were released into each intake bay at various elevations and lateral locations. They were filmed as they passed through the stay vane and wicket gate region. The high-speed video was then reviewed, and the individual beads analyzed as discussed above. Results for beads released into all bays were combined into one data set for each of the three operating test points. These operating points corresponded to the peak, upper $1 \%$, and an operating point between the upper $1 \%$ and the TOL (all at $55 \mathrm{ft}$ head). Results for these experiments are provided in tabular format in Plate 11. These three operating points do not cover the entire operation range of the turbine, but they do cover a significant part of the wicket gate rotation range for the B1 MGR runner.

Average bead contact score for the three operating points (Plate 12) was virtually the same (varying from 5.56 to 5.58 ). Higher scores indicate a better passage condition with 6.0 being a perfect score. The percentage of beads experiencing a severe contact (1s and 2s) with a surface was also nearly the same, varying from $3.9 \%$ to $4.1 \%$ with a standard error (SE) between $0.6 \%$ and $0.7 \%$ (Plate 13).

There was no meaningful difference in the average change-in-direction score for the three operating points (3.63 to 3.65). Also, there was not a significant difference in the percentage of beads experiencing a severe change-in-direction score. The percentage of beads observed to exhibit a severe change-in-direction score of 1 varied between 4.1 (SE.0.6\%) to $4.3 \%$ (SE $0.7 \%$ ). The percentage of beads observed to have a sudden change-indirection score of 1 and 2 was lower for $\mathrm{AB} 1 \%$ operating point (11.6\%, SE 1.1\%) compared to stay vane passage at peak (12.1\%, SE 1.1\%). However, the difference is not highly significant. Graphical representations of change-in-direction scores and beads exhibiting a severe change in direction, during stay vane cascade passage, are shown in Plates 14 and 15.

Very little difference in the three operating points is indicated when comparing the product bead score for the three operating points. The product score is obtained by multiplying the contact score by the changein-direction score and is an indication of the overall impact of passage through the stay vane and wicket gate cascade (the higher the score the 
better the passage route). The product scores (Plate 16) varied very little across the evaluated operational range (21.01 to 21.14).

The rate of bead passage through the stay vane and wicket gate gap was also determined for each of the three test conditions identified above. Results are reported as a percentage of the overall number of beads in the data set. The highest gap passage rate occurred at the operating point corresponding to the peak (1.3\%), and the lowest passage rate (0.0\%) occurred at the $\mathrm{AB} 1 \%$ operating point. A graphical representation of stay vane-to-wicket gate passage is shown in Plate 17.

For minimizing gap passage, it would be better to operate at operating points higher than peak efficiency.

\section{Runner results}

Beads were released between the stay vanes to evaluate the impact of the runner for each of the three runner regions per the procedure described previously.

The beads were analyzed according to the procedure outlined previously in this report.

\section{Runner hub region}

Between 650 and 691 beads were released at the stay vanes such that they passed near the hub area of the MGR for each of the five operating points at $55 \mathrm{ft}$ of head. The distribution of beads exiting the runner for all hub releases is provided in Plates 18-22. Bead evaluation results for the hub region in tabular format are shown in Plate 23.

The bead passage contact scores for passage through the runner hub region were lowest (5.68) for operating point corresponding to the L1\% and highest at TOL (5.81). The higher the number is, the better the operating point is for reducing surface contact. Based on ERDC experience, the difference between these two contact scores is somewhat significant. The contact score includes all surface contacts through the runner including minor contacts as well as severe contacts. Contact score for peak was 5.73 (UP1\% 5.74) and 5.80 for the $\mathrm{AB} 1 \%$ operating point. This shows a trend for fewer overall contacts at higher BAs. To reduce overall contacts of juvenile salmon in the hub region, it would be better to operate 
the turbine at higher BAs. A plot of contact scores across the operating range is provided in Plate 24.

The percentage of beads exhibiting a severe contact (1s and 2s) with a surface in the hub area was lowest at TOL (0.3\%, SE 0.2\%) and highest at peak efficiency (1.6\%, SE 0.5\%). At the operating point corresponding to the L1\%, $0.8 \%$ (SE $0.3 \%$ ) of the beads made severe contact with the blade compared to $1.0 \%$ (SE 0.4\%) at peak and 1.5\% (SE 0.5) at AB1\% operating point. For severe contacts, the hub region performs well throughout the operation range but best at the highest blade angle tested (Plate 25).

The change-in-direction score was lower for operating points corresponding to the L1\% and peak compared to the other evaluated operating points (Plate 26). The L1\% score and peak score was 2.91 and 3.00 compared to 3.21 and 3.33 at the two steepest BAs. Higher change-indirection scores are better than lower scores indicating smoother hydraulics with less potential for shear.

The percentage of beads observed to make a severe change in direction (1s) passing through the hub region was much higher at operating points corresponding to the L1\% (12.5\%, SE 1.3\%) and peak efficiency (10.7\%, SE $1.2 \%$ ) compared to the three other evaluated operating points at steeper BAs. The percentage of beads exhibiting a severe change-in-direction score was best at the operating point corresponding to the $\mathrm{AB} 1 \%$ operating point (1.6\%, SE0.5\%). Plate 27 shows the differences across the evaluated operating points. Operating at or above the $1 \%$ operating point would be best to minimize undesirable hydraulic zones for juvenile salmon passing through the hub region. Operating at L1\% or peak efficiency should be avoided to minimize exposure to poor hydraulic conditions fish would encounter in the hub region. Although the distribution of fish entering the turbine is uncertain, without bypass screens in place at the project, a significant number of fish would be expected to pass through this region.

The hub bead passage product score for the upper two evaluated operating points was significantly higher (18.91 and 19.51) compared to L1\% and peak operating points (16.88 and 17.53). Higher scores are better and indicate better operating points to operate for fish. Plate 28 graphically shows the difference across the evaluated operational points. These product scores indicate that a much better operational zone for fish passing near the hub would be at and above the UP1\% operating point 
(steeper BAs), and operating at flatter BAs should be avoided. Values of 16.88 and 17.53 are low values for a classical Kaplan (with gaps) and are unexpectedly low for a MGR.

\section{Runner mid-blade region}

Beads were released at the entrance to the stay vane cascade resulting in runner mid-blade region passage. The release was positioned at a mid-stay vane height between the stay vanes and positioned to ensure that there was no bead contact with any stay vanes or wicket gates. The distribution on beads exiting the runner for each operating point is shown in Plates 29-33. Fewer beads were released for the mid-blade evaluation than for the hub or tip regions of the runner. This is because mid-blade region is expected to be a better passage route than the blade tip or hub region (based on ERDC experience on other runner evaluations) resulting in lower blade surface contact and lower incidences of severe changes in direction. This allows for releasing fewer beads to obtain the same precision as other passage routes with higher expected runner interactions. Initially, 500 beads was the targeted sample size. This sample size was used for three operating points. Based on results from the evaluations of these operating points, the sample size was reduced to 350 beads for the two other operating points. Plate 34 shows the results for the mid-blade region including sample size and precision obtained at each operating point.

Contact scores for beads passing through the mid-blade runner region were highest at the two steepest BAs (5.96 and 5.95) and lowest for two flatter blades angles corresponding to the low $1 \%$ and peak operating points (5.86 and 5.86). Higher contact scores are better and indicate fewer contacts with the runner. The contact score for the upper $1 \%$ was 5.92 . These scores indicate that for the mid-blade region, it is better to operate at steeper BAs to reduce overall contacts of beads (fish) with the blade surface. A graphical representation of the contact score through the evaluated operation points is provided in Plate 35 .

Percentage of severe bead contacts (1s and 2s) with the runner in the midblade region was highest at the operating points corresponding to the low $1 \%(1.7 \%$, SE $0.7 \%)$ and peak efficiency (1.8\%, SE 0.6\%) and lowest at the operating point $\mathrm{AB} 1 \%$ (0.2\%, SE $0.2 \%)$. Percent of severe bead contacts was $1.2 \%$ (SE $0.5 \%$ ) at the upper $1 \%$ operating point and $0.6 \%$ (SE $0.4 \%$ ) at the TOL. This data indicates that it is better to operate at steeper BAs to reduce the potential for fish encountering a severe contact with the runner 
blade at the mid-blade region. Operation at flatter BAs increases the potential for severe contact with the runner blade in the mid-blade region. Although the distribution of fish passing through the runner is unknown, a significant percentage of fish passing through the runner would be expected to pass through the mid-blade region. This would be expected with or without screens in place. A plot of the percentage of severe contacts versus blade angle is shown in Plate 36.

Change-in-direction scores for the mid-blade region (Plate 37) was highest at the operating point corresponding to the $\mathrm{L} 1 \%$ (3.51) and the $\mathrm{AB} 1 \%$ operating point (3.46.) The change-in-direction score was lowest at upper $1 \%$ (3.39). The change-in-direction score at peak was 3.43 and 3.44 at TOL. This data indicates that when slight (3s), moderate-to-severe (2s), and severe changes (1s) in directions are all combined, a trend to operating in a particular operating zone could not be identified.

The percentage of beads experiencing a severe change in direction (1s) was lowest for the $\mathrm{AB} 1 \%$ operating point between $0.2 \%$ (SE $0.2 \%$ ) and TOL (0.6\%, SE 0.4\%). The operating points with the highest percentage of changes in direction occurred at peak efficiency (2.0\%, SE 0.6\%) and L1\% (1.7\%, SE 0.7\%). This data indicates that it is better to operate at steeper BAs to reduce the percentage of beads (fish) experiencing a severe change in direction in the mid-blade region. Operating at flatter blades angles increases the potential for fish to experience a severe change in direction (high shear) in the mid-blade region. A graphical representation of percentage of beads with severe changes in direction for beads passing through the mid-blade region is provided in Plate 38.

Product score for the mid-blade region did not differ significantly throughout the operating points that were evaluated. The product score was highest at the low 1\% (20.85) and lowest at the upper 1\% (20.24). A graphical representation of the product scores for beads passing through the mid-blade region is provided in Plate 39.

\section{Runner blade tip region}

Between 649 and 700 beads were released at the stay vanes (bottom of stay vanes) such that they passed through the runner blade tip region of the MGR for each of the five operating points at $55 \mathrm{ft}$ of head. The release points were positioned between pairs of stay vanes to ensure that there was no contact with stay vanes or wicket gates and as close to the invert of 
the stay ring as possible. The distribution on beads exiting the runner for each operating point in the tip region is shown in Plates 40-44. Also, the bead evaluation results for the tip region are shown in Plate 45 .

For beads passing through the blade tip region, contact scores were highest for BAs of $22.4^{\circ}\left(5.83\right.$ at U1\%) and the steepest blade angle of $31^{\circ}$ (5.82 at TOL). The lowest contact scores for the tip region occurred at the flattest blade angle of $16^{\circ}$ (5.61 at L1\%, 5.69 at peak) and at a blade angle of $27.5^{\circ}$. This data indicates that when considering all contacts in the blade tip region it is better to avoid operating the units at the flat BAs of $16.5^{\circ}$ and $17.5^{\circ}$ and would be better to operate near the U1\% (22.4 $\left.{ }^{\circ} \mathrm{BA}\right)$. A graphical representation of the contact scores for the blade tip passage region is provided in Plate 46.

The percentage of beads observed encountering a severe contact with the blade in the tip region was highest at the flatter BAs of $16.5^{\circ}$ and $17.5^{\circ}$, $3.9 \%$ (SE $0.8 \%$ ) at the L1\% operating point, and 3.7\% (SE 0.7\%) at peak. Passage through this region was much better at the three steeper BAs with the percentage of severe contacts varying between 1.3\% (SE 0.4\%) and 1.1\% (SE 0.4\%). A graphical representation of the percentage of beads having a severe surface contact through the blade tip region is provided in Plate 47. The bead passage evaluation indicates that steeper BAs provide fewer opportunities for fish to make severe contacts with the runner blade in the blade tip region. It also indicates that flatter BAs should be avoided to reduce risk of fish injury due to direct contact with the runner blades in this region.

Change-in-direction scores for the tip region (Plate 48) were nearly the same for blades angles between $16^{\circ}$ and $27.5^{\circ}$ varying between 3.08 and 3.15. The change-in-direction score was highest (3.34) at the steepest blade angle of $31^{\circ}$. Higher change-in-direction scores are indicators of better relative overall passage conditions within the subject passage region.

Percentage of beads observed to make a sudden change in direction (1s) decreased when the blade angle was increased (Plate 49). This was true throughout the operational zone investigated. At the flattest BAs $\left(16.5^{\circ}\right.$ and $17.5^{\circ}$ ), the percentage of beads encountering a sudden change in direction was 6.5\% (SE 1.0\%) at L1\% and 5.0 \% (SE 0.8\%) at peak. At the two steepest BAs, the percentage of beads experiencing a sudden change in 
direction was 4.3\% (SE 0.8\%) and 3.4\% (SE 0.7\%). This evaluation indicates that in order to improve fish passage conditions at the tip region, the turbine should be operated at steeper BAs, and the flat BAs of $16.5^{\circ}$ and $17.5^{\circ}$ should be avoided.

Product scores calculated for the tip passage region (Plate 50) were lowest for the $16.5^{\circ}(17.74)$ and $22.7^{\circ}(17.77)$ blade angle compared to 18.76 at $17.5^{\circ}$ blade angle and were highest for the steepest blade angle of $31^{\circ}$ (19.73). The difference between a product score of 17.74 and 19.73 indicates an overall better passage operational point for the tip region for the steepest blade angle. The product scores reflects all contacts and all changes in direction including all minor contacts and minor changes in direction. Based on ERDC experience, product scores of 17 to 18 are not abnormally low for the tip passage region, and scores of 19 to 20 would be considered high scores for classical Kaplans with blade tip gaps. However, 17 to 18 are lower values than expected for a MGR runner.

The lateral and depth distribution of fish approaching the B1 powerhouse is uncertain. Seasonal and diel changes affect fish distribution as well project operations. In addition, fish redistribution within the intake structure probably occurs as fish react to hydraulic conditions in the intake before entering the runner. Thus, the distribution of fish passing through the runner region is unknown. However, without screens in place, fewer fish would be expected to pass through the blade tip region compared to the hub and mid-blade region.

\section{Runner all regions combined}

Bead data for hub, mid-blade, and blade tip passage routes were combined into one data set per operating point. Performing a data analysis on all the beads from all three passage routes together provides a good indication of passage conditions through the runner, assuming all passage zones are weighted equally. This allows for comparison of the operating points throughout the potential operation of the MGR and will indicate where the turbine should be operated as well as operating points to avoid, minimizing the impacts of the turbine on migrating juvenile salmon. Results for all releases combined are shown in tabular format in Plate 51.

The bead contact score was lowest for $16.5^{\circ}$ blade (5.72) and at a $17.5^{\circ}$ blade angle (5.76). The three steeper BAs contact scores were somewhat higher and varied from 5.81 to 5.86. This indicates that when considering 
all severities of bead contacts with the runner, it is better to operate at steeper BAs. A plot of contact score versus blade angle for all releases combined is shown in Plate 52.

The percentage of severe bead contacts decreased as the runner blade angle was increased (Plate 53). The percentage of severe bead contacts was $2.1 \%$ (SE $0.4 \%$ ) at a $16.5^{\circ} \mathrm{BA}$ and was nearly the same at $17.5^{\circ} \mathrm{BA}(2.4 \%$, SE $0.3 \%$ ). This dropped to $1.2 \%$ (SE $0.2 \%$ ) at a $22.4^{\circ} \mathrm{BA}$ and $0.9 \%$ (SE $0.2 \%$ ) at a $27.5^{\circ} \mathrm{BA}$. The percentage of beads observed to make a severe contact was lowest at the steepest BA of $31^{\circ} \mathrm{S}(0.7 \%, \mathrm{SE} 0.2 \%)$. This indicates that the runner should be operated at steeper BAs to decrease the potential for fish to make a severe contact with the runner blade. Flatter BAs should be avoided if possible.

The bead change-in-direction scores for $16.5^{\circ} \mathrm{BA}$ was 3.16 and 3.19 for the $17.5^{\circ}$ blade angle. It was higher for the $27.5^{\circ} \mathrm{BA}(3.25)$ and highest for $31^{\circ}$ BA (3.37). This indicates a better overall passage condition for steeper BAs (reduced changing in direction) compared to flatter BAs. A graphical representation of change-in-direction scores versus blade for all regions combined is provided in Plate 54 .

Percentage of beads experiencing a severe change in direction was highest for the two flattest BAs (Plate 55). At a $16.5^{\circ} \mathrm{BA}, 6.9 \%$ (SE 0.6\%) beads were observed to experience a higher rate of severe change-in-direction events in the runner region compared to $3.1 \%$ (SE $0.4 \%$ ) at $22.4^{\circ} \mathrm{BA}$ and $2.0 \%$ (SE $0.3 \%$ ) at $27.5^{\circ} \mathrm{BA}$. The number of beads experiencing a sudden change in direction at a $17.5^{\circ} \mathrm{BA}(5.9 \%, \mathrm{SE} 0.5 \%)$ was also significantly higher than the steepest three BAs evaluated. This comparison indicates that the runner should be operated at steeper BAs to reduce impacts of shear on fish passing through the runner region. Flatter BAs should be avoided.

Product scores generally showed an increasing value with an increase in blade angle. $16.5^{\circ}$ blade angle product score was 18.49 compared to 19.09 at $27.5^{\circ} \mathrm{BA}$ and 19.93 at $31^{\circ} \mathrm{BA}$. This indicates a better overall passage conditions at steeper BAs. A plot of the product score for all releases combined is shown in Plate 56. 


\section{Draft tube elbow passage region}

The draft tube elbow is the area below the runner exit where the flow is turned from vertical to horizontal with a $90^{\circ}$ bend along with a flow expansion. At the exit of the draft tube elbow, the Bonneville draft tube has a horizontal splitter pier along with one main vertical splitter pier and several small vertical piers. This draft tube evaluation includes the leading edges of these piers. Between 600 and 900 beads were released at various locations within each of the three intake bays. There beads were tracked with three high-speed digital cameras at 500 frames/sec as they passed through the draft tube elbow. Multiple release locations were used to give a broad distribution of beads passing through the draft tube elbow. This would be representative of fish having a wide vertical and lateral distribution as they pass through the intake structure and turbine runner. Bead evaluations were conducted at five operating points at $55 \mathrm{ft}$ head. Results from draft tube elbow evaluations, provided in tabular format, are shown in Plate 57.

Bead contact scores were lowest for peak operating point (5.63) followed by the L1\% operating point (5.68). The contact score at TOL was 5.70. The highest scores occurred at U1\% (5.76) and AB1\% (5.76) operating points. This indicates that to reduce overall contacts with structure in the draft tube elbow, it would be best to operate between BAs of $22.4^{\circ}$ and $27.5^{\circ}$. A graphical presentation of these results is shown in Plate 58.

The percentage of beads observed to make a severe contact with structure in the draft tube elbow was nearly the same for L1\% (2.3\%, SE 0.6\%), U1\% (2.2\% 0.6\%), and $\mathrm{AB} 1 \%$ (2.2\%, SE 0.5\%). It was highest at peak efficiency (2.7\%, SE 0.7) and 2.4\% (SE 0.6\%) at TOL. The difference among all operating points is not large, but the trend indicates that for minimizing severe contact with draft tube elbow structure, it would be best to operate the turbine runner between blades angles of $22.4^{\circ}$ and $27 \cdot 5^{\circ}$. A graphical presentation of these results is shown in Plate 59.

Change-in-direction scores were lowest at L1\% (3.43) and TOL (3.45) and were highest at $\mathrm{U} 1 \%$ (3.59) and $\mathrm{AB} 1 \%$ (3.63). The score for peak was 3.54. This indicates that when considering all magnitudes of bead direction changes, it is better to operate between $17.5^{\circ}$ and $27.5^{\circ}$ BAs. A graphical presentation of these results is shown in Plate 60. 
The percentage of beads experiencing a severe to moderate change in direction was lowest at $\mathrm{AB} 1 \%(5.7 \%$, SE $0.8 \%)$ and nearly the same for UP1\% (6.0\%, SE 1.0 \%). The percentage was significantly higher at L1\% (9.0\%, SE 1.1\%) and TOL (8.7\%, SE 1.1\%) and was highest at peak (10.0\%, $\mathrm{SE}$ 1.2\%). The change-in-direction scores evaluation recommends an operating range from $17.5^{\circ}$ to $27.5^{\circ} \mathrm{BA}$ to minimize the effect of turbulence and shear on draft tube elbow passage. However, when considering the percentage of beads having a significant change in direction, it would be better to operate the runner with blades angles between $22.4^{\circ}$ and $27.5^{\circ}$. A graphical presentation of these results is shown in Plate 61.

The product score was highest at AB1\% (21.37) and U1\% (21.09) operating points. The product score was lowest for L1\% (19.5) followed by TOL (20.08) and peak (20.5). Higher product scores are an indication of better overall passage conditions. A graphical presentation of these results is provided in Plate 62. This evaluation indicates that for minimizing the effects of passage through the draft tube elbow region, it is best to operate the runner with blade angles between $22.4^{\circ}$ and $27.5^{\circ}$.

While it is not known if passage through the draft tube elbow region results in significant direct mortality, it can influence indirect mortality rates. Velocities are lower in this region (compared to the runner region), and contact with the turbine runner blades would be more severe. However, the more stress in terms of pier nose impact and the turbulence and shear that the fish encounter, the more likely they will pass into the tailrace in a more disoriented and possibly injured condition. This would potentially degrade the fish's ability to avoid predation in the tailrace region after exiting the draft tube. Note that this analysis is based on a broad distribution of intake passage. If the distribution is weighted higher in the intake (more hub to mid-blade passage), the percentage of fish encountering shear and moderate-to-severe changes in direction in the draft tube elbow region will be much higher than what is reported.

\section{Draft tube exit region}

The horizontal velocity components (upstream to downstream) of flow through each draft tube barrel were measured with an LDV system for five operating points at $55 \mathrm{ft}$ head and two operating points at $60 \mathrm{ft}$ of head. The two operating points at $60 \mathrm{ft}$ of head were added to determine if different heads with similar discharges would affect the quality of draft tube flow. Plots of the velocities obtained at the test cross section for all 
seven operating points are provided in Plates 63-69. The velocity from these cross sections were used to determine the flow split between the two draft tube barrels, determine the uniformity of flow, and the draft tube barrel turbulence intensity. Results from the evaluation are provided in tabular form in Plate 70.

The flow split determined from the measured velocities was nearly the same throughout the operational points as well as for both heads tested. Barrel C (right barrel looking downstream) carried approximately $40 \%$ of the flow compared to $60 \%$ for Barrel A. Based on other studies conducted by ERDC on other Kaplan turbines, Barrel A normally carries more flow that Barrel $\mathrm{C}$ for most of the operation zone. Normally, the lower the turbine loading is, the more unbalanced the flow will be between the draft tube barrel. The draft tube barrel balance also normally improves with increasing loading (discharge). The draft tube splitter pier configuration is the main reason that the flow split between the two draft tube barrels remained nearly the same for all operating points. The B1 draft tube is unique compared to other USACE projects on the Lower Columbia River. It has a horizontal splitter pier. More draft tube structure controls the flow through the draft tube elbow and controls the barrel flow split. A graphical presentation of the data is provided in Plate 71.

AT $55 \mathrm{ft}$ head, the Barrel A turbulence intensity was highest at L1\% (41.5\%) and was lowest for U1\% (33.1\%). It was nearly the same at the other three operating points, varying from $34.4 \%$ to $35.5 \%$. For Barrel C, the turbulence intensity was consistently higher compared to Barrel A. It was highest at L1\% (75.1\%) and second highest at peak (55.6\%). It was lowest at $\mathrm{AB} 1 \%$ (40.9\%). These data indicate that quality of flow at the draft tube exit is very poor for L1\% $\left(16.5^{\circ} \mathrm{BA}\right)$ and poor at peak. The turbulence intensity improved with increasing turbine loading until the $\mathrm{AB} 1 \%$ operating point $\left(27.5^{\circ} \mathrm{BA}\right)$. This indicates the unit should be operated above U1\% $\left(22.4^{\circ} \mathrm{BA}\right)$ to minimize the effects of turbulence near the draft tube exit on fish disorientation and stress. Turbulence intensity values determined at $60 \mathrm{ft}$ of head did not differ significantly from the results at $55 \mathrm{ft}$ of head. A graphical presentation of the results is provided in Plate 72.

Draft tube uniformity evaluation shows that flow exiting the draft tube was non-uniform throughout the entire operating range tested at $55 \mathrm{ft}$ head. Barrel A flow was less uniform than Barrel C flow except at the L1\% operating point. The L1\% had the worst uniformity of flow (62.6\% Barrel A, 
73.7\% Barrel C) compared to all other operating points followed by peak (59\% Barrel A, 53.8 Barrel C) and TOL (57.4\% Barrel A, 48.3\% Barrel C). Flow exiting the draft tube was most uniform at $\mathrm{AB} 1 \%$ (58.4\% Barrel A, 40.8\% Barrel C) followed by U1\% (57.1\% Barrel A, 44.2\% Barrel C). A graphical presentation of the results is provided in Plate 73. This evaluation shows that to provide the most uniform flow exiting the draft tube, it is best to operate between $\mathrm{U} 1 \%\left(22.4^{\circ} \mathrm{BA}\right)$ and $\mathrm{AB} 1 \%\left(27.5^{\circ} \mathrm{BA}\right)$. It also indicates that at the L1\% operating point, uniformity of flow is very poor.

\section{Egress evaluation}

The draft tube exiting flow is turbulent, unsteady, and changes throughout the operational points of the turbine. All of this is captured and can be evaluated with the turbine model. This model is the best tool available for evaluating local effects of turbine operations on downstream egress. In the model, the area downstream of the draft tube is in a confined flume. This is not representative of conditions at the prototype. However, since B1 has a tailrace that is isolated from the spillway, it is a reasonable approximation for a unit that has the adjacent units running. Additionally, this model egress evaluation does give a relative comparison of the affect that varying turbine operating points will locally have on fish exiting the draft tube (e.g., potential for backroll entrainment, average depth of tailrace passage, average time it takes to pass the turbine boil). Project operations will affect predator horizontal and vertical distibutions as well as overall tailrace conditions. Between 840 and 900 beads were released in the intake for three operating points at $55 \mathrm{ft}$ head. These operating points were Peak, U1\%, and $\mathrm{AB} 1 \%$. The beads were imaged as they exited the draft tube to a point 175 prototype $\mathrm{ft}$ downstream of the draft tube exit. Results from the egress evaluation are provided in tabular format in Plate 74.

The percentage beads entrained into the backroll did not vary much for the three operating points (20.3\% to $21.9 \%$ ) with peak having the lowest entrainment rate and UP1 having the highest entrainment rate. Lower backroll entrainment rates are considered to better. The backroll area has the potential to have higher rates of avian and fish predation. A graphical representation of the backroll entrainment rates is provided in Plate 75 .

As beads passed through the tailrace area, the number of beads that were observed to come into contact with the water surface or within $5 \mathrm{ft}$ of the water surface was documented. The percentage of beads coming into contact with the water surface was lowest for Peak (11.1\%) and increased to 
$13.1 \%$ at $\mathrm{U} 1 \%$ and to $13.7 \%$ at $\mathrm{AB} 1 \%$. However, the trend was reversed when the beads passed within $5 \mathrm{ft}$ of the water surface. It was lowest at $\mathrm{AB} 1 \%$ (22.6\%) and highest at peak (25.6\%). The lower in the water column, the more likely the fish would pass downstream with reduced exposure to predation. A graphical representation of the results is provided in Plate $76-77$.

The time it took the bead to exit the draft tube and pass $175 \mathrm{ft}$ downstream was recorded for each bead. The average time was the shortest for $\mathrm{AB} 1 \%$ $(55.1 \mathrm{sec})$ and longest for Peak (65.9 sec). Shorter time would indicate a shorter exposure time to predation in the turbine boil area. A graphical representation of the results is provided in Plate 78.

Overall the egress evaluation provided mixed results. Lower turbine loadings caused a smaller percentage of beads to become entrained into the backroll and had fewer beads coming into contact with water surface (to a distance of $175 \mathrm{ft}$ downstream). Higher turbine loadings had fewer percentages of beads exposed to the top $5 \mathrm{ft}$ of the water surface, and the average bead took less time to move beyond the turbine boil. 


\section{Conclusions and Recommendations}

Experiments were conducted to compare entire turbine passage routes that affect direct and indirect fish survival throughout the complete operating range of the B1 MGR. The results will assist in determining the TOR to minimize impacts on juvenile salmon passing through the B1 powerhouse. Operation within the TOR should reduce fish mortality, injury, stress, and fish disorientation, thereby increasing fish survival for fish passing through the B1 MGRs. The experiments are not direct predictors of survival but are a relative comparison of operating points throughout the complete operation zone at $55 \mathrm{ft}$ of head.

\section{Stay vane passage}

Experiments for stay vane passage indicate that when considering surface contact and shear, all three operating points evaluated performed nearly the same. This is because all B1 stay vanes are smoothly shaped and fairly well aligned with flow entering the stay vane cascade. This allows for very little flow separation at the leading edge. This influences the hydraulics along the stay vane surface in a positive manner. Shaped stay vanes are desirable and are presently being considered in other USACE project rehabilitations. However, stay vane-to-wicket gate gap passage did decrease with increasing wicket gate angle. This gap passage is considered to be negative and is a potential injury point for juvenile salmon. Stay vane passage optimization is important for minimizing fish injury, disorientation, and stress. However, turbine blade angle optimization is more important, but it is not necessarily exclusive. Increasing wicket gate angles correspond with steeper BAs.

\section{Runner hub region passage}

Observed severe blade contact was low throughout the complete TOR. However, severe changes in direction were significantly higher at the flatter BAs of $16.5^{\circ}$ and $17.5^{\circ}$ compared to the steeper BAs. Rates of beads exhibiting a severe change in direction through the runner region occurred at a rate of at least 3.5 times higher for flatter BAs compared to steeper BAs for hub passage. Without screens in place, a significant percentage of the total fish population would be expected to pass through the hub region. 


\section{Runner mid-blade region passage}

Overall mid-blade passage was observed to be the best passage route through the turbine when compared to hub and near blade tip passage. The number of beads observed to have a severe contact event with the blade was low throughout the complete TOR. However, the mid-blade evaluation shows a trend of decreasing severe contact events with increasing blade angle (1.7\% at $16.5^{\circ} \mathrm{BA}$ and $0.6 \%$ at $\left.31^{\circ} \mathrm{BA}\right)$.

Beads observed to exhibit severe changes in direction had the same rate of occurrence as severe contacts. This indicates that all severe change-indirection events occurred as the result of severe contact. When the moderate change-in-direction events are added to the severe events, the rate of event occurrence is significantly higher at flatter BAs.

A significant percentage of the total fish population would be expected to pass through the mid-blade region.

\section{Runner tip region passage}

The percentage of beads making severe contact with the runner blade was significantly higher at the two flattest BAs when compared to the three steepest BAs. Also, the rate of beads observed to exhibit a severe change in direction had a trend of reduction as the blade angle was increased. Without screens in place, fewer fish would be expected to pass through the tip region when compared to the other two passage regions. However, some fish would be expected to pass though this region.

\section{All turbine region combined passage}

Since the distribution of fish entering is unknown, data from the three passage routes were combined into one data set. The data indicate a trend of decreasing severe contact with the turbine blade with increasing blade angle. The same trend can be seen in the data when looking at the rates of severe change-in-direction events during turbine passage. Steeper BAs should provide better fish passage conditions compared to flatter BAs.

\section{Draft tube elbow passage}

The percentage of beads observed to have a severe contact with the splitter piers was fairly consistent throughout the operation range, varying from $2.7 \%$ at $17.5^{\circ}$ BA to $2.2 \%$ at $22.4^{\circ} \mathrm{BA}$. The sudden-change-in-direction 
evaluation indicates that the BAs with the lowest number beads exhibiting severe to moderate change-in-direction scores were between $22.4^{\circ}$ and $27.5^{\circ} \mathrm{BA}$. Note that this analysis is based on a broad distribution of intake passage. If the distribution is weighted higher in the intake (more hub to mid-blade passage), the percentage of fish encountering shear and moderate to severe changes in direction in the draft tube elbow region will be much higher than what is reported. This would especially be true at the flatter BAs. Beads observed below the runner with hub-released beads exhibit much higher incidences of sudden changes in direction at flatter BAs.

The turbine should be operated at higher BAs to provide for better passage conditions through the draft tube elbow. While passage through the draft tube elbow may or may not significantly contribute to direct mortality, it most certainly will affect the condition of the juvenile salmon delivered to the tailrace.

\section{Draft tube exit passage}

The flow split between the two draft tube barrels was consistent throughout the entire operational range of the turbine (independent of discharge or head). This is unusual compared to other Kaplan-type turbines on the Columbia and Snake Rivers. Normally, flow distribution between the two barrels is poor at flat BAs but improves as the turbine blades are increased (turbine is operated at higher outputs). Quality of flow (turbulence intensity and draft tube uniformity) within each draft tube barrel was worst at the $16.5^{\circ} \mathrm{BA}$ and improved at other BAs. This indicates that to achieve better draft exit flow, it is better to operate the turbine at steeper BAs.

\section{Egress passage}

Egress results were mixed. The number of beads entrained into the backroll area was a little less for $17.5^{\circ}$ BA compared to the two steeper BAs evaluated. Also, the percentage beads near the water surface were less for the flatter blade angle. However, the other metrics of passage time, distance downstream to achieve minimum depth, and beads within $5 \mathrm{ft}$ of water surface were better for the steepest BA $\left(27.5^{\circ}\right)$ evaluated. 


\section{Overall turbine passage conclusion}

While the model data is not a direct predictor of fish mortality, it is a good method for defining and comparing hydraulic and passage conditions between turbine operating points. It is clear from the model evaluation that steeper BAs (if operated at peak efficiency for that subject blade angle) provide for better passage conditions for fish. Fewer severe contacts with the turbine runner and less severe change in direction occur at steeper BAs. The draft tube elbow performs better at steeper BAs, and the quality of flow exiting the draft tube is better at steeper BAs.

In fact, the flatter BAs of $16.5^{\circ}$ and $17.5^{\circ}$ should be avoided during juvenile fish passage season, if possible. From this model evaluation, the TOR for fish would be from $22.4^{\circ}$ to $31^{\circ}$ BA with the best operating point being at $22.4^{\circ}$. This does not constrain the operating of the turbine to TOR but only recommends operation of the turbine within the TOR when possible and avoidance of operating at the flattest BAs. This TOR is also supported by some field studies. However, additional pressure information is needed to fine tune the upper of end of the recommended TOR.

Turbine passage pressure effects and project operations are important factors for a full determination of TOR for fish passage but could not be directly addressed in this study. To fully refine the TOR, these two factors should explored and combined with the results of this model study. 


\section{References}

Bell, M. C., A. C. DeLacy, and G. J. Paulik. 1967. A compendium on the success of passage of small fish through turbines. U.S. Army Corp of Engineers, North Pacific Division.

Bell, M. C. 1981. Recommendation for turbine generator loadings and blade gate relationships for the best survival of juvenile migrants at the eight Columbia basin dams operated by the Corps of Engineers. Prepared for the U.S. Army Corps of Engineers, Portland, OR, Portland District.

Bell, M. C. 1986. Fisheries handbook of engineering requirements and biological criteria. Fish passage development and evaluation program. Portland, OR: U.S. Army Corps of Engineers, North Pacific Division.

Fisheries, National Oceanic and Atmospheric Administration (NOAA). 200o. Endangered Species Act-Section 7, Consultation, Biological Opinion. Reinitiation of consultation on operation of the federal Columbia River power system, including the juvenile fish transportation program, and 19 Bureau of Reclamation projects in the Columbia Basin. December 21, 2001. Seattle WA: Northwest Region.

Normandeau Associates Inc. 2000. Direct survival and condition of juvenile chinook salmon passed through an existing and new minimum gap runner turbines at Bonneville Dam first powerhouse, Columbia River. Drumore, PA: Normandeau Associates.

U.S. Army Corps of Engineers (USACE). 2004. Turbine survival program (TSP): Phase 1 report: 1997-2003. Portland, OR: U.S. Army Corps of Engineers, Northwest Division.

USACE. 2013. Turbine optimization for passage of juvenile salmon at hydropower projects on the Columbia and Lower Snake Rivers. Turbine Survival Program 2013. Phase II Main Report, Revision o. U.S. Army Corps of Engineers. https: / $/$ www.google.com/url?sa =t\&rct=j\&q=\&esrc=s\&source=web\&cd=1\&cad=rja\&uact=8\&ve d=0ahUKEwju6onLtgrNAhVIxmMKHVUDChoQFggeMAA\&url=https\%3A\%2F\%2Fwww.salmonrecove ry.gov\%2FFiles\%2FAPR\%2FSection\%25202\%2520Literature\%2520Cited\%2FACOE\%25202013a _TSP-Phase-II-Main-Report.pdf\&usg=AFQjCNHKnwKvDAmMt1eefYiaf8yWJnYhHg 


\section{Appendix A: ERDC Test Precision Determination}




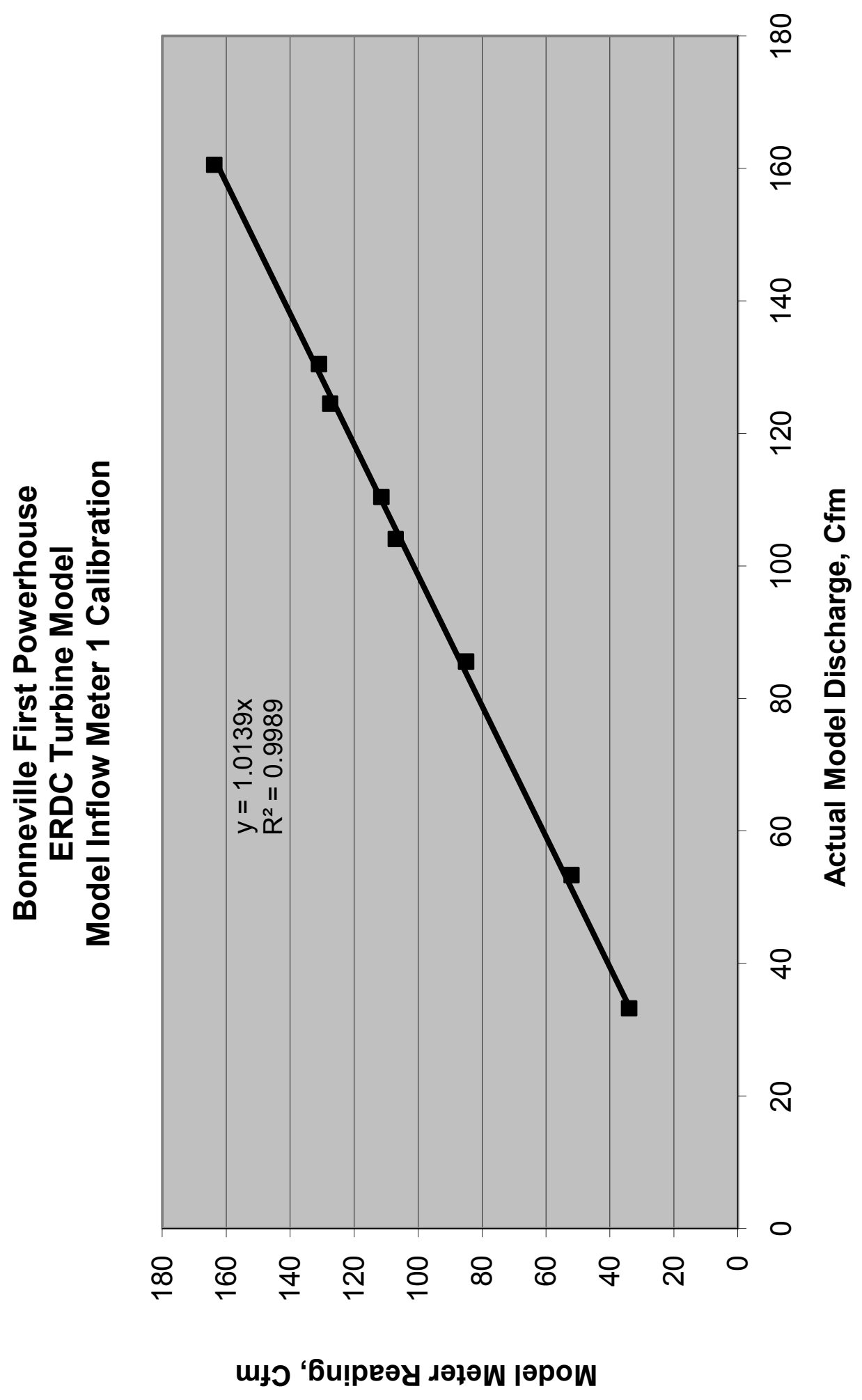

Plate 1 


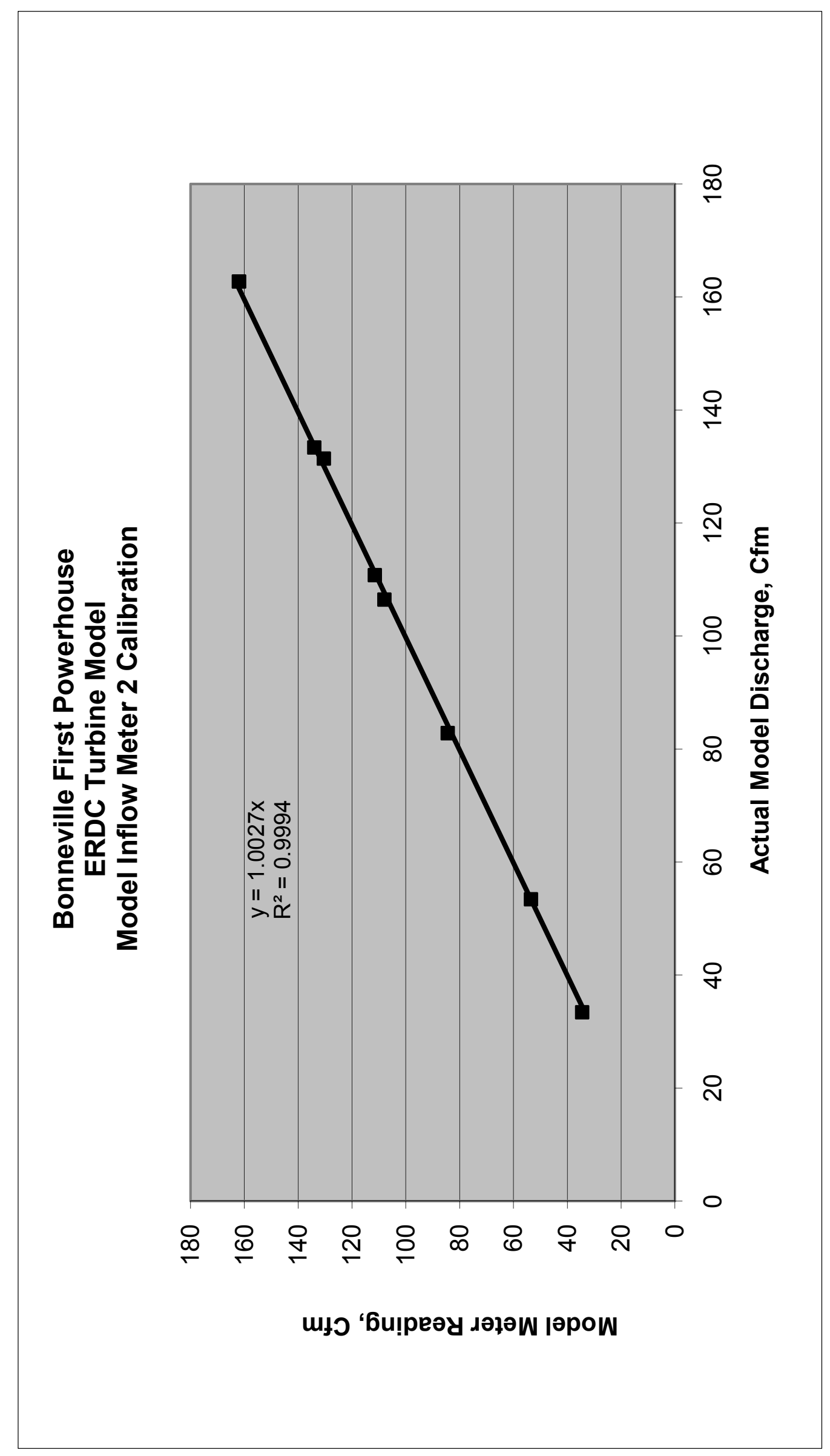

Plate 2 


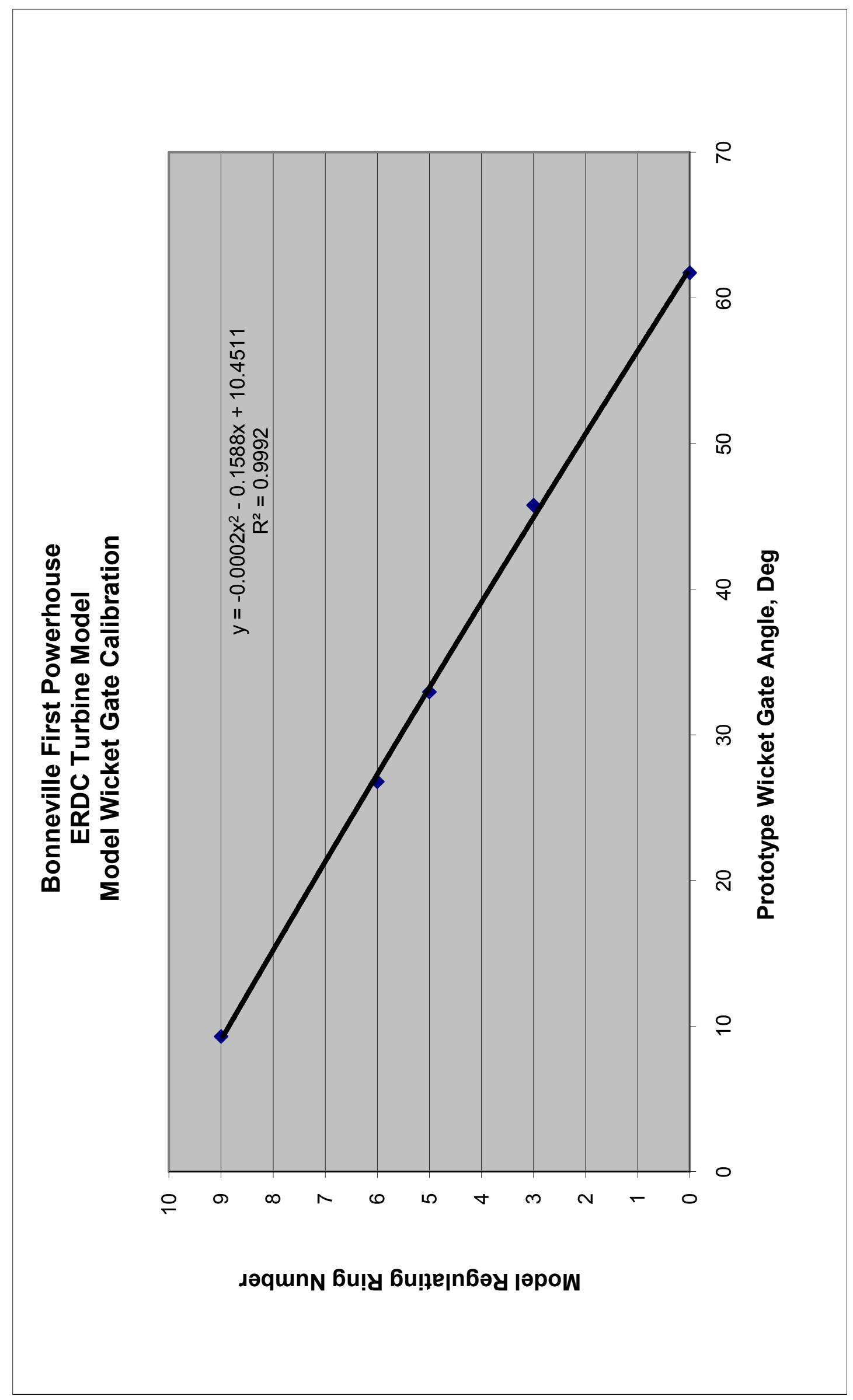

Plate 3 


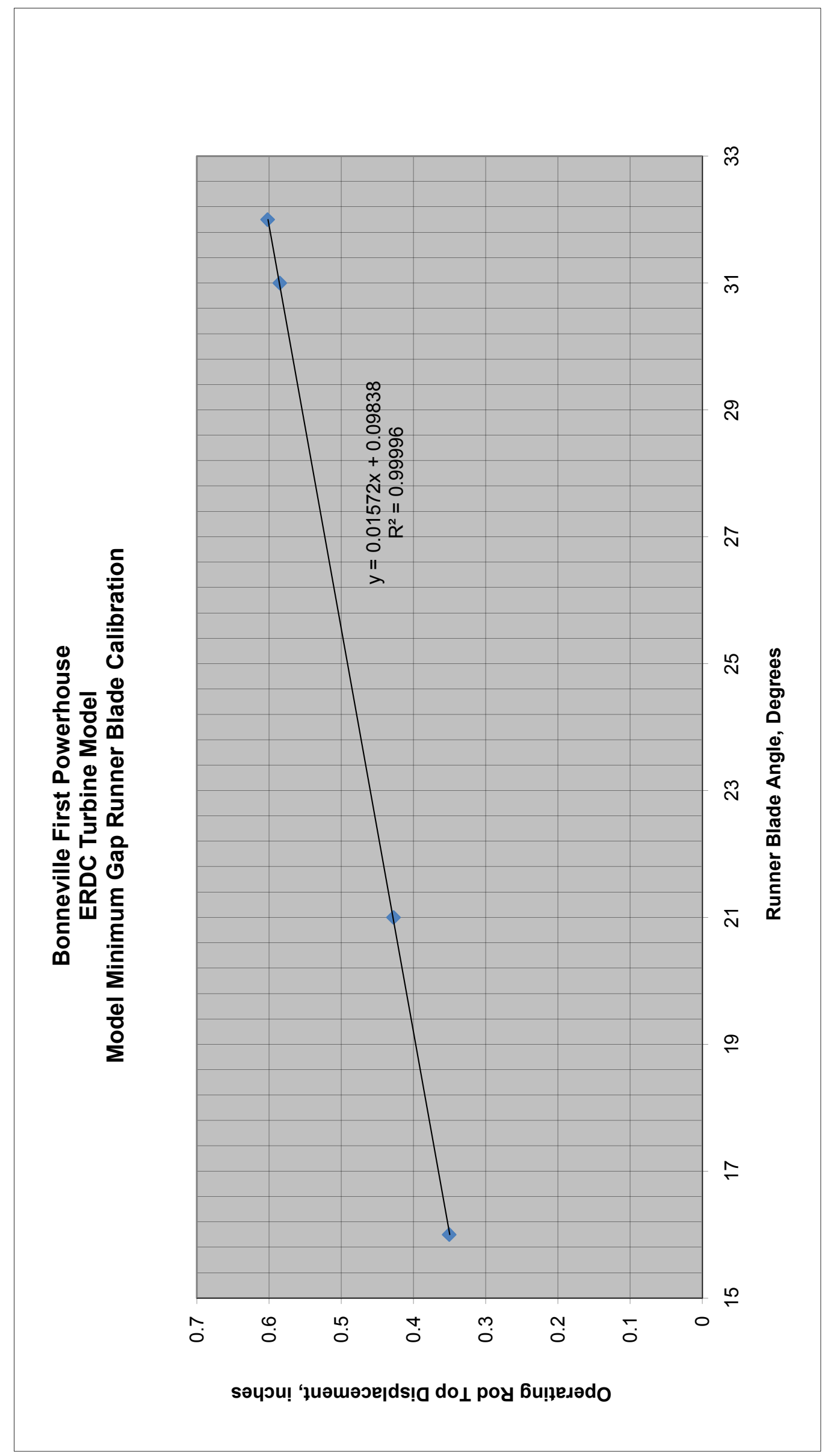

Plate 4 


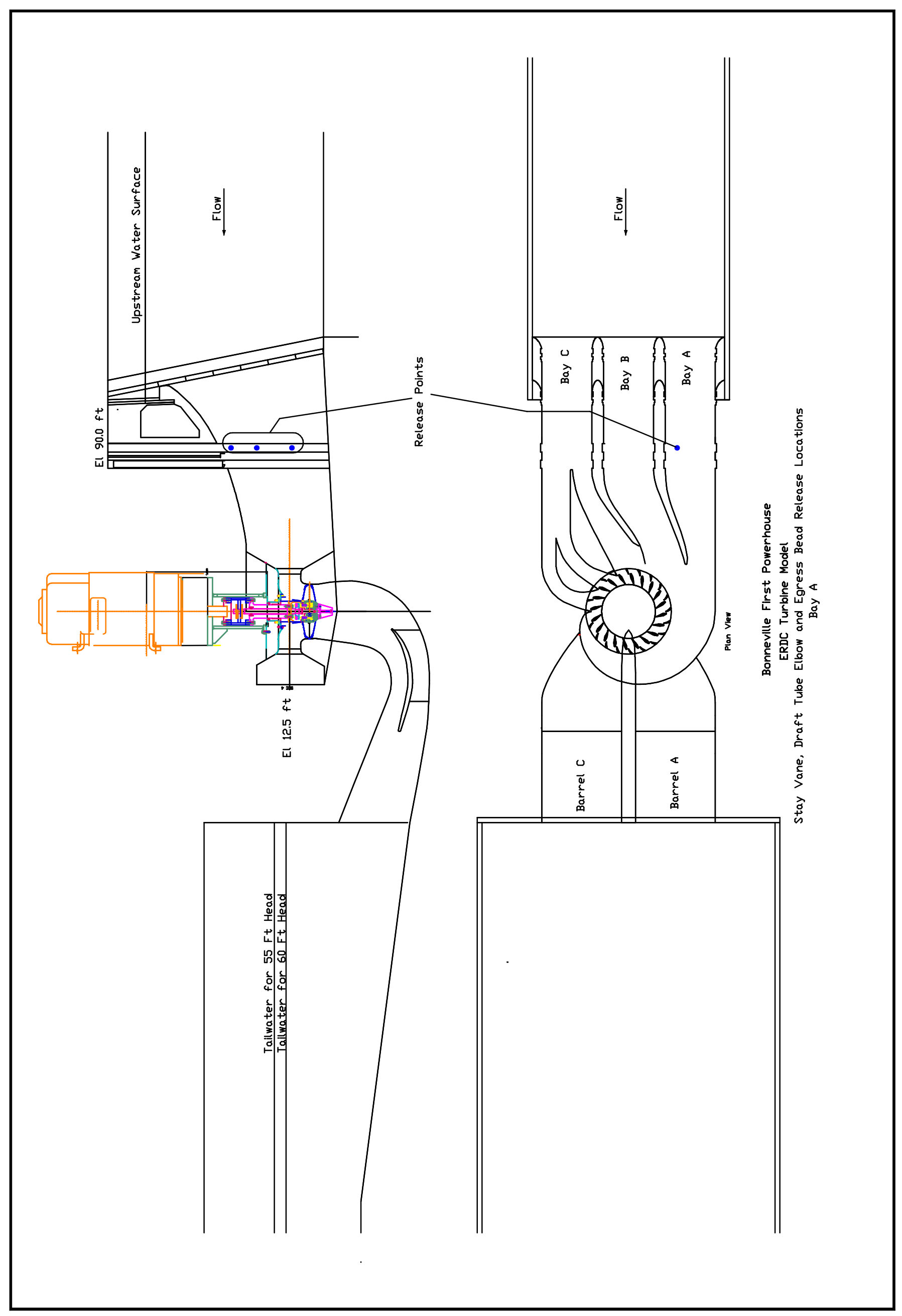

Plate 6 


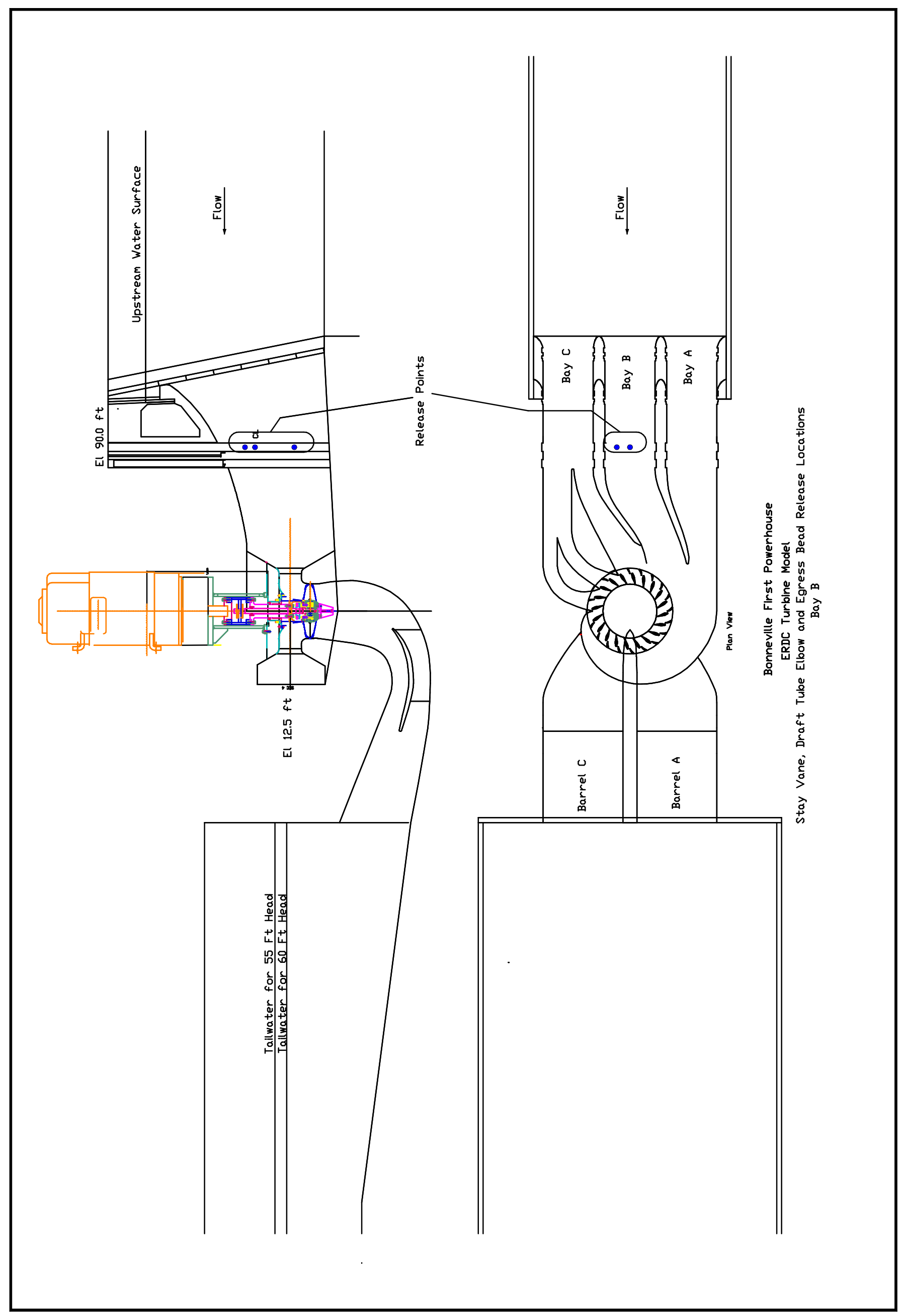

Plate 7 


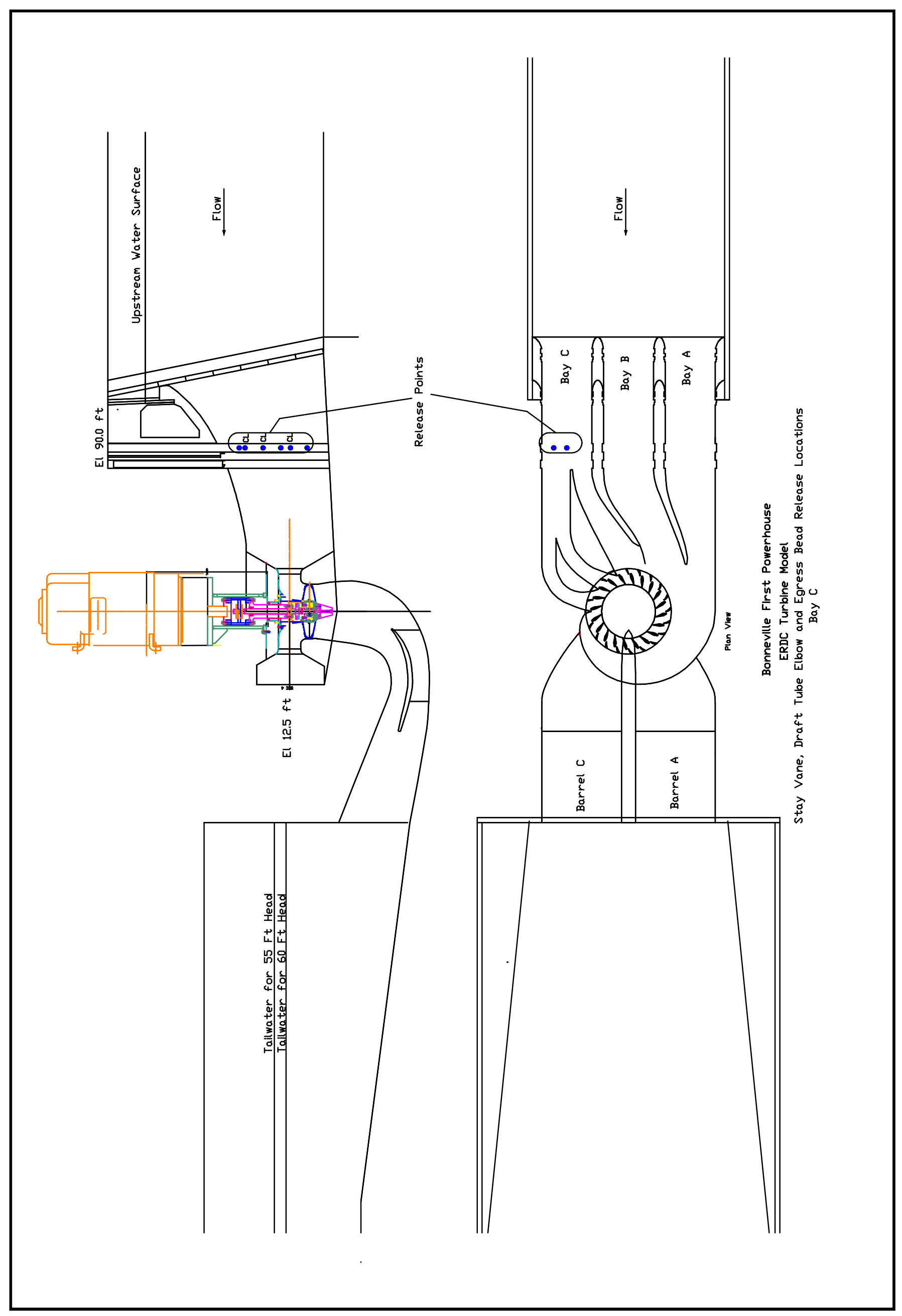

Plate 8 


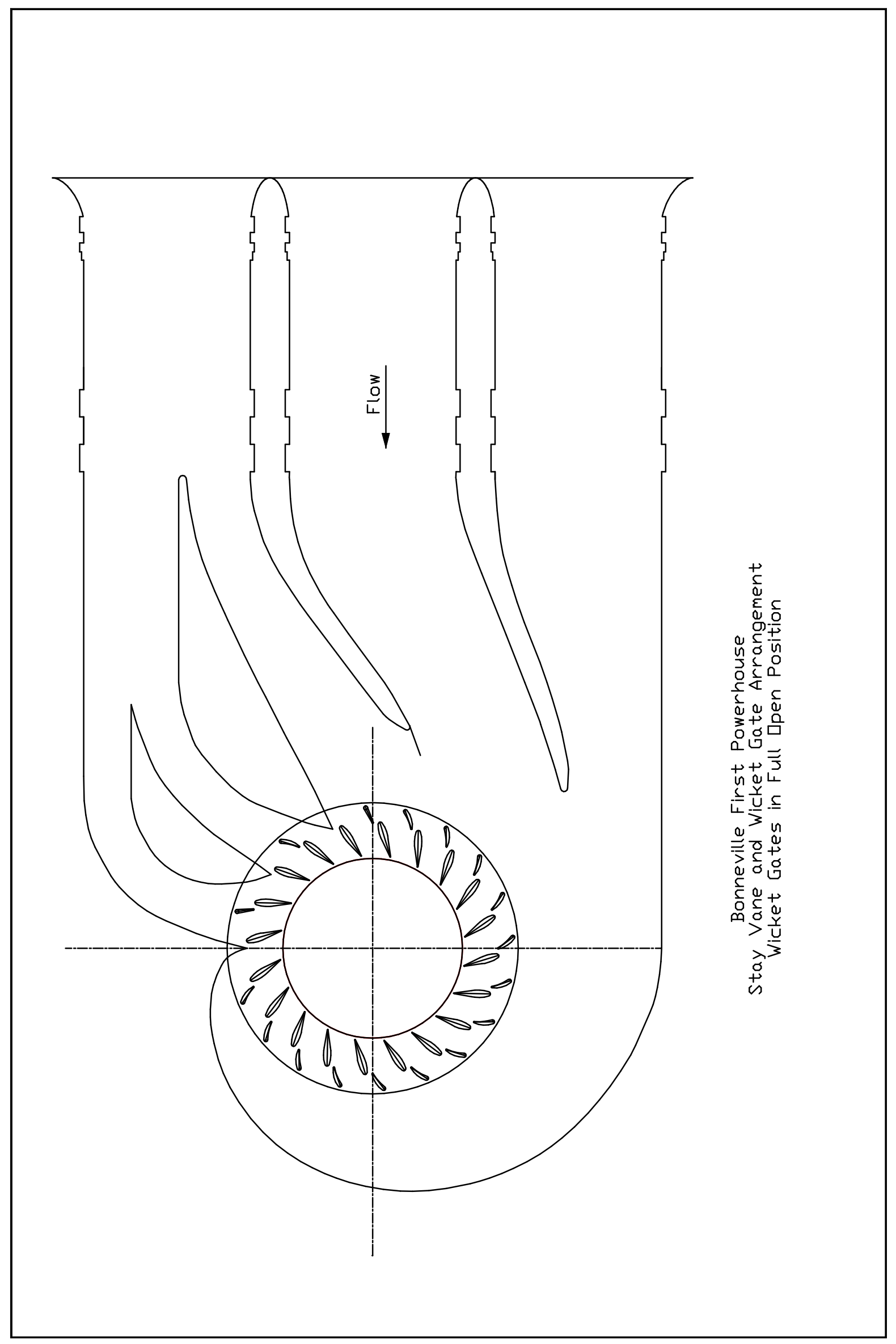

Plate 9 


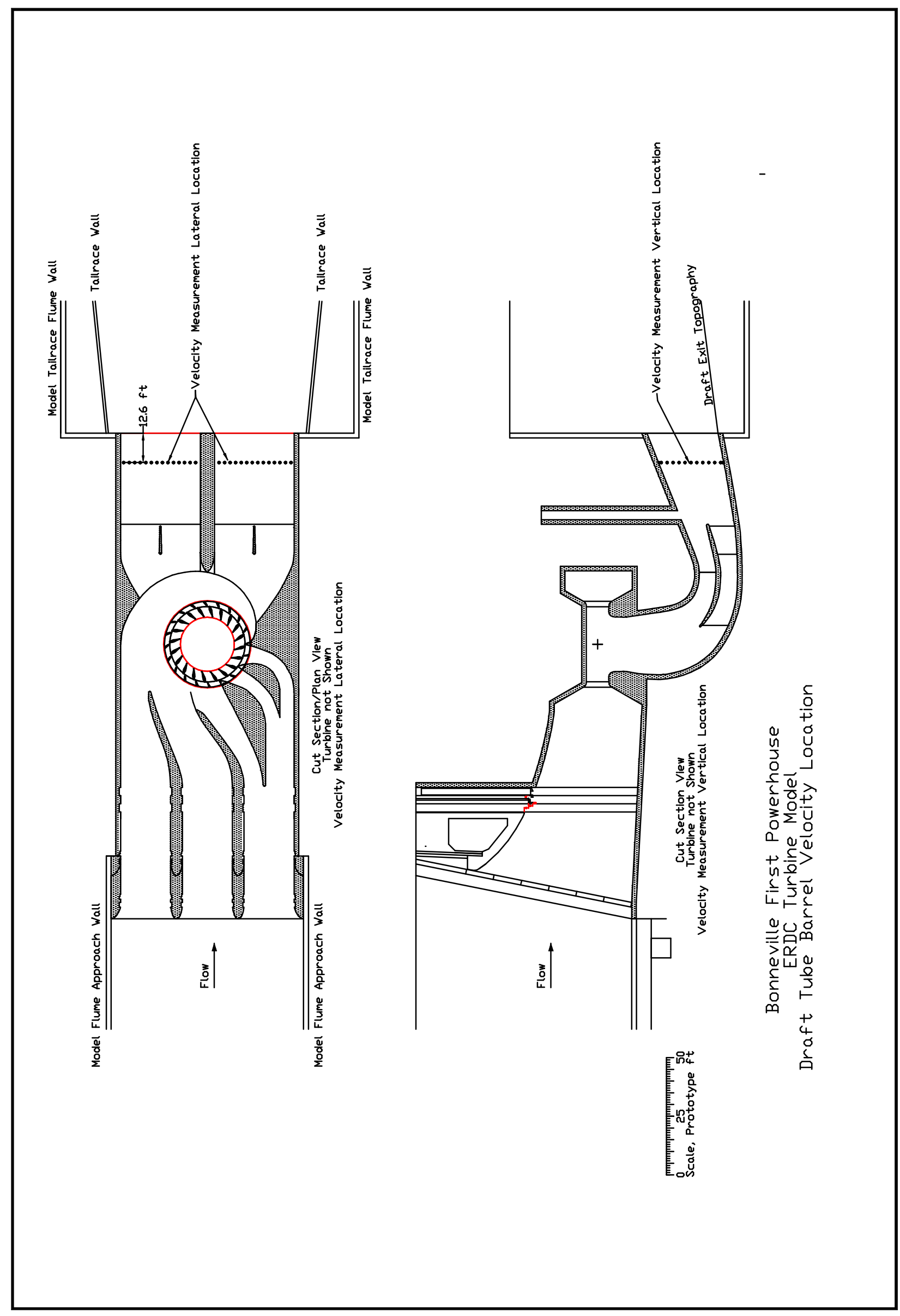

Plate 10 

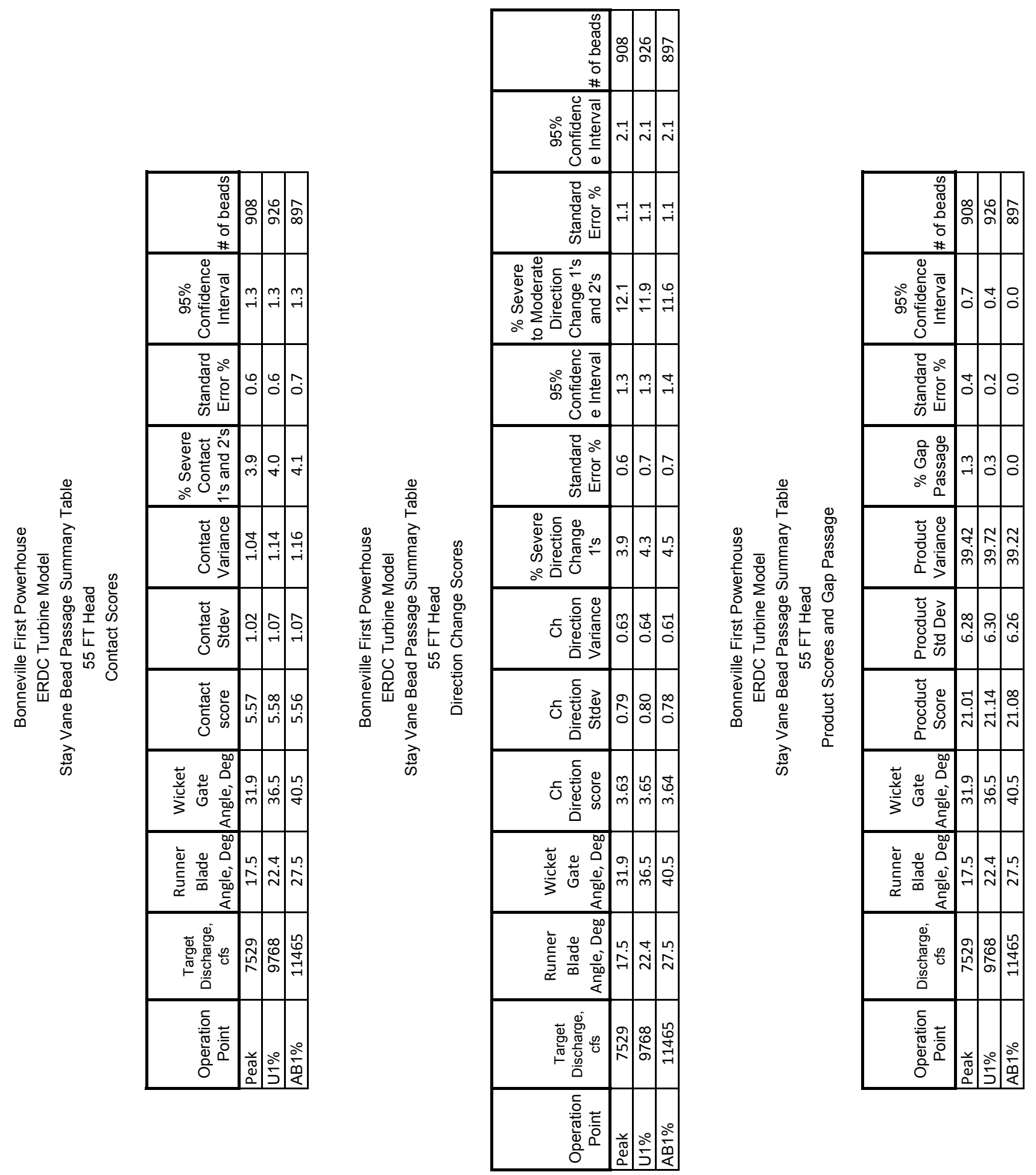


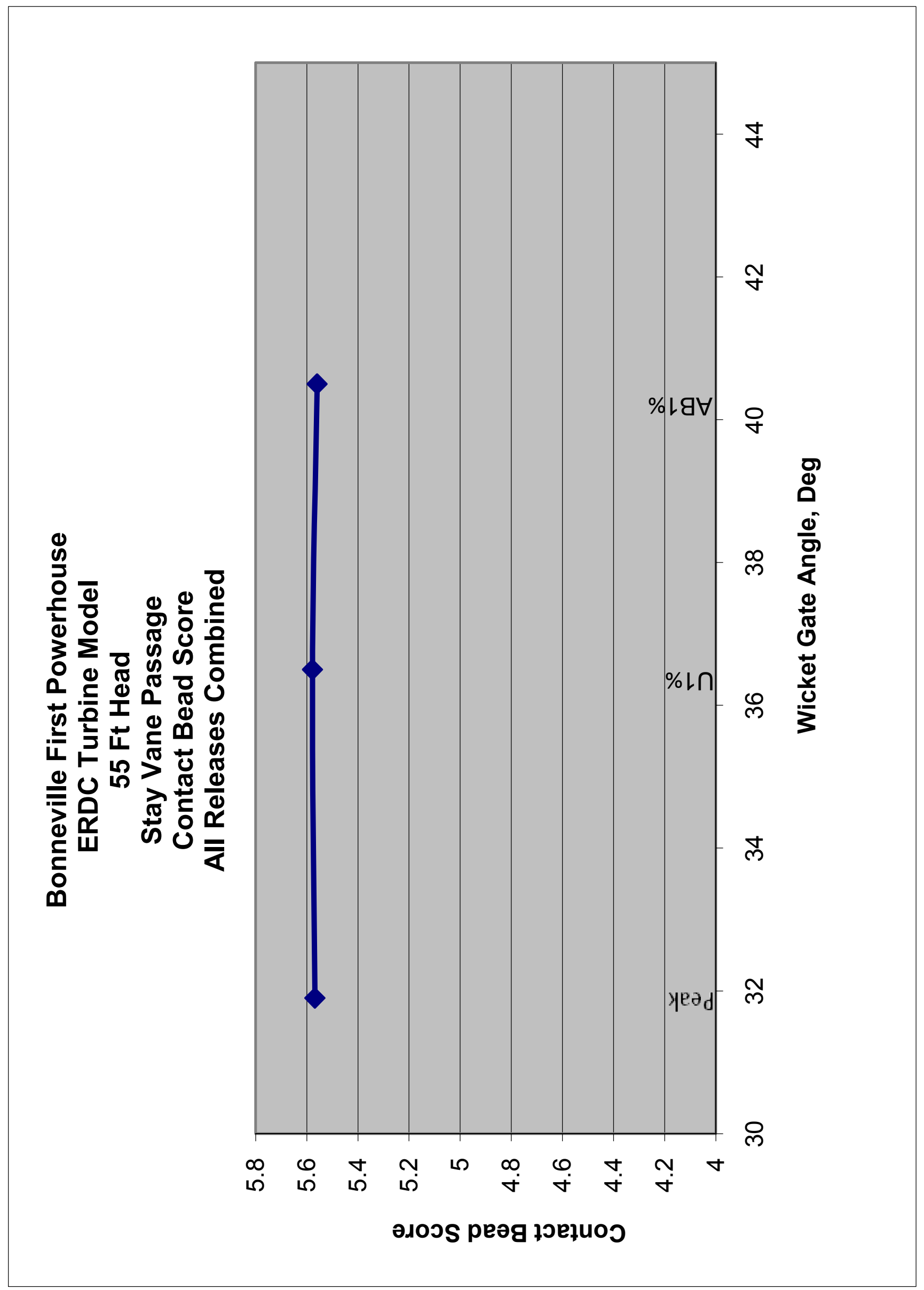




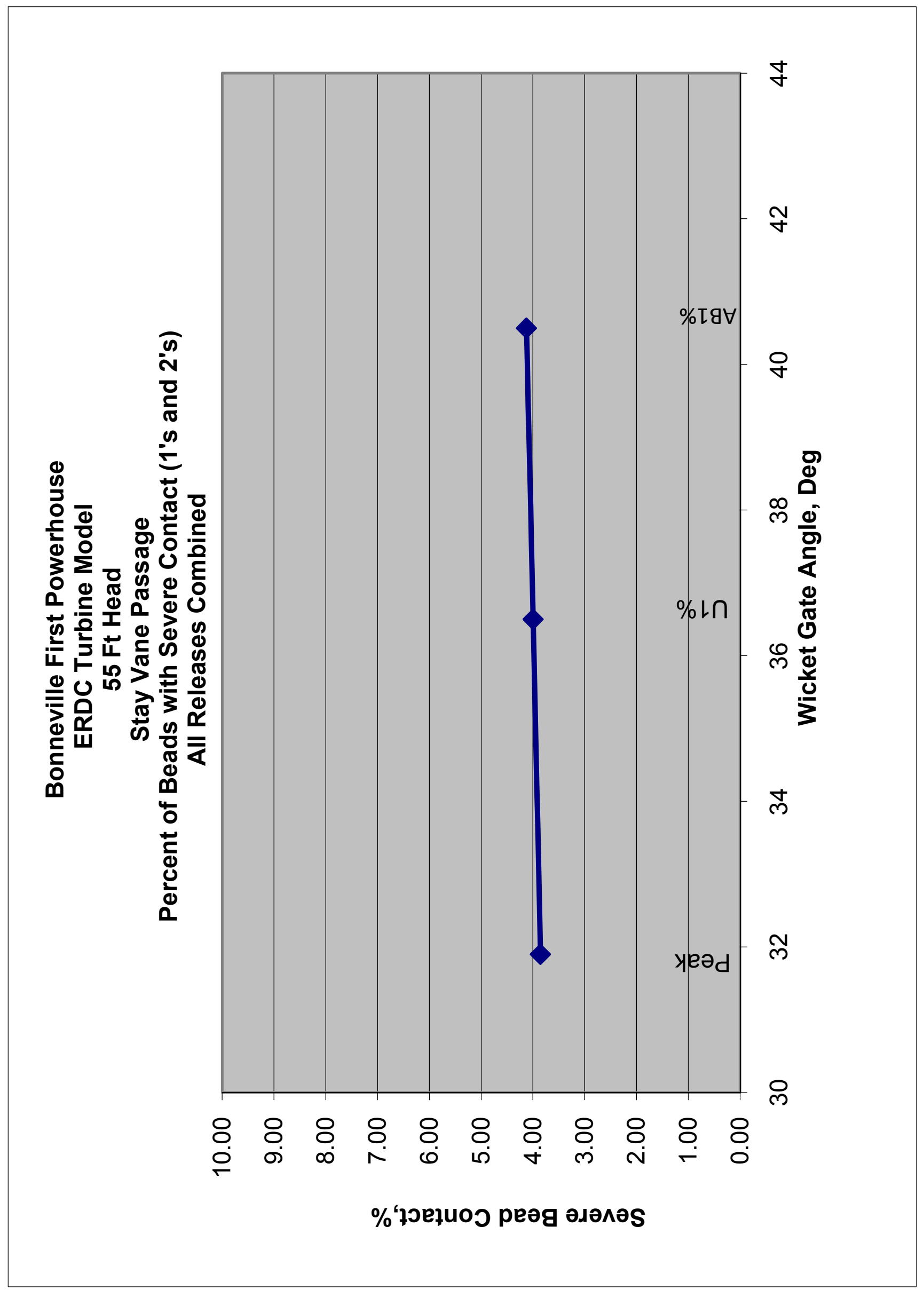

Plate 13 


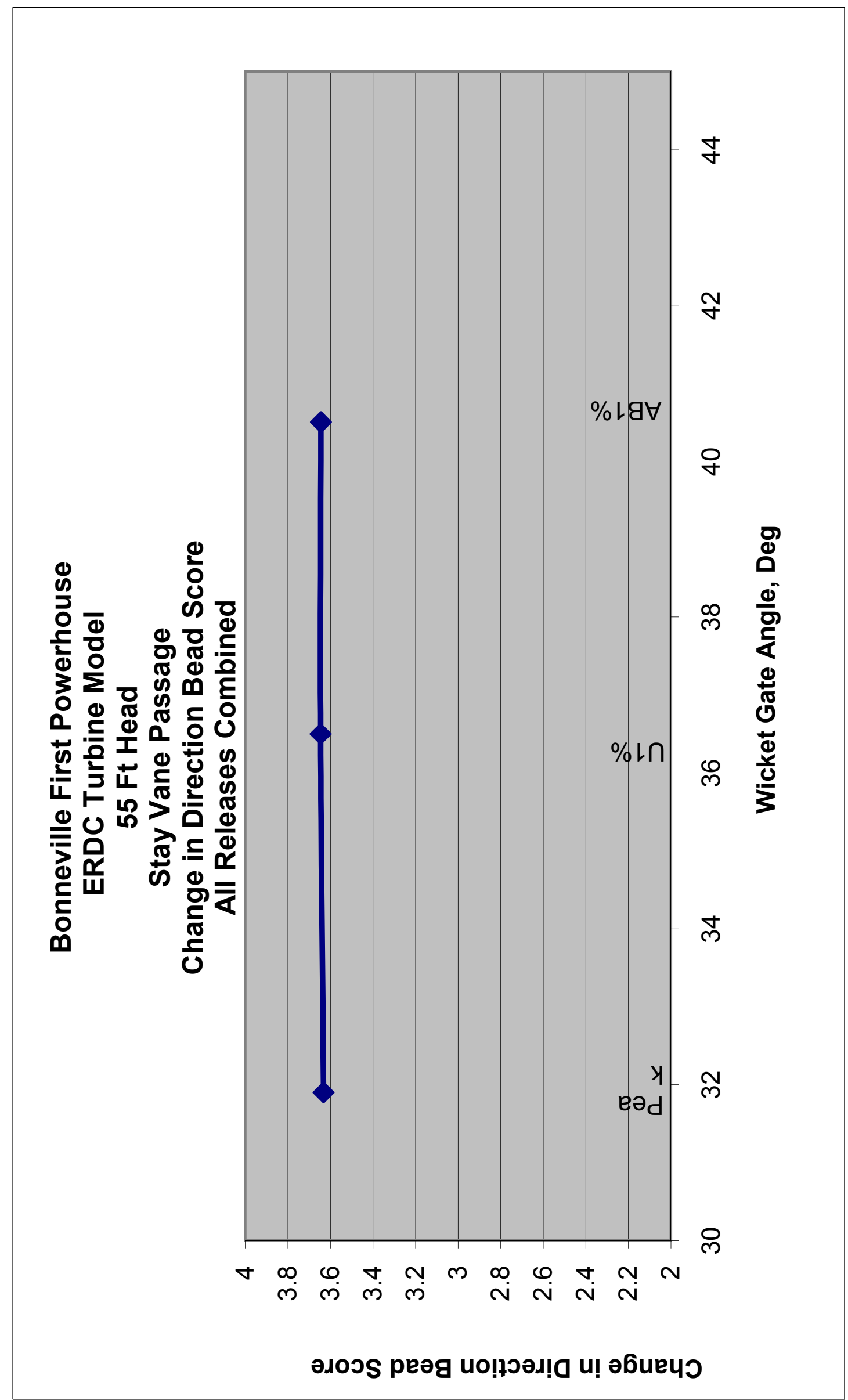

Plate 14 


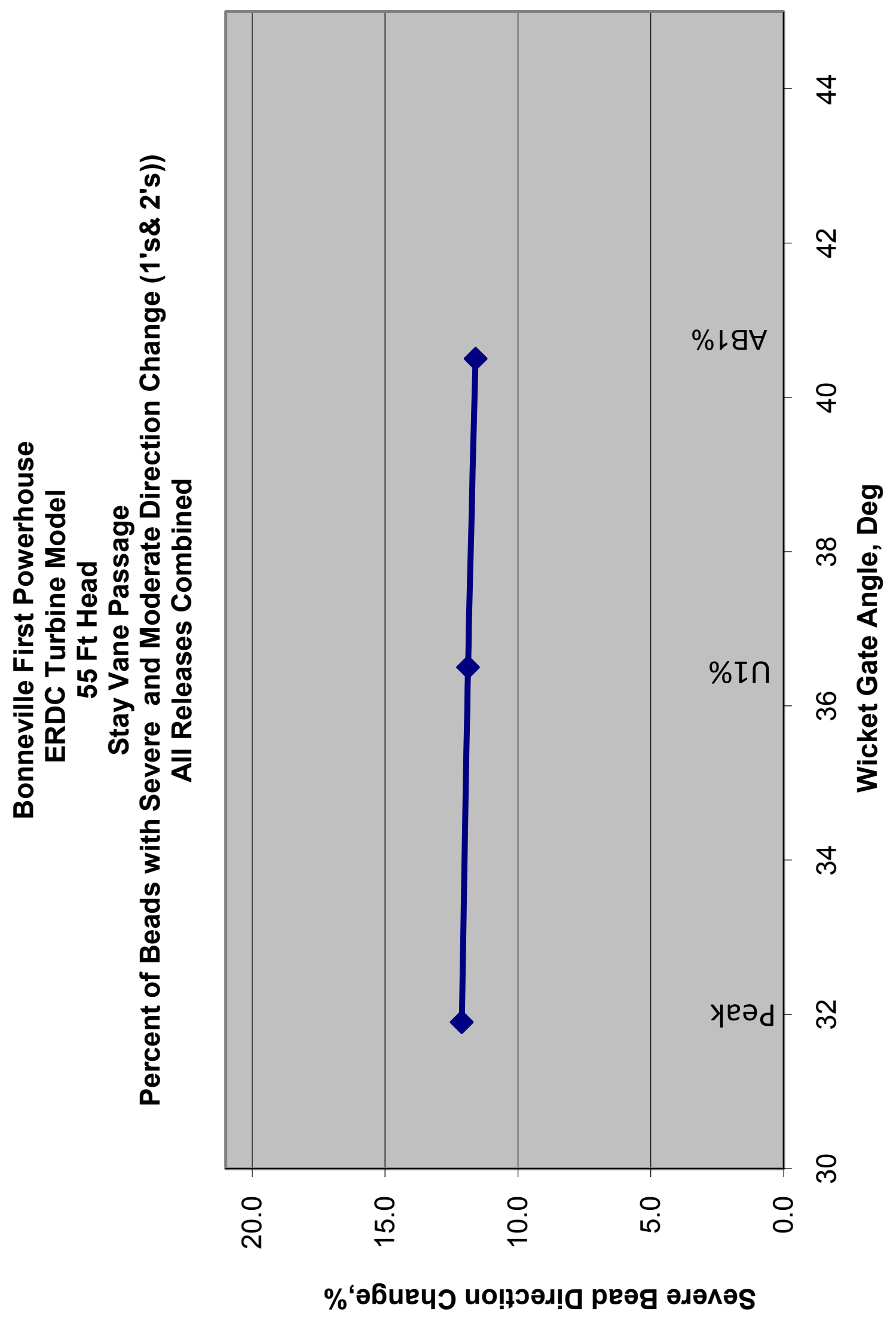




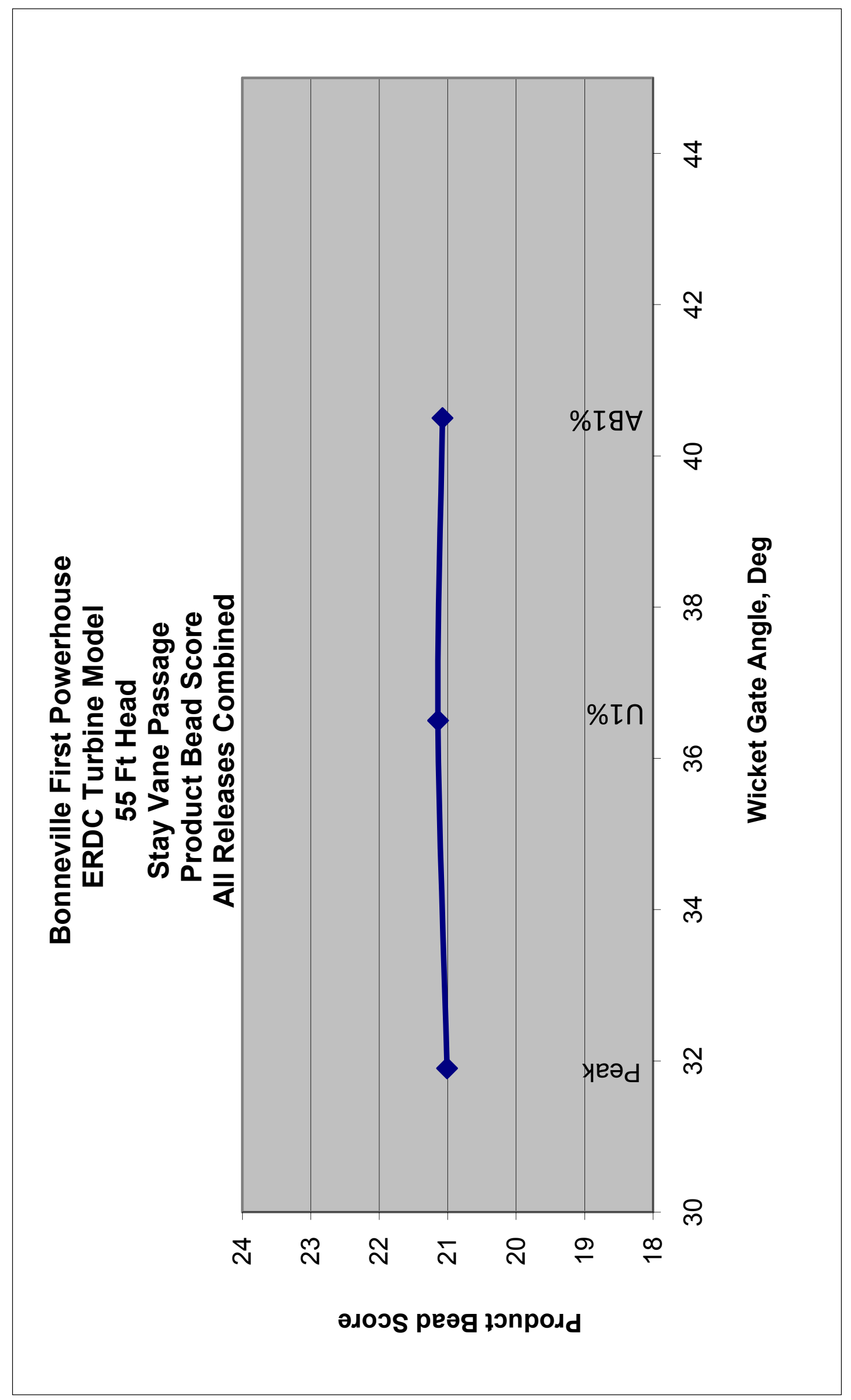

Plate 16 


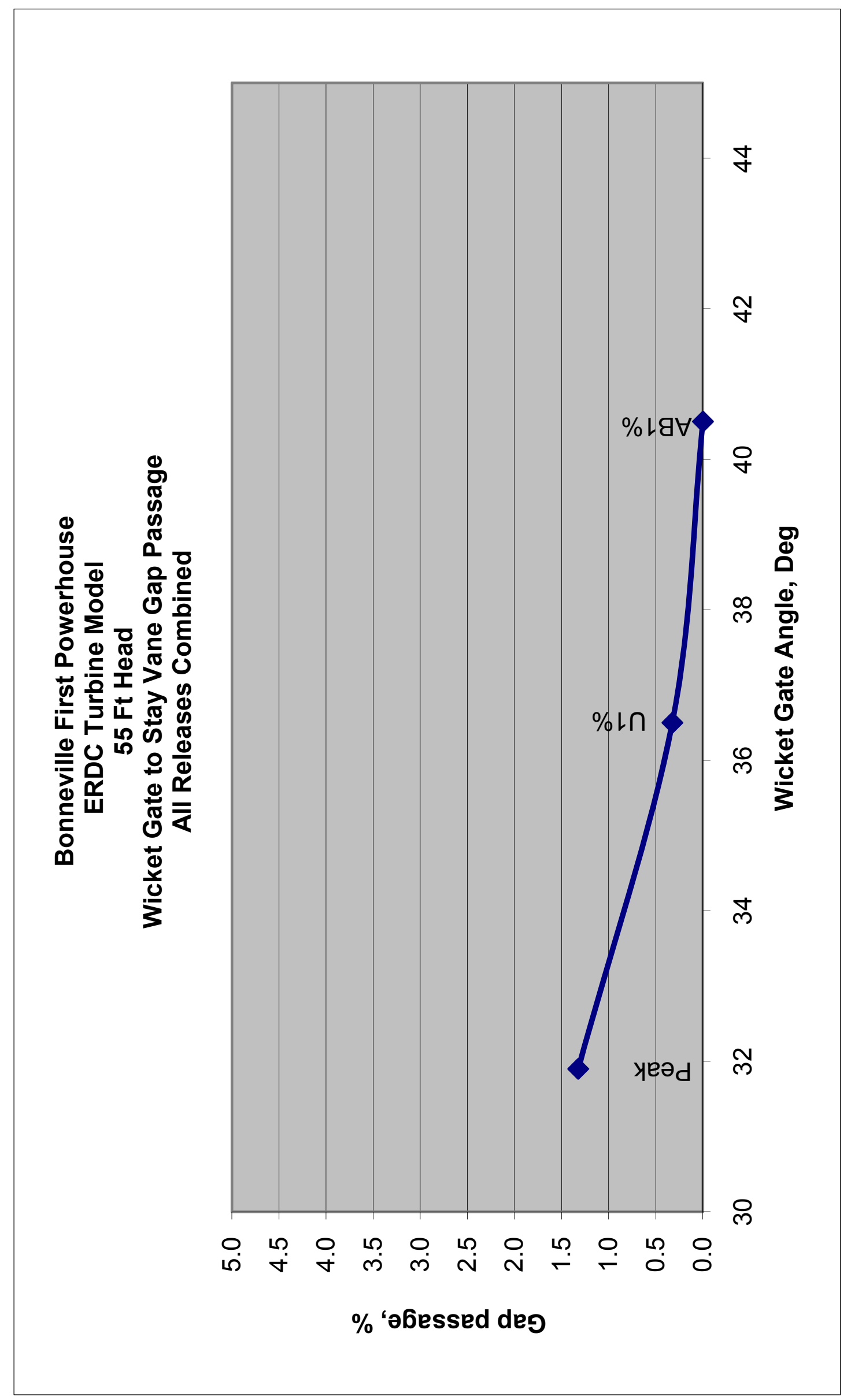

Plate 17 


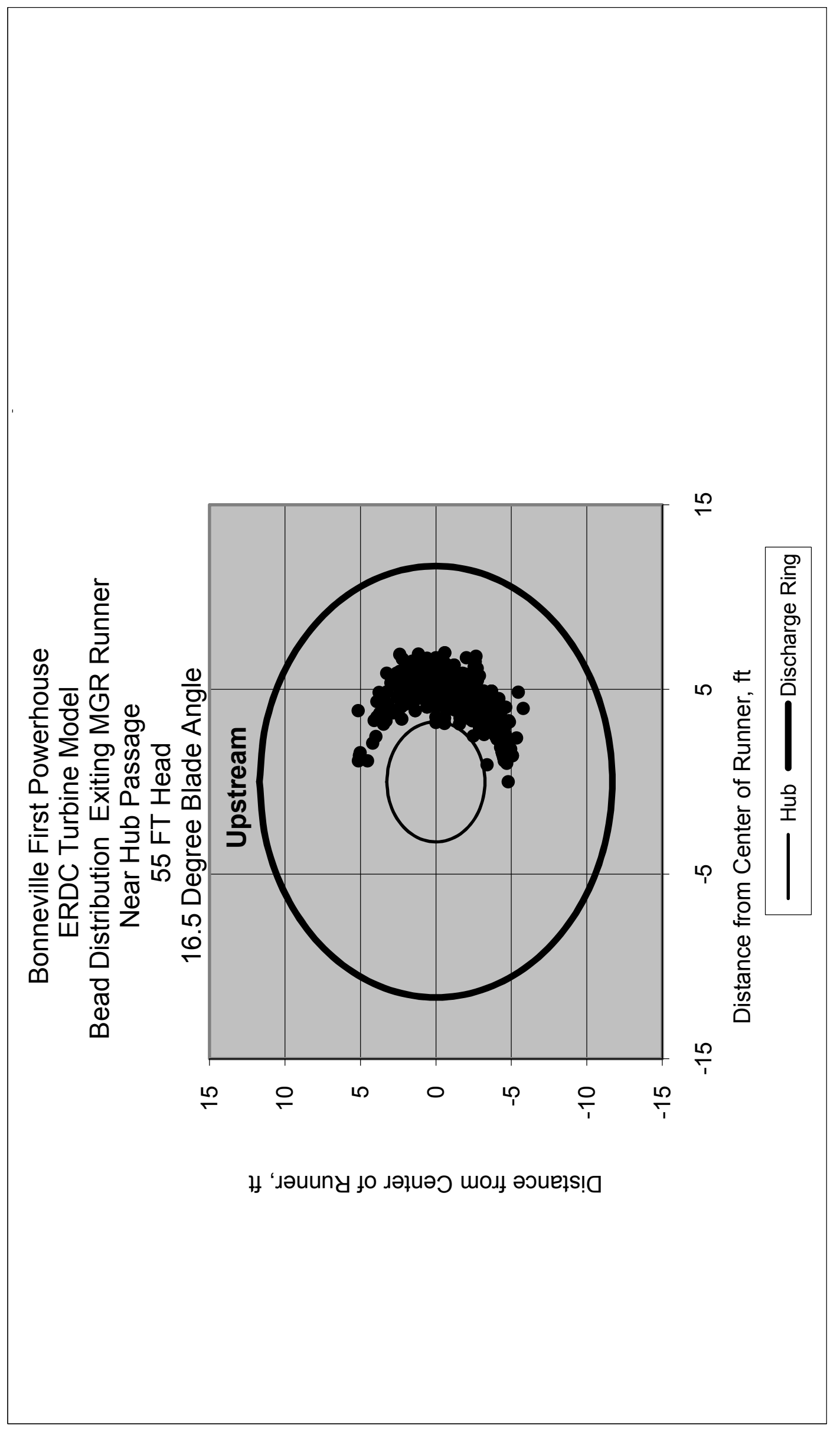

Plate 18 


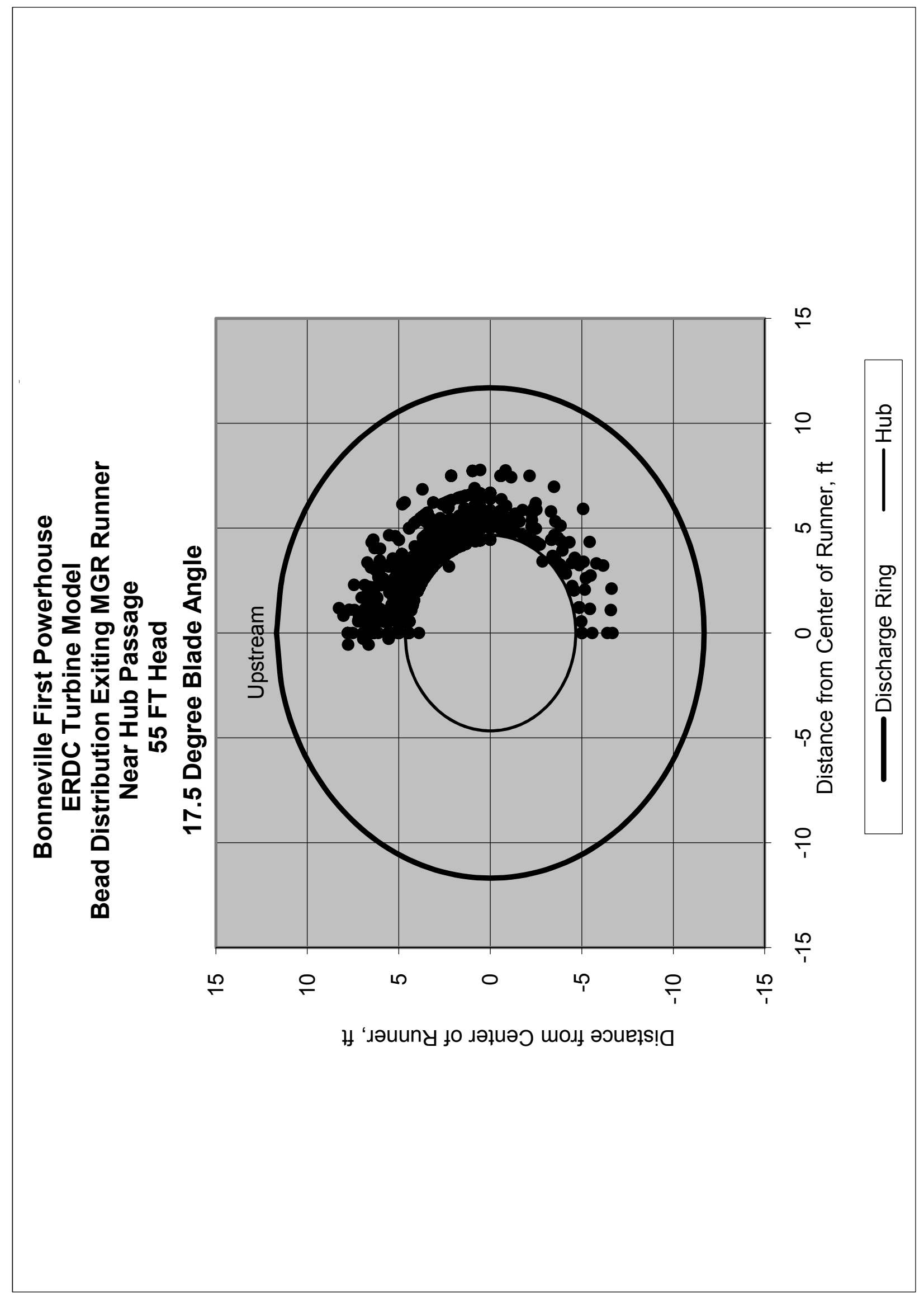

Plate 19 


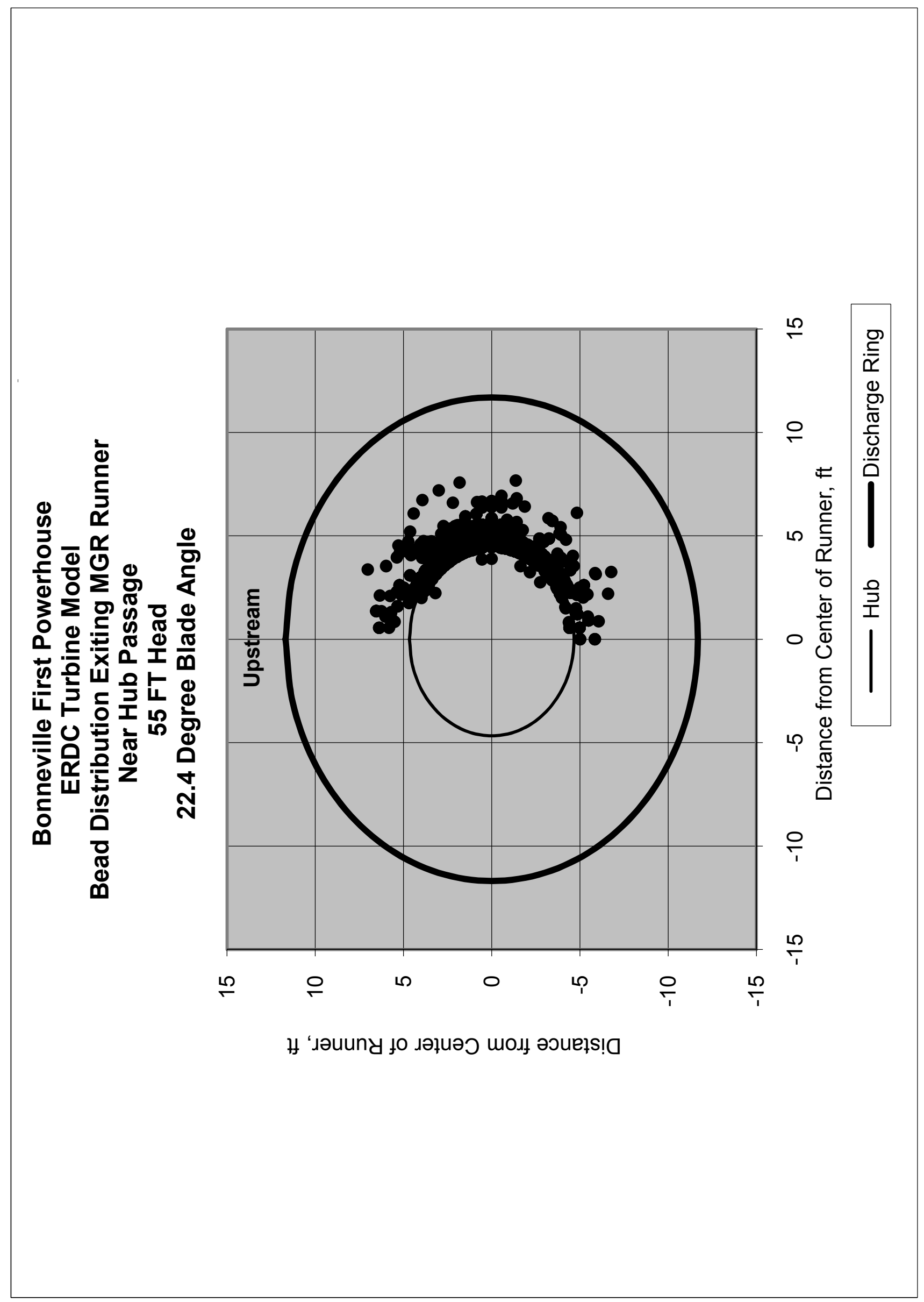




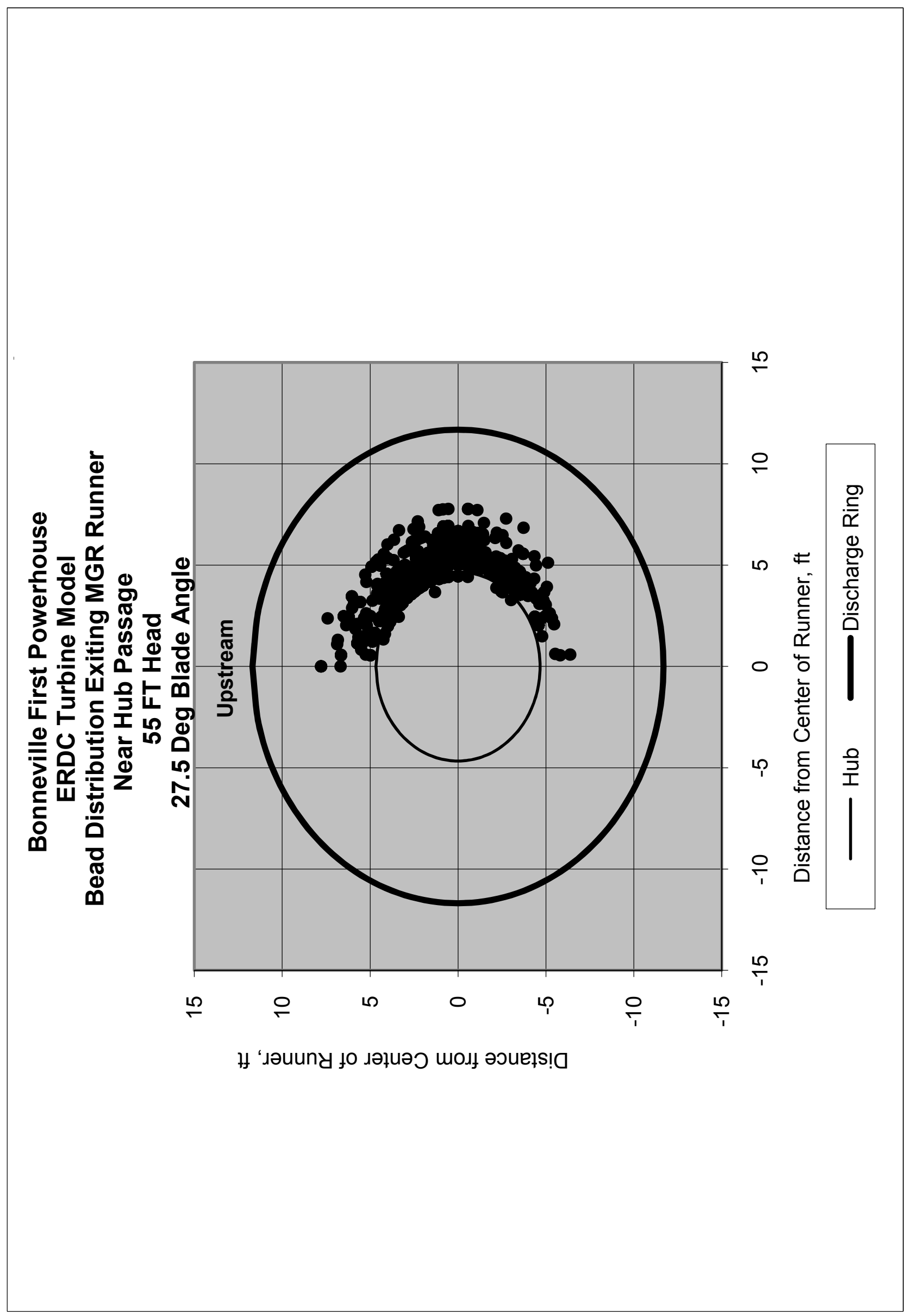

Plate 21 


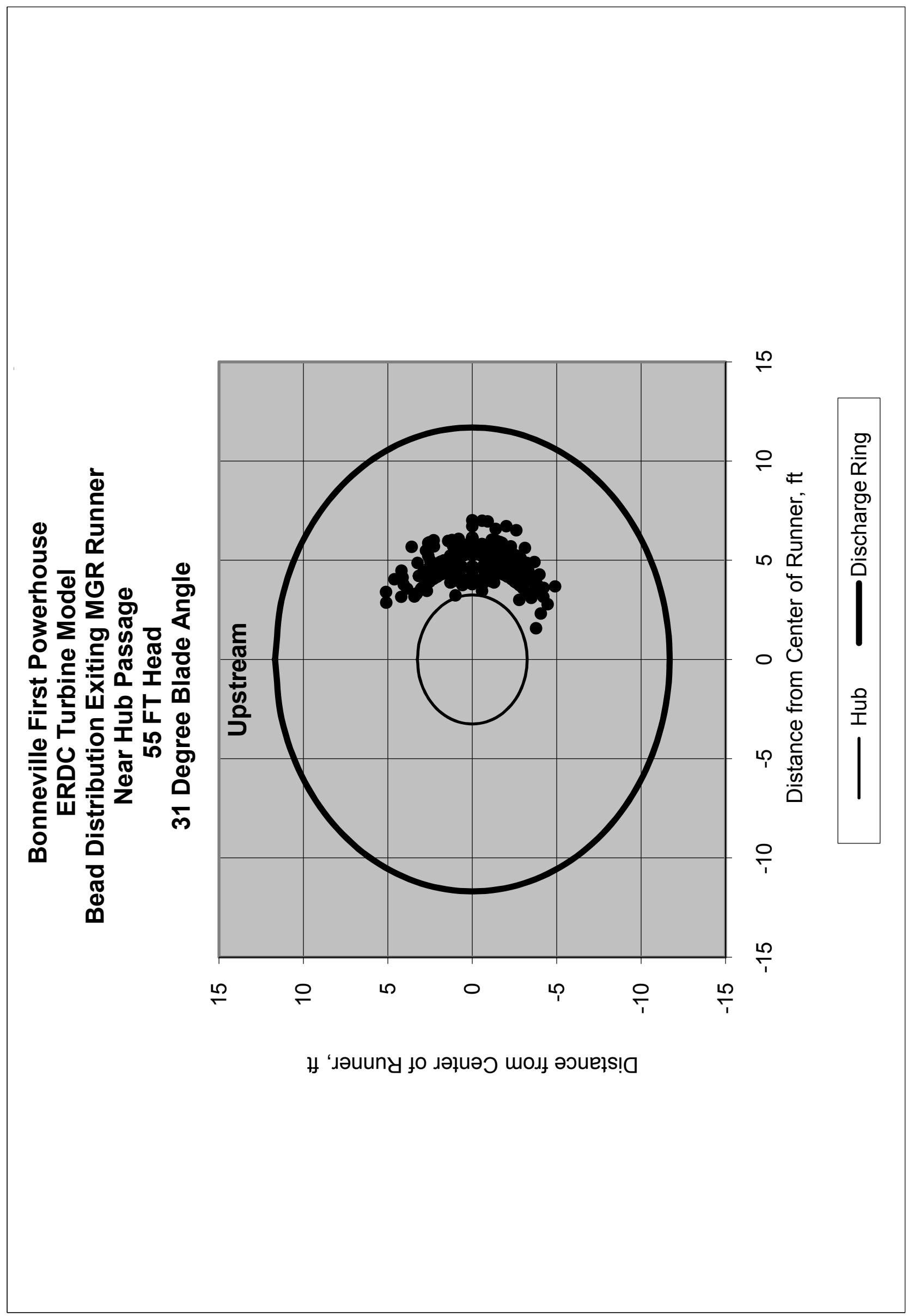

Plate 22 
Bonneville First Powerhouse

ERDC Turbine Model

Runner Contact Bead Passage Scores

55 FT Head

Hub Region (Top Of Stay Vane Release)

\begin{tabular}{|c|c|c|c|c|c|c|c|c|c|c|c|}
\hline $\begin{array}{c}\text { Blade } \\
\text { Angle, } \\
\text { Deg }\end{array}$ & $\begin{array}{c}\text { Target } \\
\text { Discharge, } \\
\text { cfs }\end{array}$ & $\begin{array}{c}\text { Contact } \\
\text { score }\end{array}$ & $\begin{array}{c}\text { Contact } \\
\text { Stdev }\end{array}$ & $\begin{array}{c}\text { Contact } \\
\text { Variance }\end{array}$ & $\begin{array}{c}\text { \% severe } \\
\text { contact 1's } \\
\text { and 2's }\end{array}$ & $\begin{array}{c}\text { Standard } \\
\text { error \% }\end{array}$ & $\begin{array}{c}95 \% \\
\text { Confidence } \\
\text { interval }\end{array}$ & $\begin{array}{c}\% \text { contact } \\
1 \text { 's }, \begin{array}{c}2 \text { s } \\
\text { and 3's }\end{array}\end{array}$ & $\begin{array}{c}\text { Standard } \\
\text { error \% }\end{array}$ & $\begin{array}{c}\text { Confidence } \\
\text { interval }\end{array}$ \\
\hline 16.5 & 7266 & 5.68 & 0.59 & 0.35 & 0.8 & 0.3 & 0.7 & 0.8 & 0.3 & 0.7 & 650 \\
\hline 17.5 & 7529 & 5.73 & 0.75 & 0.56 & 1.6 & 0.5 & 0.9 & 4.7 & 0.8 & 1.6 & 698 \\
\hline 22.4 & 9768 & 5.74 & 0.67 & 0.45 & 1.0 & 0.4 & 0.7 & 1.4 & 0.5 & 0.9 & 691 \\
\hline 27.5 & 11465 & 5.80 & 0.62 & 0.38 & 1.5 & 0.5 & 0.9 & 2.1 & 0.5 & 1.1 & 682 \\
\hline 31 & 13248 & 5.81 & 0.47 & 0.22 & 0.3 & 0.2 & 0.4 & 0.6 & 0.3 & 0.6 & 650 \\
\hline
\end{tabular}

Bonneville First Powerhouse

ERDC Turbine Model

Runner Change in Direction Bead Passage Scores

55 FT Head

Hub Region (Top Of Stay Vane Release)

\begin{tabular}{|c|c|c|c|c|c|c|c|c|c|c|c|}
\hline $\begin{array}{c}\text { Blade } \\
\text { Angle, } \\
\text { Deg }\end{array}$ & $\begin{array}{c}\text { Target } \\
\text { Discharge, } \\
\text { cfs }\end{array}$ & $\begin{array}{c}\text { Ch } \\
\text { Direction } \\
\text { score }\end{array}$ & $\begin{array}{c}\text { Ch } \\
\text { Direction } \\
\text { Stdev }\end{array}$ & $\begin{array}{c}\text { Ch } \\
\text { Direction } \\
\text { Variance }\end{array}$ & $\begin{array}{c}\% \text { severe } \\
\text { Ch } \\
\text { Direction } \\
1 \text { 's }\end{array}$ & $\begin{array}{c}\text { Standard } \\
\text { error \% }\end{array}$ & $\begin{array}{c}95 \% \\
\text { Confidence } \\
\text { interval }\end{array}$ & $\begin{array}{c}\text { \% Ch } \\
\text { Direction } \\
\text { 1's and 2's }\end{array}$ & $\begin{array}{c}\text { Standard } \\
\text { error } \%\end{array}$ & $\begin{array}{c}(95 \% \\
\text { Confidence } \\
\text { interval }\end{array}$ & \# of beads \\
\hline 16.5 & 7266 & 2.91 & 0.90 & 0.80 & 12.5 & 1.3 & 2.5 & 19.7 & 1.6 & 3.1 & 650 \\
\hline 17.5 & 7529 & 3.00 & 0.86 & 0.75 & 10.7 & 1.2 & 2.3 & 15.9 & 1.4 & 2.7 & 698 \\
\hline 22.4 & 9768 & 3.06 & 0.74 & 0.55 & 3.6 & 0.7 & 1.4 & 17.1 & 1.4 & 2.8 & 691 \\
\hline 27.5 & 11465 & 3.21 & 0.59 & 0.35 & 1.6 & 0.5 & 0.9 & 6.3 & 0.9 & 1.8 & 682 \\
\hline 31 & 13248 & 3.33 & 0.71 & 0.50 & 3.2 & 0.7 & 1.4 & 7.5 & 1.0 & 2.0 & 650 \\
\hline
\end{tabular}

Bonneville First Powerhouse

ERDC Turbine Model

Runner Product Bead Passage Scores

55 FT Head

Hub Region (Top Of Stay Vane Release)

\begin{tabular}{|c|c|c|c|c|c|}
\hline $\begin{array}{c}\text { Blade } \\
\text { Angle, } \\
\text { Deg }\end{array}$ & $\begin{array}{c}\text { Target } \\
\text { Discharge, } \\
\text { cfs }\end{array}$ & $\begin{array}{c}\text { Product } \\
\text { Score }\end{array}$ & $\begin{array}{c}\text { Product } \\
\text { Std Dev }\end{array}$ & $\begin{array}{c}\text { Product } \\
\text { Variance }\end{array}$ & \# of beads \\
\hline 16.5 & 7266 & 16.88 & 5.85 & 34.26 & 650 \\
\hline 17.5 & 7529 & 17.53 & 5.78 & 33.36 & 698 \\
\hline 22.4 & 9768 & 17.85 & 5.11 & 26.10 & 691 \\
\hline 27.5 & 11465 & 18.81 & 4.23 & 17.94 & 682 \\
\hline 31 & 13248 & 19.51 & 4.77 & 22.71 & 650 \\
\hline
\end{tabular}




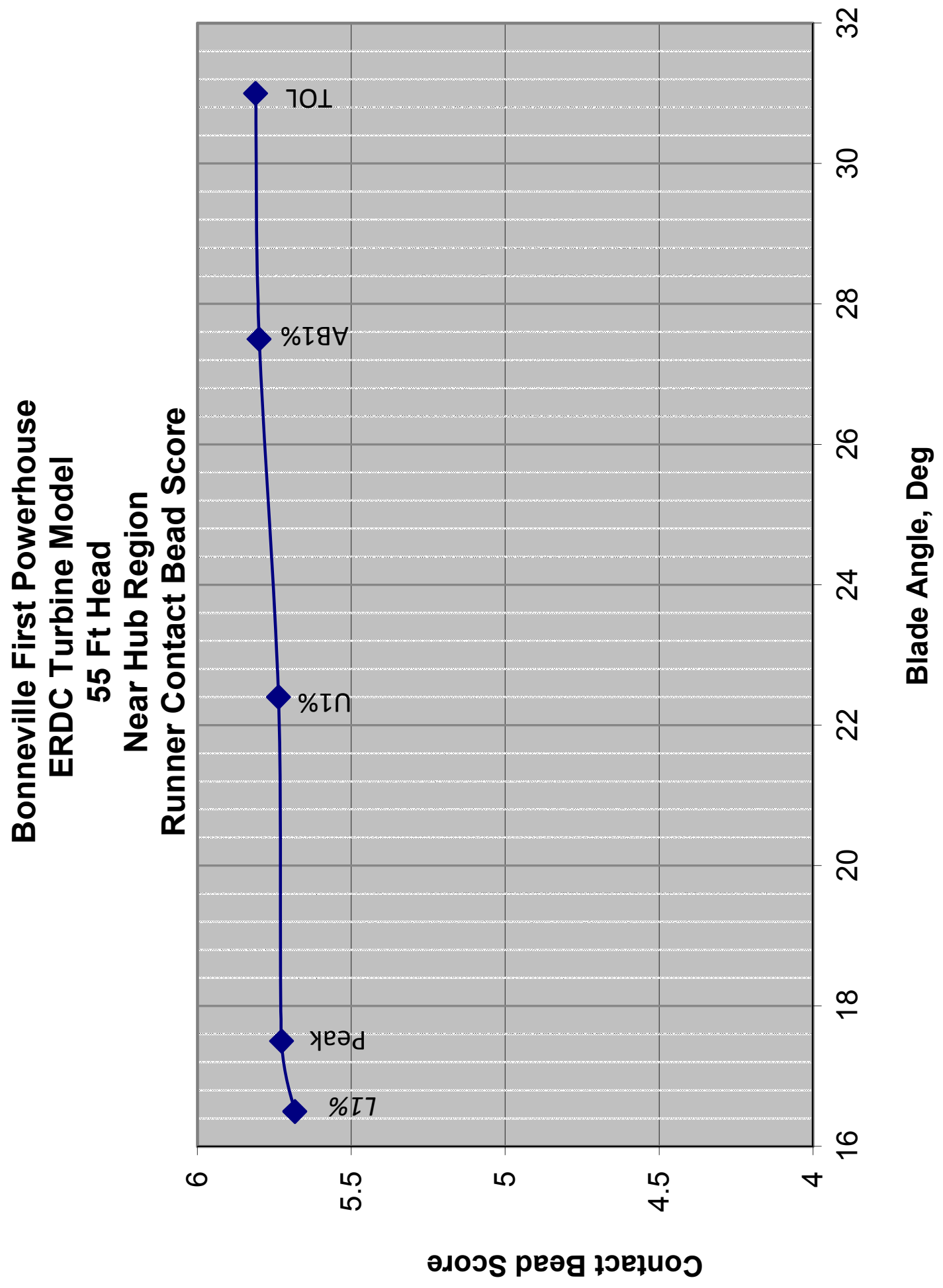

Plate 24 


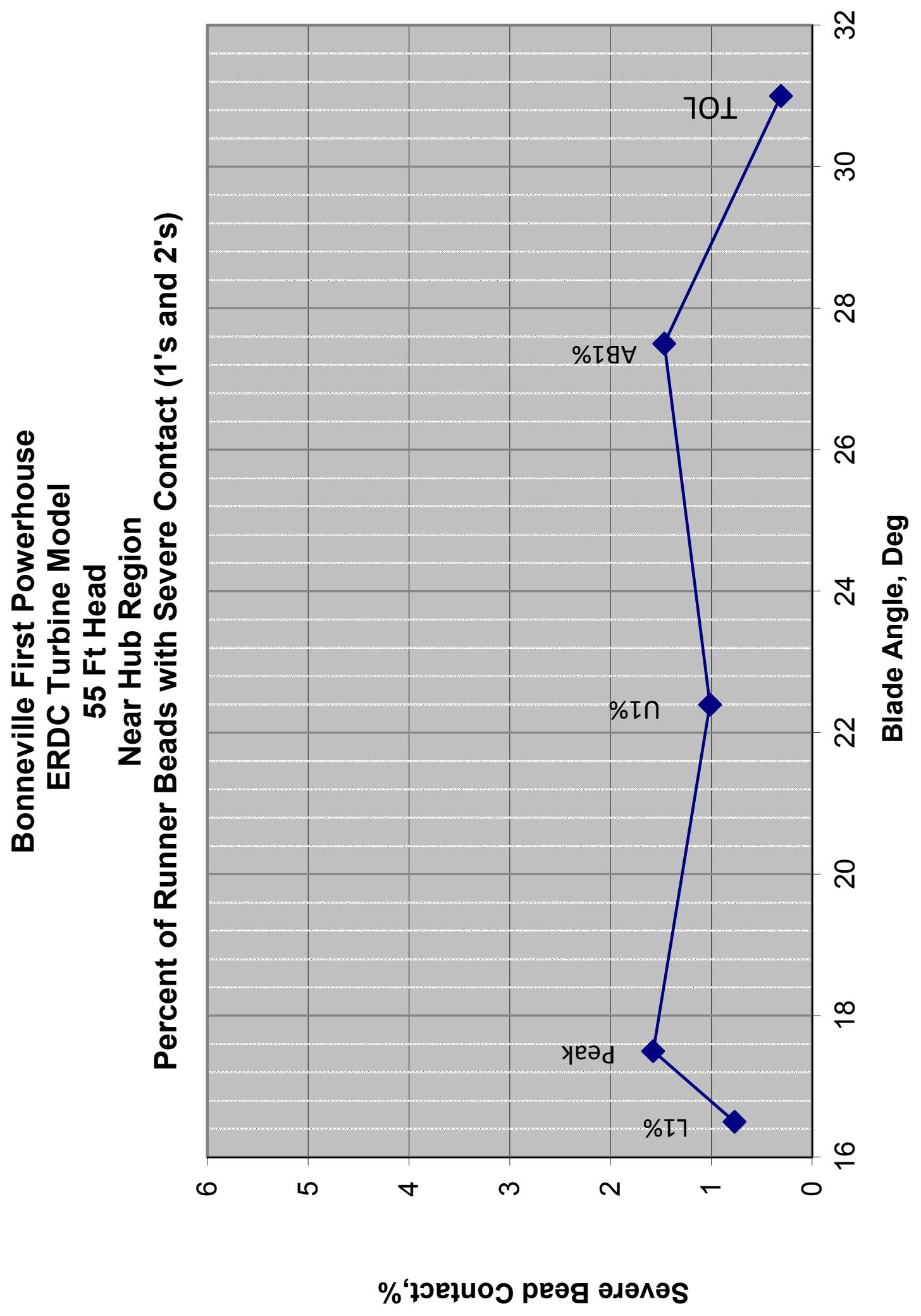

Plate 25 


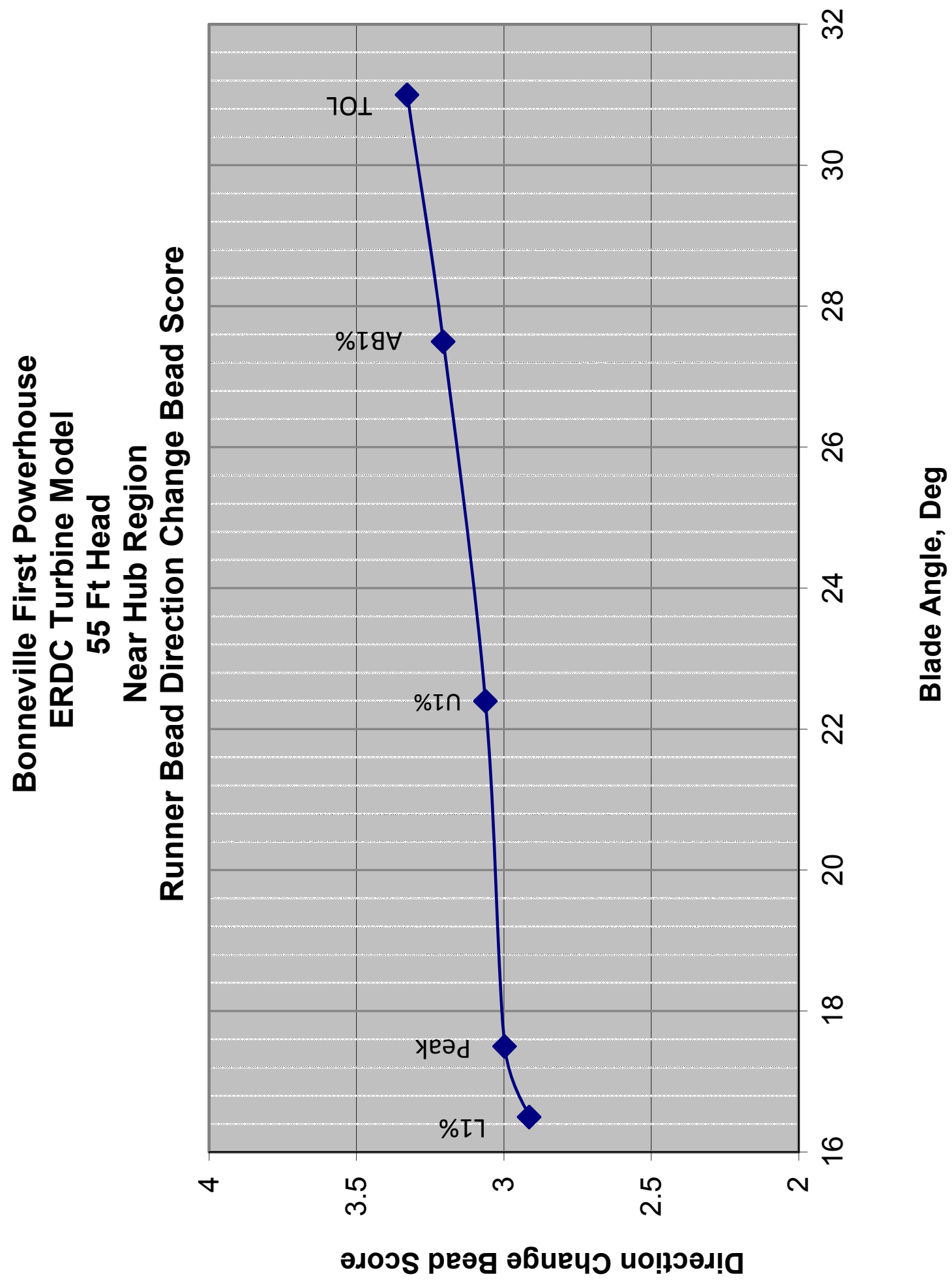




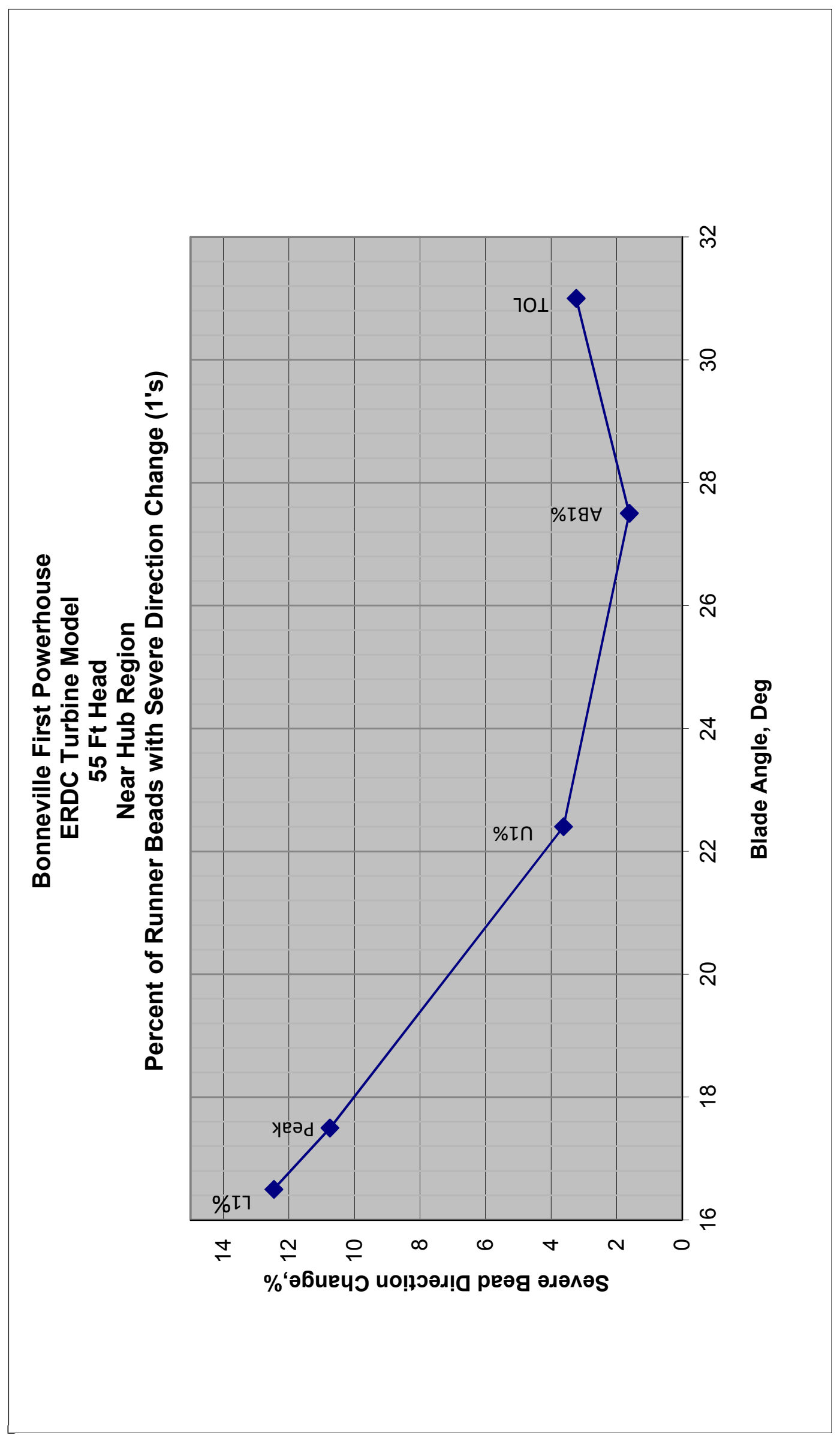




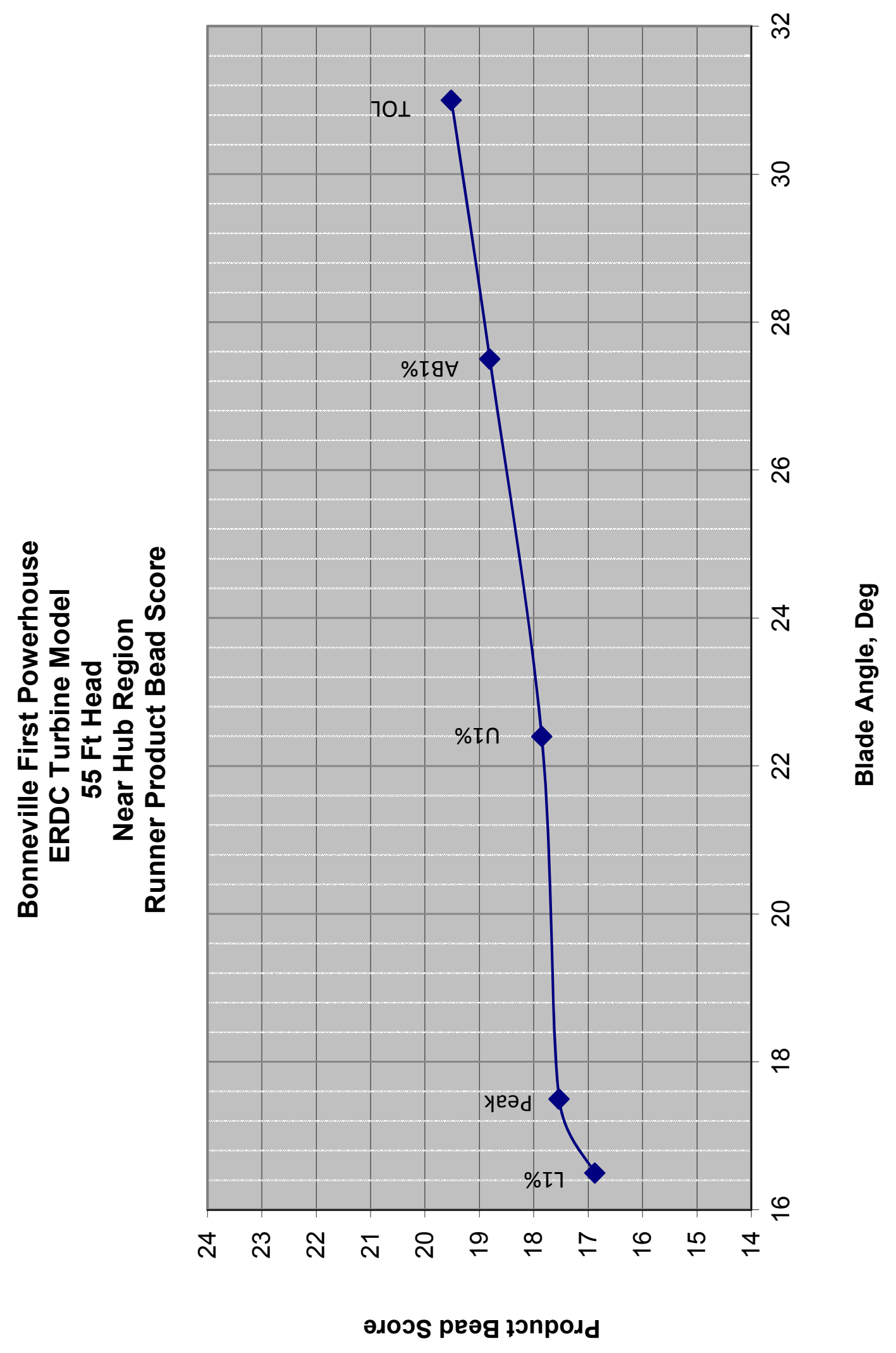




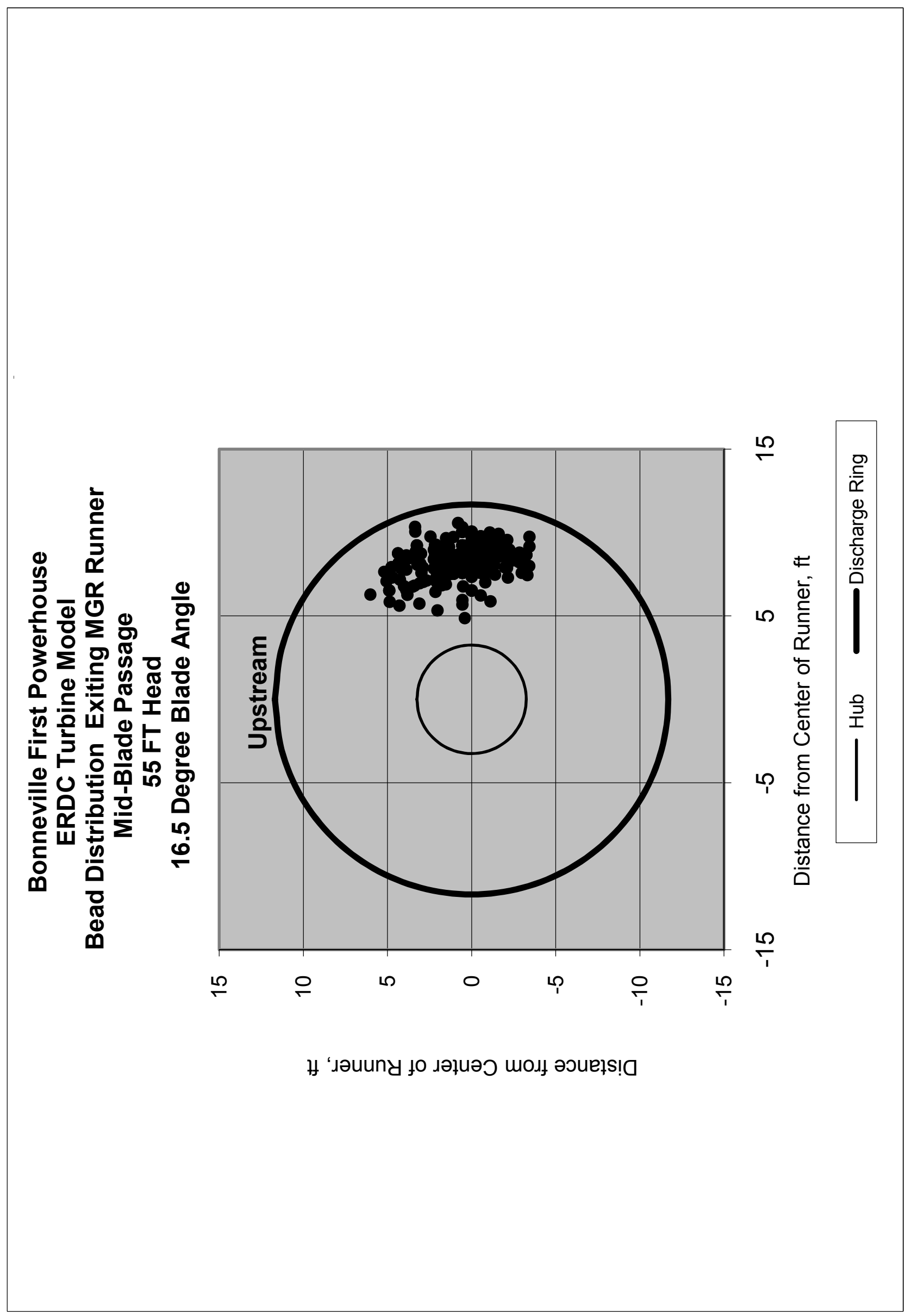

Plate 29 


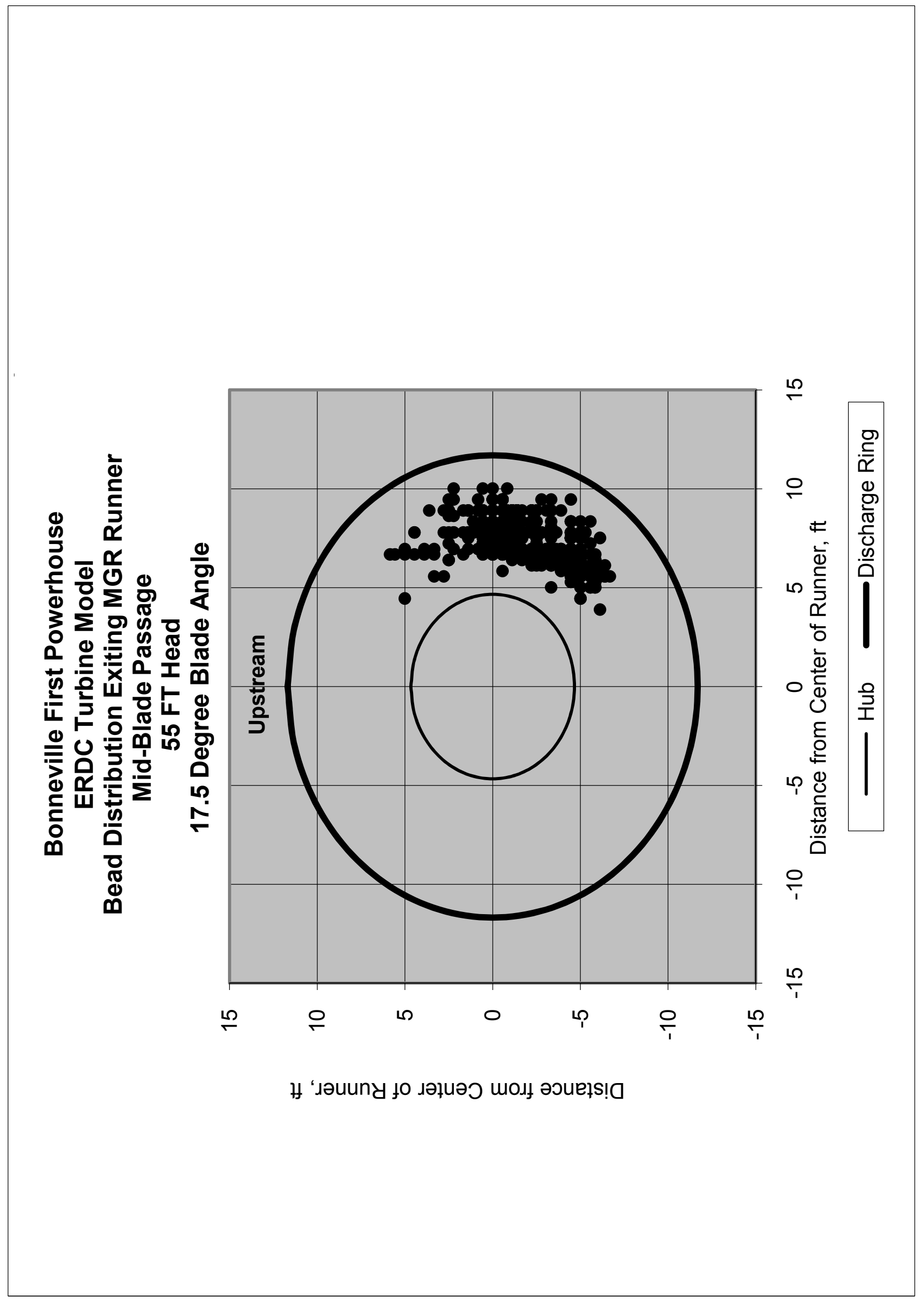




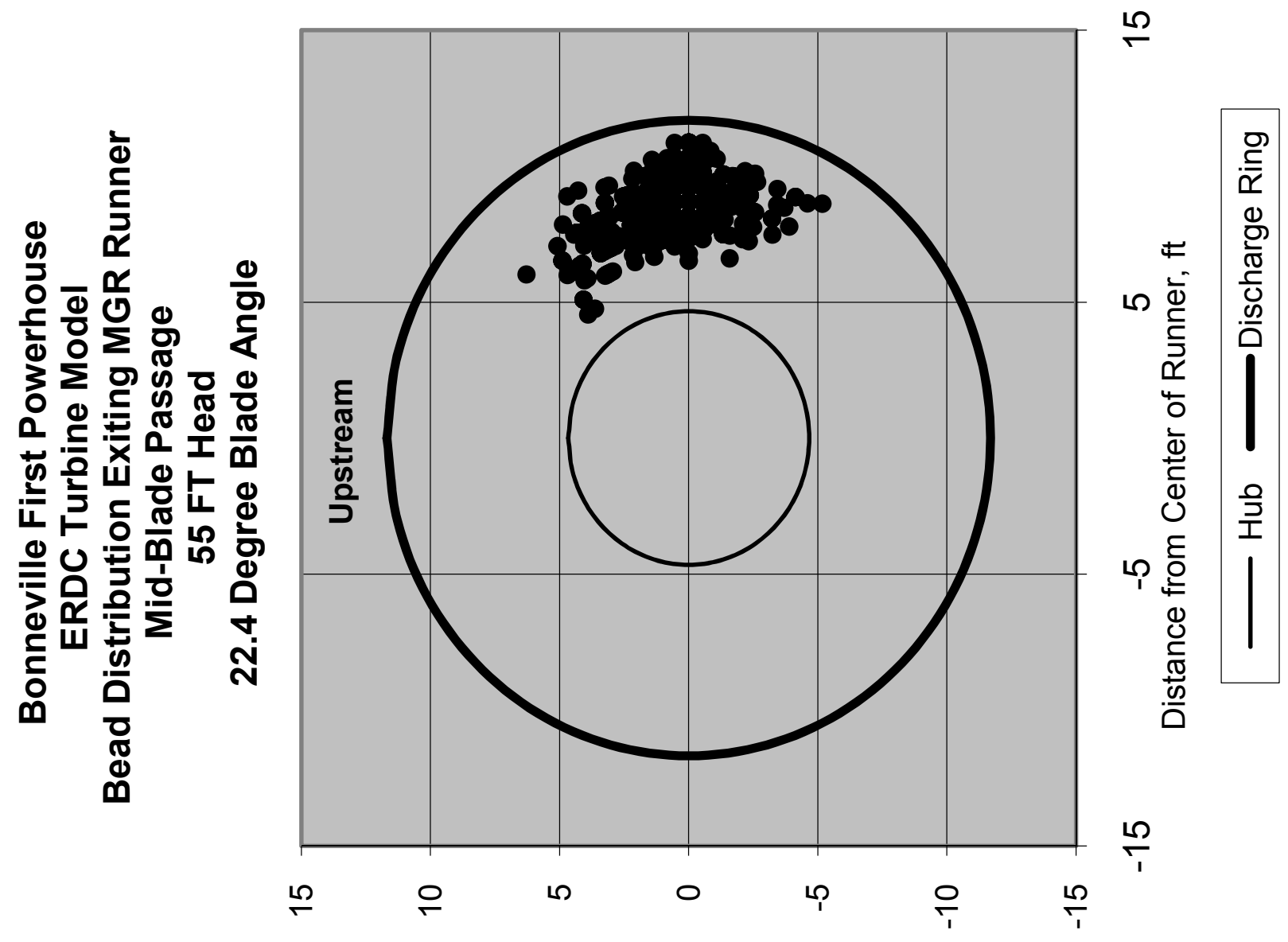

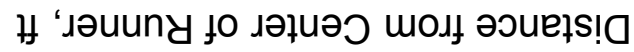




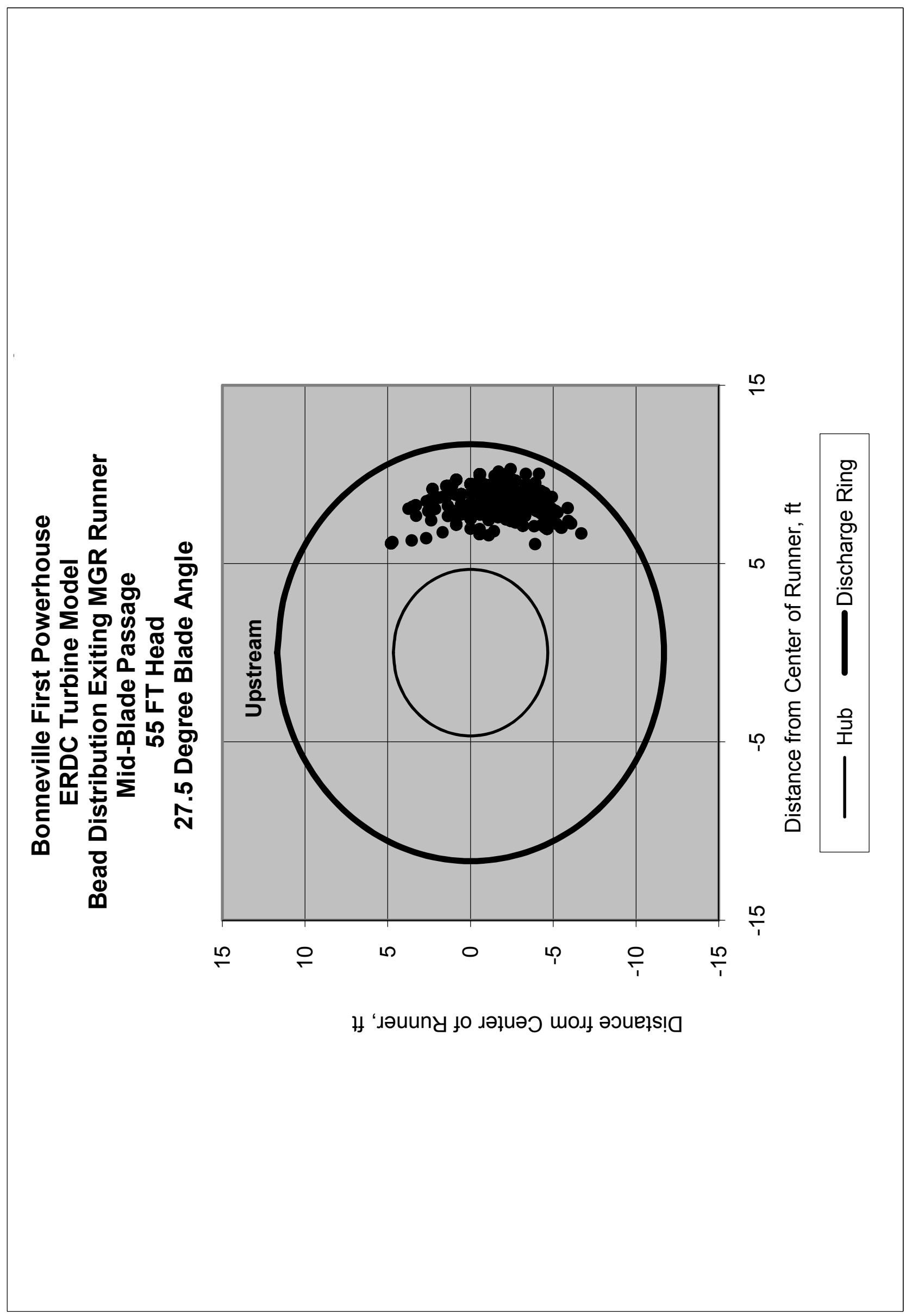

Plate 32 


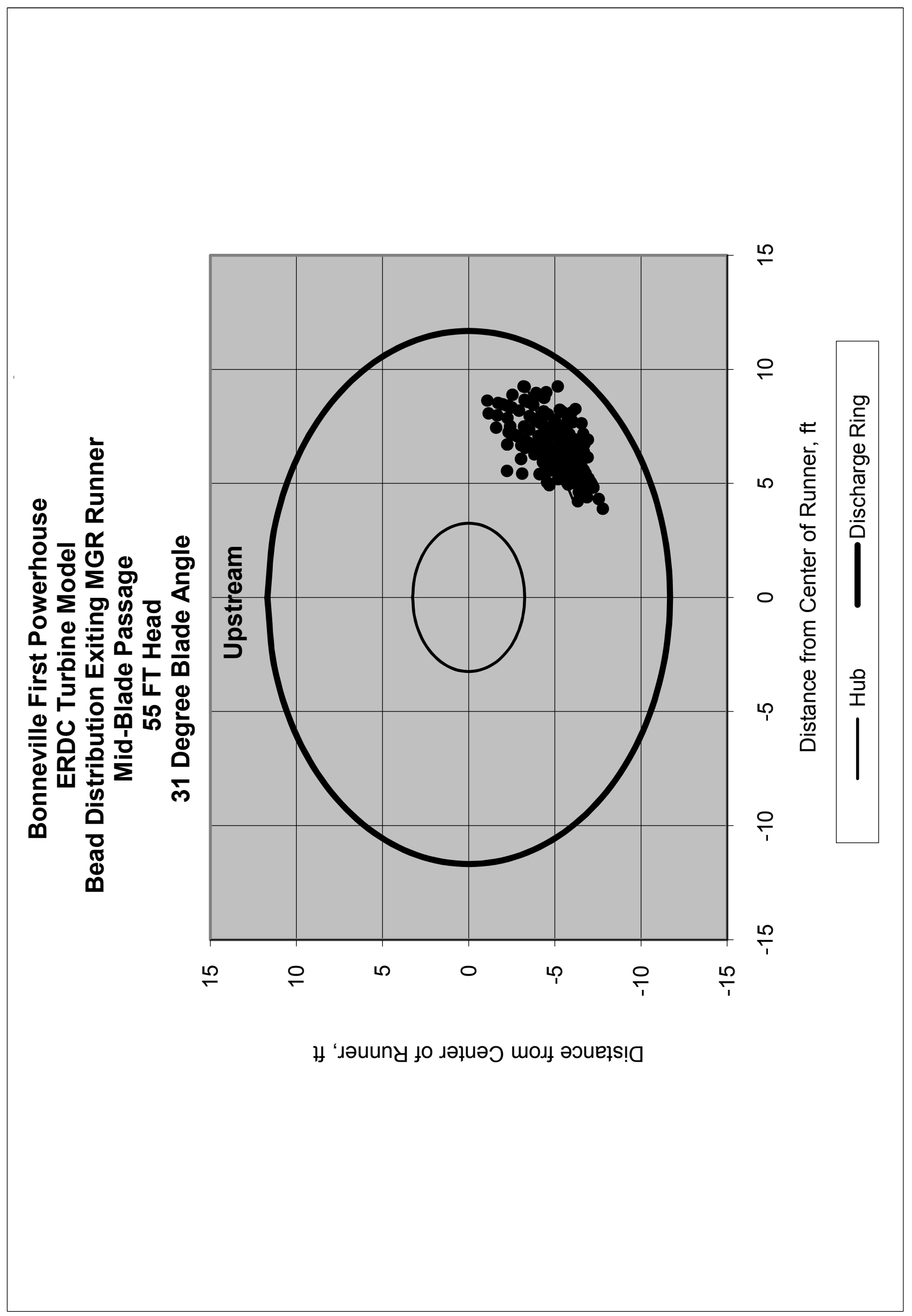


Bonneville First Powerhouse

ERDC Turbine Model

Runner Contact Bead Passage Scores

55 FT Head

Mid-blade Region (Middle Of Stay Vane Release)

\begin{tabular}{|c|c|c|c|c|c|c|c|c|c|c|c|}
\hline $\begin{array}{c}\text { Blade } \\
\text { Angle, } \\
\text { Deg }\end{array}$ & $\begin{array}{c}\text { Target } \\
\text { Discharge, } \\
\text { cfs }\end{array}$ & $\begin{array}{c}\text { Contact } \\
\text { score }\end{array}$ & $\begin{array}{c}\text { Contact } \\
\text { Stdev }\end{array}$ & $\begin{array}{l}\text { Contact } \\
\text { Variance }\end{array}$ & $\begin{array}{c}\% \text { severe } \\
\text { contact } \\
1 \text { 's and 2's }\end{array}$ & $\begin{array}{c}\text { Standard } \\
\text { error } \%\end{array}$ & $\begin{array}{c}95 \% \\
\text { Confidence } \\
\text { interval }\end{array}$ & $\begin{array}{c}\% \text { contact } \\
1 \text { 's , 2's } \\
\text { and } 3 \text { 's }\end{array}$ & $\begin{array}{c}\text { Standard } \\
\text { error } \%\end{array}$ & $\begin{array}{c}95 \% \\
\text { Confidence } \\
\text { interval }\end{array}$ & \# of beads \\
\hline 16.5 & 7266 & 5.86 & 0.66 & 0.44 & 1.7 & 0.7 & 1.4 & 2.0 & 0.7 & 1.5 & 350 \\
\hline 17.5 & 7529 & 5.86 & 0.66 & 0.44 & 1.8 & 0.6 & 1.1 & 2.0 & 0.6 & 1.2 & 545 \\
\hline 22.4 & 9768 & 5.92 & 0.53 & 0.28 & 1.2 & 0.5 & 1.0 & 1.2 & 0.5 & 1.0 & 500 \\
\hline 27.5 & 11465 & 5.96 & 0.30 & 0.09 & 0.2 & 0.2 & 0.4 & 0.2 & 0.2 & 0.4 & 494 \\
\hline 31 & 13248 & 5.95 & 0.39 & 0.16 & 0.6 & 0.4 & 0.8 & 0.9 & 0.5 & 1.0 & 350 \\
\hline
\end{tabular}

Bonneville First Powerhouse

ERDC Turbine Model

Runner Change in Direction Bead Passage Scores

55 FT Head

Mid-blade Region (Middle Of Stay Vane Release)

\begin{tabular}{|c|c|c|c|c|c|c|c|c|c|c|c|}
\hline $\begin{array}{c}\text { Blade } \\
\text { Angle, } \\
\text { Deg }\end{array}$ & $\begin{array}{c}\text { Target } \\
\text { Discharge, } \\
\text { cfs }\end{array}$ & $\begin{array}{c}\text { Ch } \\
\text { Direction } \\
\text { score }\end{array}$ & $\begin{array}{c}\text { Ch } \\
\text { Direction } \\
\text { Stdev }\end{array}$ & $\begin{array}{c}\text { Ch } \\
\text { Direction } \\
\text { Variance }\end{array}$ & $\begin{array}{c}\text { \% severe } \\
\text { Ch } \\
\text { Direction } \\
1 \text { 's }\end{array}$ & $\begin{array}{c}\text { Standard } \\
\text { error \% }\end{array}$ & $\begin{array}{c}\text { 95\% } \\
\text { Confidence } \\
\text { interval }\end{array}$ & $\begin{array}{c}\text { Ch } \\
\text { Direction } \\
1 \text { 's and 2's }\end{array}$ & $\begin{array}{c}\text { Standard } \\
\text { error } \%\end{array}$ & $\begin{array}{c}\text { C5\% } \\
\text { Confidence } \\
\text { interval }\end{array}$ \\
\hline 16.5 & 7266 & 3.51 & 0.63 & 0.40 & 1.7 & 0.7 & 1.4 & 4.0 & 1.0 & 2.1 & 350 \\
\hline 17.5 & 7529 & 3.43 & 0.62 & 0.39 & 2.0 & 0.6 & 1.2 & 3.1 & 0.7 & 1.5 & 545 \\
\hline 22.4 & 9768 & 3.39 & 0.57 & 0.33 & 1.0 & 0.4 & 0.9 & 2.4 & 0.7 & 1.3 & 500 \\
\hline 27.5 & 11465 & 3.46 & 0.52 & 0.27 & 0.2 & 0.2 & 0.4 & 0.6 & 0.3 & 0.7 & 494 \\
\hline 31 & 13248 & 3.44 & 0.54 & 0.29 & 0.6 & 0.4 & 0.8 & 1.1 & 0.6 & 1.1 & 350 \\
\hline
\end{tabular}

Bonneville First Powerhouse

ERDC Turbine Model

Runner Product Bead Passage Scores

55 FT Head

Mid-blade Region (Middle Of Stay Vane Release)

\begin{tabular}{|c|c|c|c|c|c|}
\hline $\begin{array}{c}\text { Blade } \\
\text { Angle, } \\
\text { Deg }\end{array}$ & $\begin{array}{c}\text { Target } \\
\text { Discharge, } \\
\text { cfs }\end{array}$ & $\begin{array}{c}\text { Product } \\
\text { Score }\end{array}$ & $\begin{array}{c}\text { Product } \\
\text { Std Dev }\end{array}$ & $\begin{array}{c}\text { Product } \\
\text { Variance }\end{array}$ & \# of beads \\
\hline 16.5 & 7266 & 20.85 & 4.38 & 19.20 & 350.00 \\
\hline 17.5 & 7529 & 20.37 & 4.29 & 18.38 & 545.00 \\
\hline 22.4 & 9768 & 20.24 & 3.80 & 14.42 & 500.00 \\
\hline 27.5 & 11465 & 20.66 & 3.33 & 11.06 & 494.00 \\
\hline 31 & 13248 & 20.54 & 3.49 & 12.15 & 350.00 \\
\hline
\end{tabular}




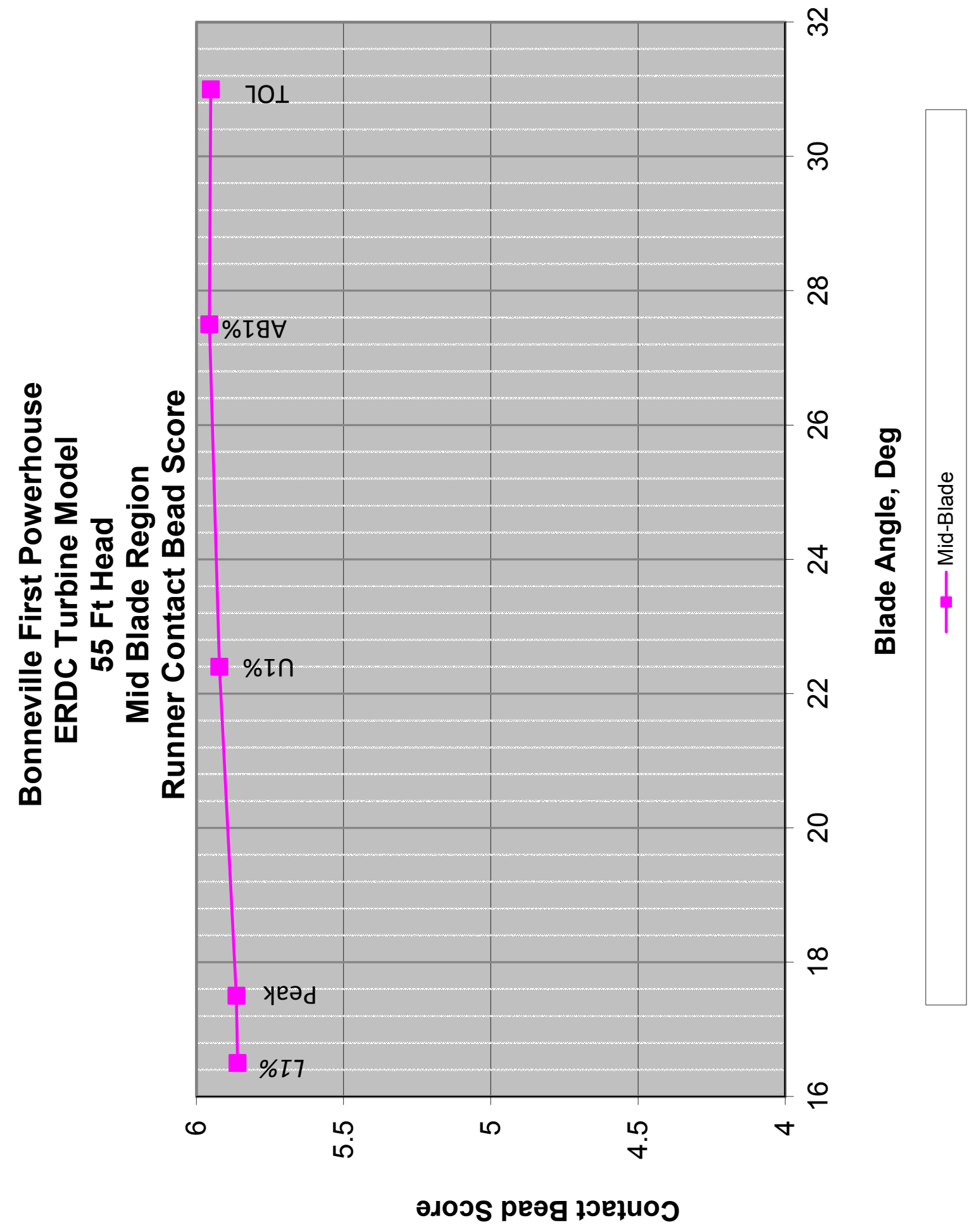

Plate 35 


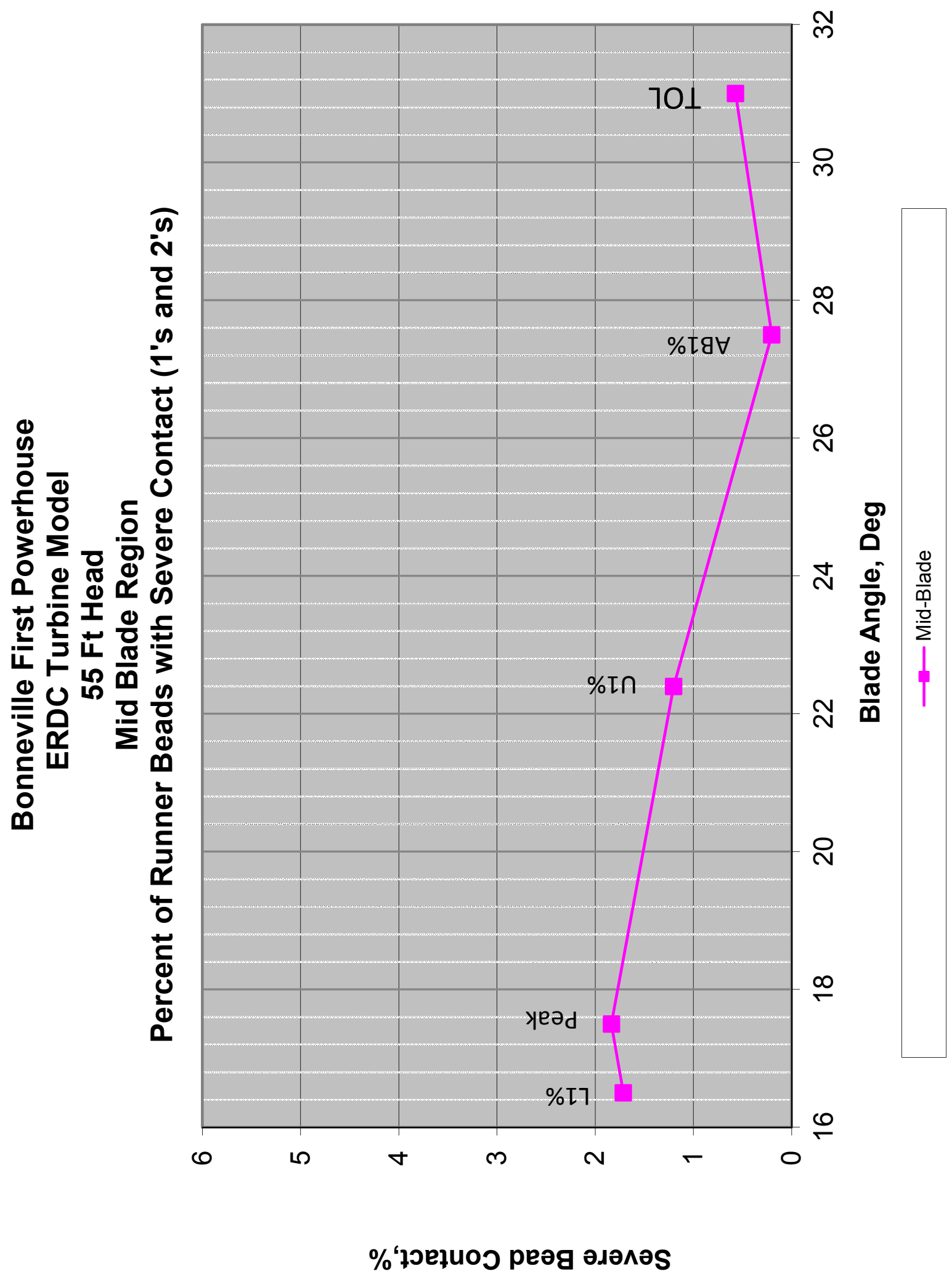




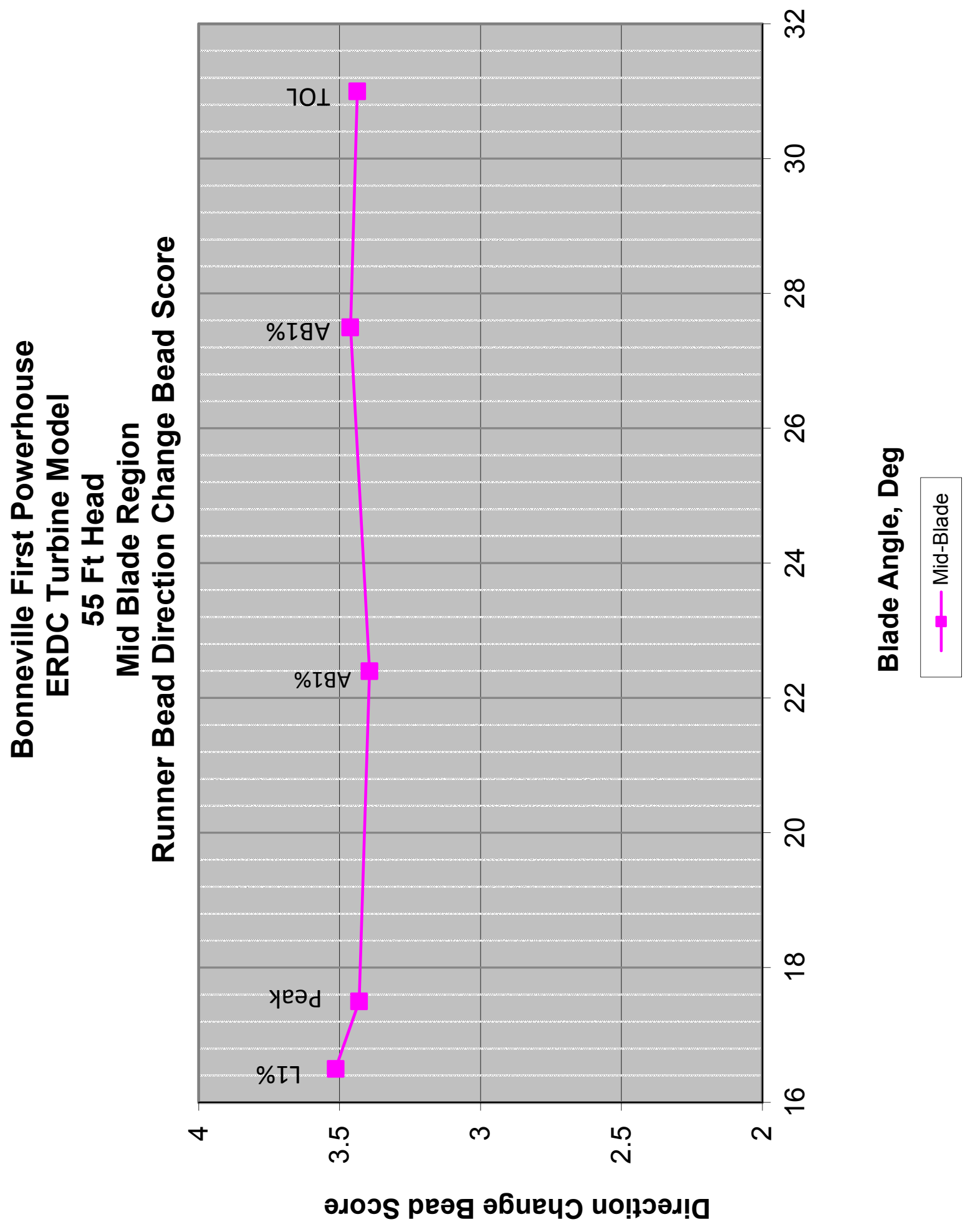

Plate 37 


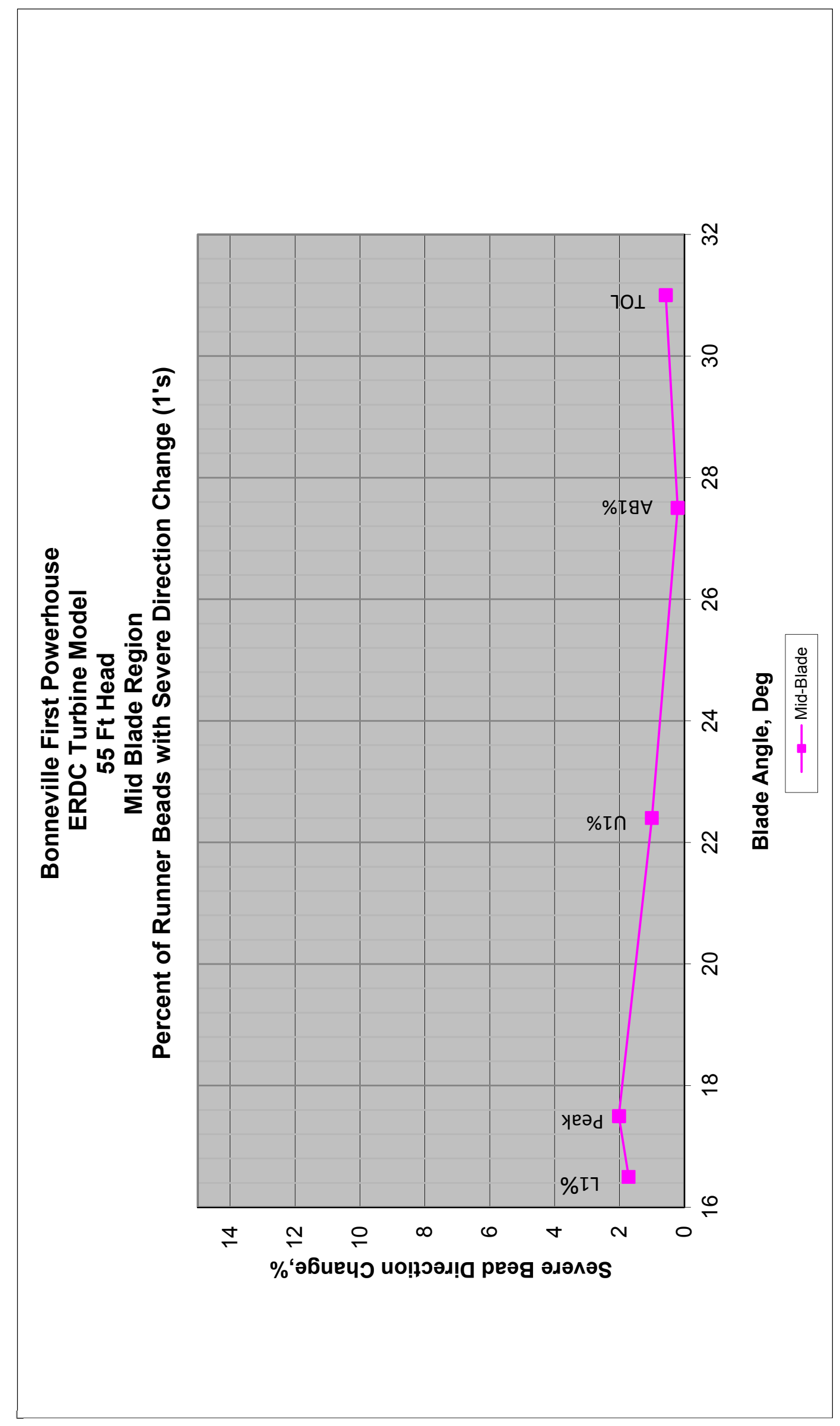

Plate 38 


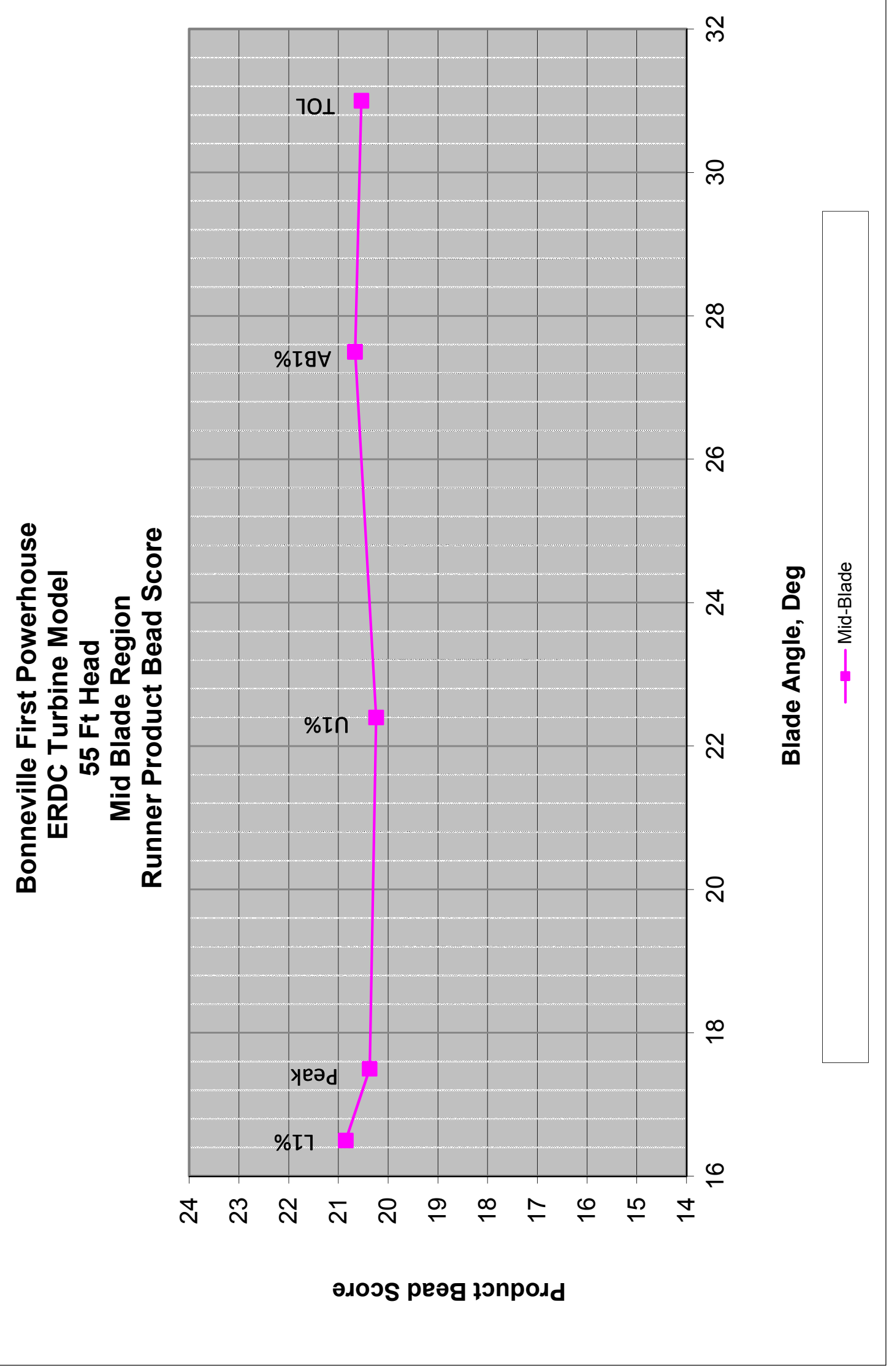

Plate 39 


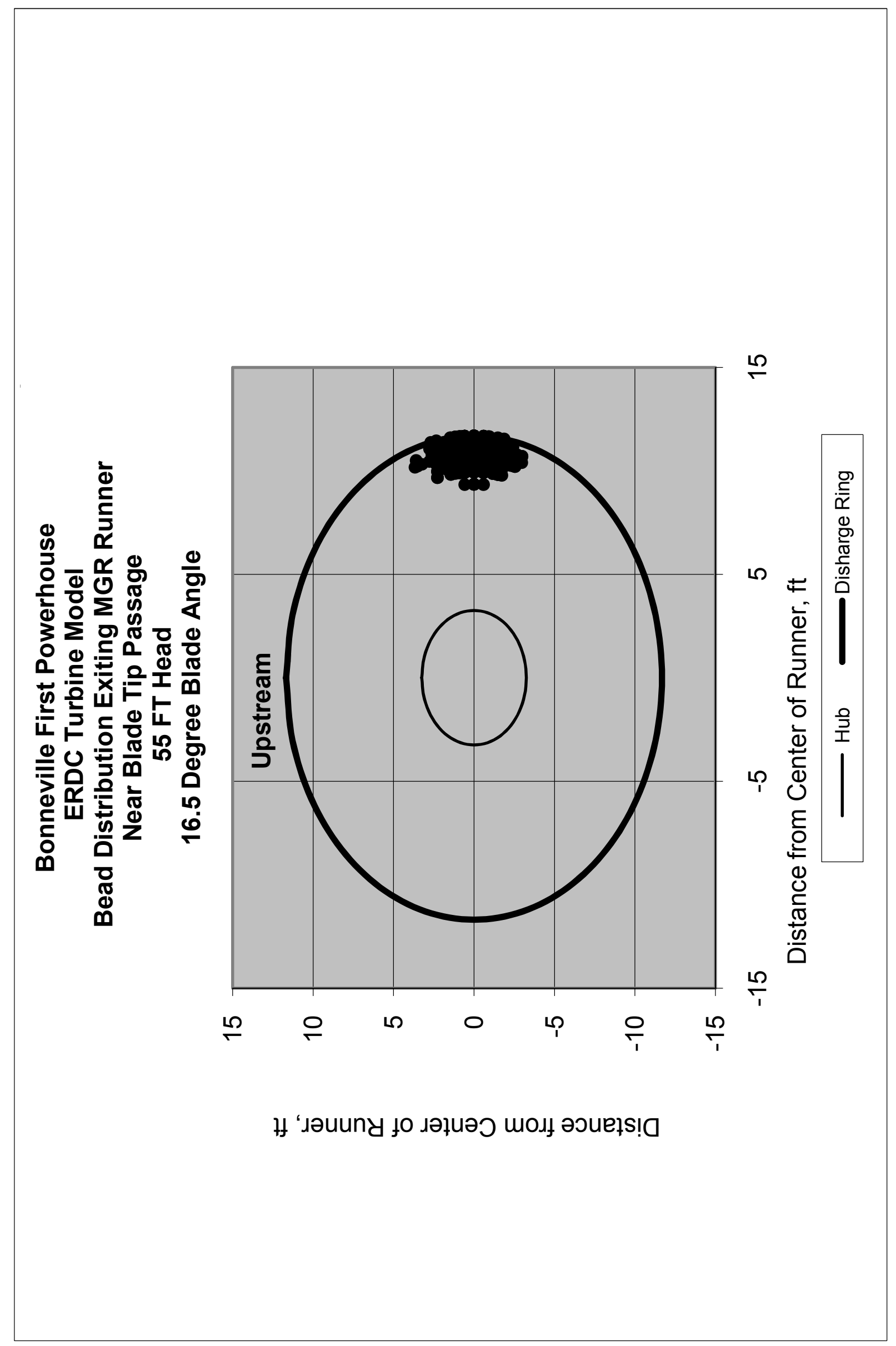




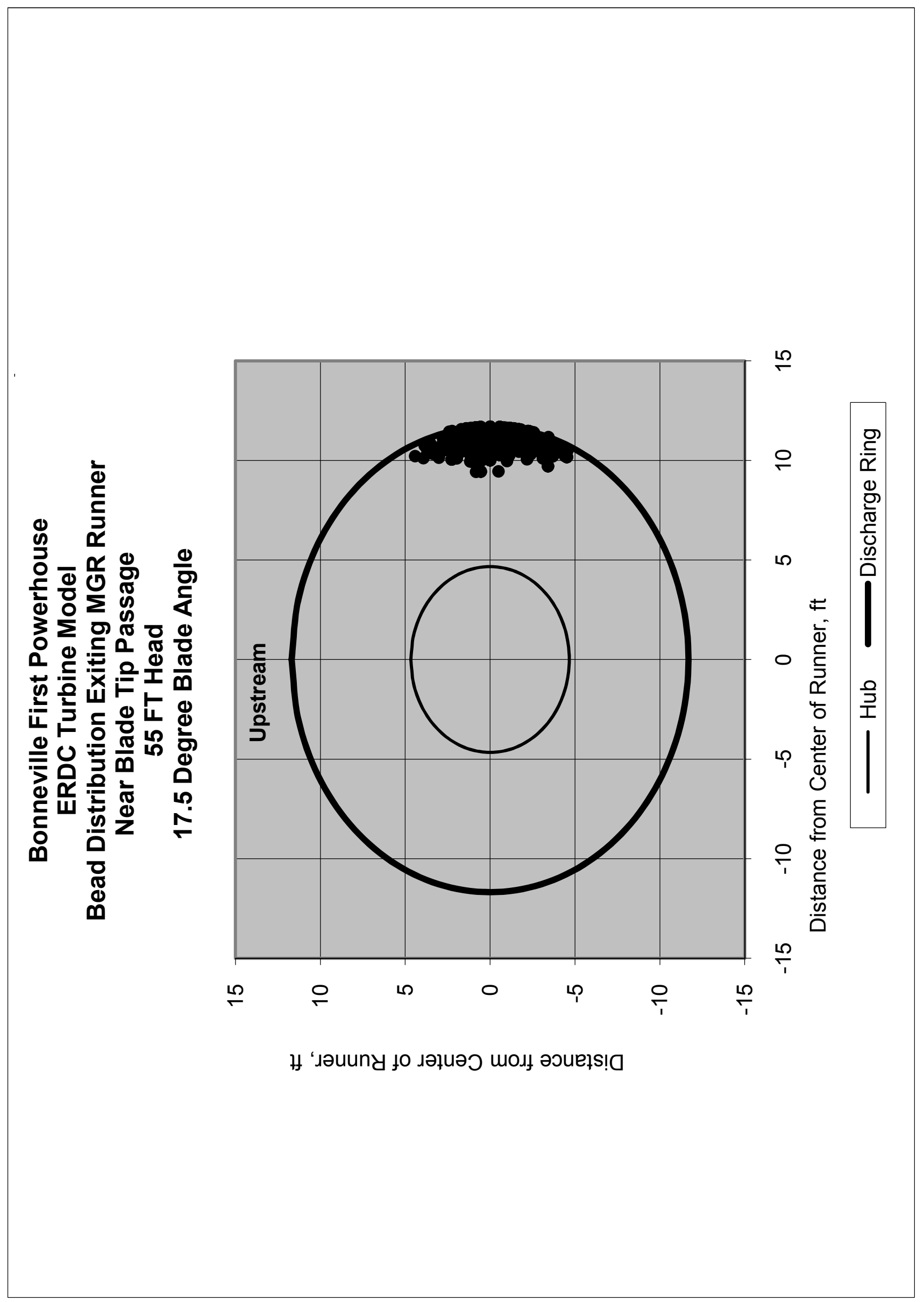

Plate 41 


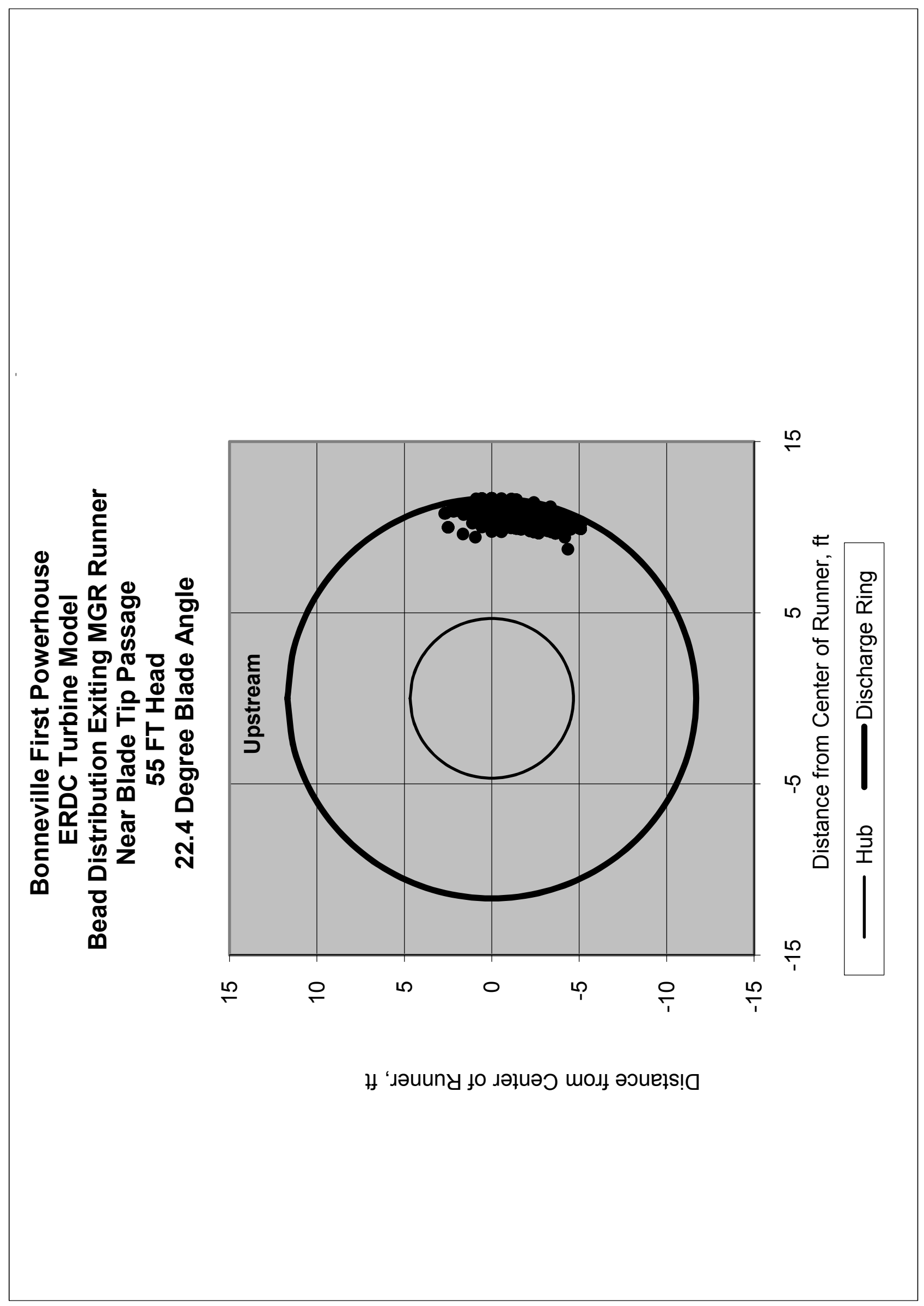




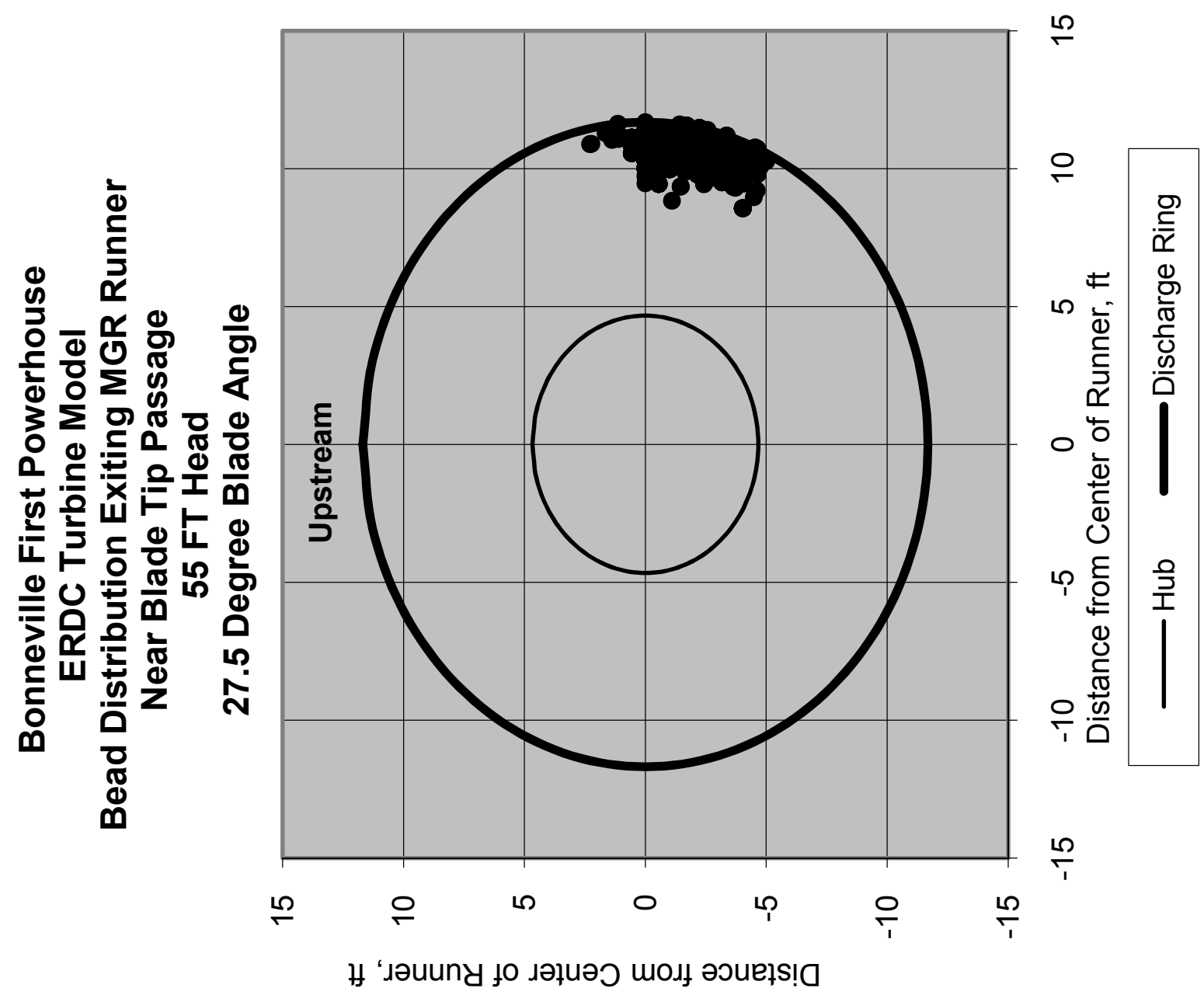

Plate 43 


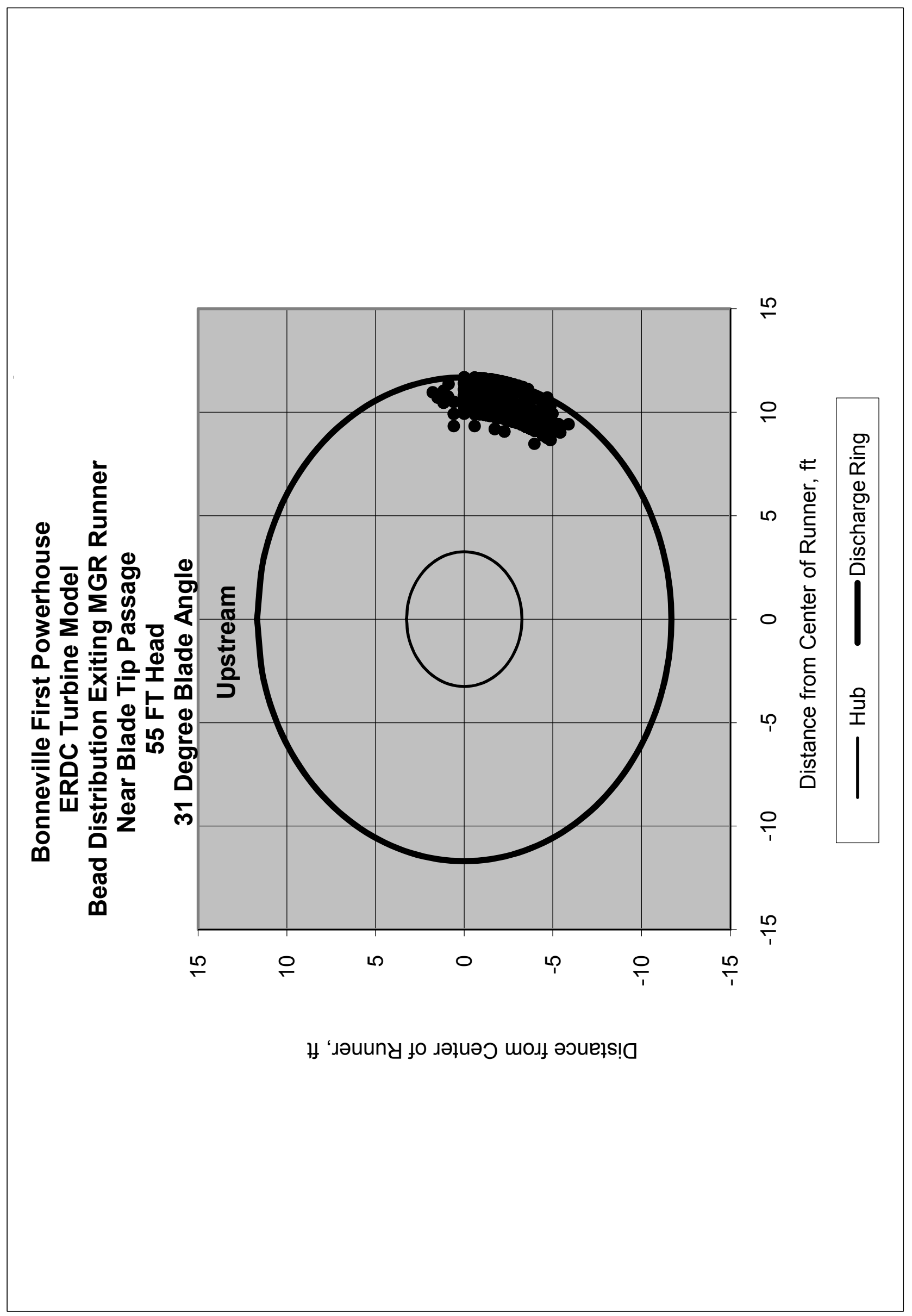

Plate 44 
Bonneville First Powerhouse

ERDC Turbine Model

Runner Contact Bead Passage Scores

55 FT Head

Tip Region (Bottom Of Stay Vane Release)

\begin{tabular}{|c|c|c|c|c|c|c|c|c|c|c|c|}
\hline $\begin{array}{c}\text { Blade } \\
\text { Angle, } \\
\text { Deg }\end{array}$ & $\begin{array}{c}\text { Target } \\
\text { Discharge, } \\
\text { cfs }\end{array}$ & $\begin{array}{c}\text { Contact } \\
\text { score }\end{array}$ & $\begin{array}{c}\text { Contact } \\
\text { Stdev }\end{array}$ & $\begin{array}{c}\text { Contact } \\
\text { Variance }\end{array}$ & $\begin{array}{c}\text { \% severe } \\
\text { contact } \\
\text { 1's and 2's }\end{array}$ & $\begin{array}{c}\text { Standard } \\
\text { error \% }\end{array}$ & $\begin{array}{c}95 \% \\
\text { Confidence } \\
\text { interval }\end{array}$ & $\begin{array}{c}\text { contact } \\
\text { 1's }, 2 \text { 's } \\
\text { and }\end{array}$ & $\begin{array}{c}\text { Standard } \\
\text { error \% }\end{array}$ & $\begin{array}{c}\text { Confidence } \\
\text { interval }\end{array}$ \\
\hline 16.5 & 7266 & 5.61 & 0.99 & 0.98 & 3.9 & 0.8 & 1.5 & 5.5 & 0.9 & 1.8 & 649 \\
\hline 17.5 & 7529 & 5.69 & 0.93 & 0.87 & 3.7 & 0.7 & 1.4 & 4.0 & 0.7 & 1.5 & 700 \\
\hline 22.4 & 9768 & 5.83 & 0.65 & 0.43 & 1.3 & 0.4 & 0.8 & 1.7 & 0.5 & 1.0 & 699 \\
\hline 27.5 & 11465 & 5.67 & 0.68 & 0.46 & 1.1 & 0.4 & 0.8 & 1.9 & 0.5 & 1.0 & 699 \\
\hline 31 & 13248 & 5.82 & 0.58 & 0.34 & 1.2 & 0.4 & 0.8 & 1.2 & 0.4 & 0.8 & 651 \\
\hline
\end{tabular}

Bonneville First Powerhouse

ERDC Turbine Model

Runner Change in Direction Bead Passage Scores

55 FT Head

Tip Region (Bottom Of Stay Vane Release)

\begin{tabular}{|c|c|c|c|c|c|c|c|c|c|c|c|}
\hline $\begin{array}{c}\text { Blade } \\
\text { Angle, } \\
\text { Deg }\end{array}$ & $\begin{array}{c}\text { Target } \\
\text { Discharge, } \\
\text { cfs }\end{array}$ & $\begin{array}{c}\text { Ch } \\
\text { Direction } \\
\text { score }\end{array}$ & $\begin{array}{c}\text { Ch } \\
\text { Direction } \\
\text { Stdev }\end{array}$ & $\begin{array}{c}\text { Ch } \\
\text { Direction } \\
\text { Variance }\end{array}$ & $\begin{array}{c}\text { \% severe } \\
\text { Ch } \\
\text { Direction } \\
1 \text { 's }\end{array}$ & $\begin{array}{c}\text { Standard } \\
\text { error \% }\end{array}$ & $\begin{array}{c}\text { 95\% } \\
\text { Confidence } \\
\text { interval }\end{array}$ & $\begin{array}{c}\text { Ch } \\
\text { Direction } \\
1 \text { 's and 2's }\end{array}$ & $\begin{array}{c}\text { Standard } \\
\text { error \% }\end{array}$ & $\begin{array}{c}\text { Confidence } \\
\text { interval }\end{array}$ \\
\hline 16.5 & 7266 & 3.06 & 0.75 & 0.56 & 6.5 & 1.0 & 1.9 & 11.9 & 1.3 & 2.5 & 649 \\
\hline 17.5 & 7529 & 3.15 & 0.73 & 0.53 & 5.0 & 0.8 & 1.6 & 10.1 & 1.1 & 2.2 & 700 \\
\hline 22.4 & 9768 & 3.06 & 0.64 & 0.41 & 4.6 & 0.8 & 1.5 & 8.2 & 1.0 & 2.0 & 699 \\
\hline 27.5 & 11465 & 3.08 & 0.71 & 0.50 & 4.3 & 0.8 & 1.5 & 11.4 & 1.2 & 2.4 & 699 \\
\hline 31 & 13248 & 3.34 & 0.72 & 0.52 & 3.4 & 0.7 & 1.4 & 8.6 & 1.1 & 2.2 & 651 \\
\hline
\end{tabular}

Bonneville First Powerhouse

ERDC Turbine Model

Runner Product Bead Passage Scores

55 FT Head

Tip Region (Bottom Of Stay Vane Release)

\begin{tabular}{|c|c|c|c|c|c|}
\hline $\begin{array}{c}\text { Blade } \\
\text { Angle, } \\
\text { Deg }\end{array}$ & $\begin{array}{c}\text { Target } \\
\text { Discharge, } \\
\text { cfs }\end{array}$ & $\begin{array}{c}\text { Product } \\
\text { Score }\end{array}$ & $\begin{array}{c}\text { Product } \\
\text { Std Dev }\end{array}$ & $\begin{array}{c}\text { Product } \\
\text { Variance }\end{array}$ & \# of beads \\
\hline 16.5 & 7266 & 17.74 & 5.42 & 29.40 & 649 \\
\hline 17.5 & 7529 & 18.36 & 5.21 & 27.10 & 700 \\
\hline 22.4 & 9768 & 18.08 & 4.35 & 18.93 & 699 \\
\hline 27.5 & 11465 & 17.77 & 5.02 & 25.18 & 699 \\
\hline 31 & 13248 & 19.73 & 4.94 & 24.41 & 651 \\
\hline
\end{tabular}




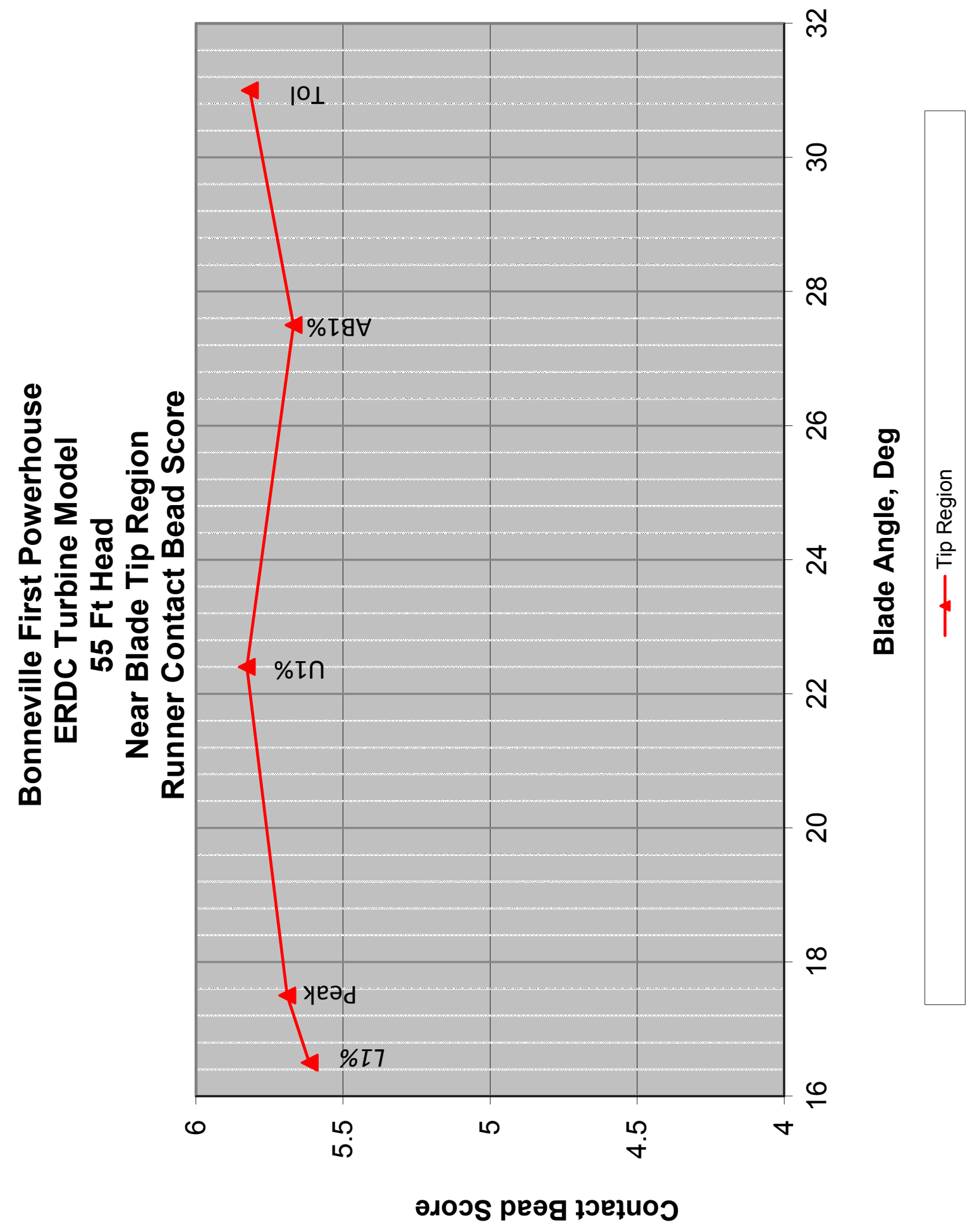

Plate 46 


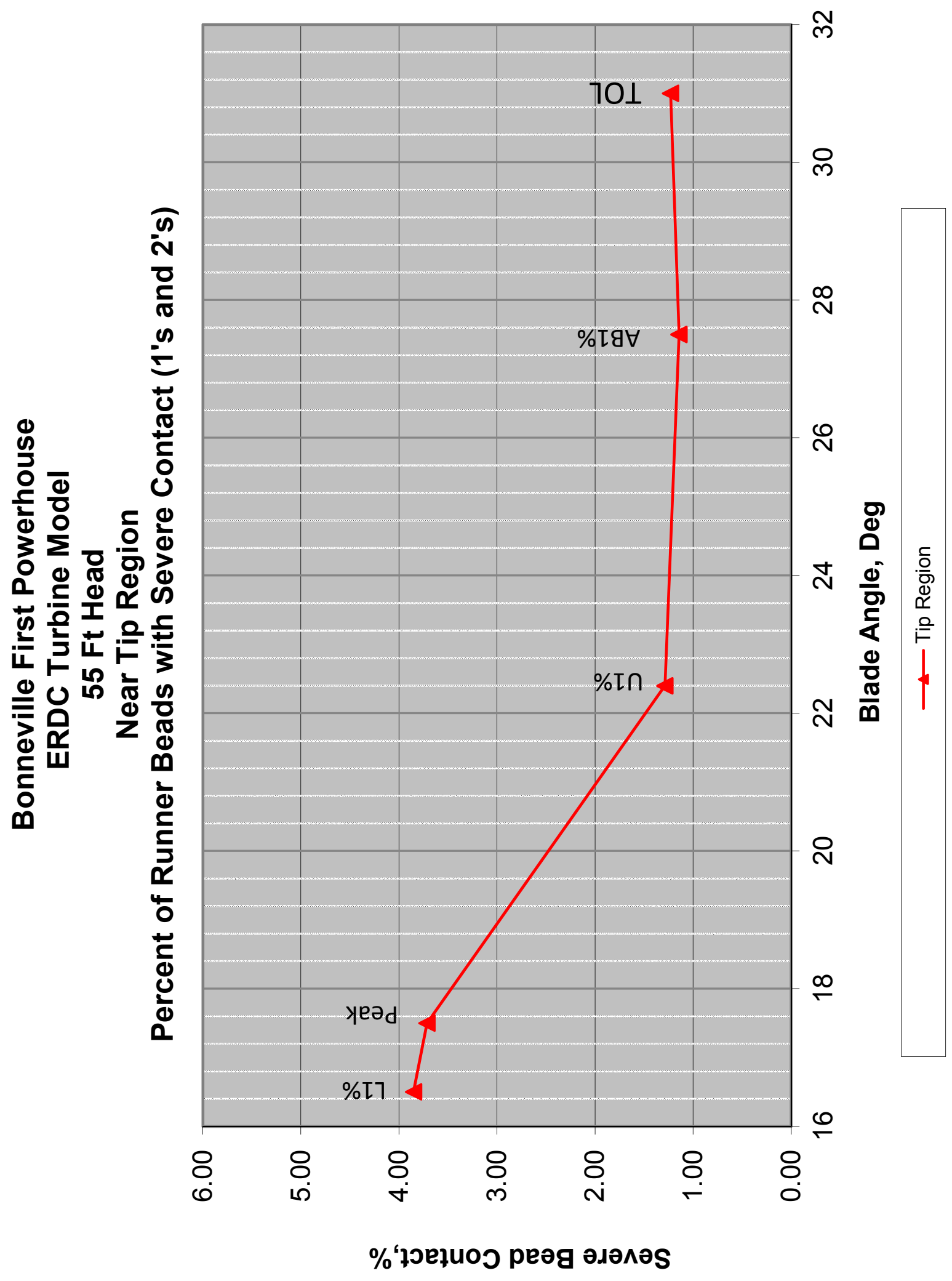




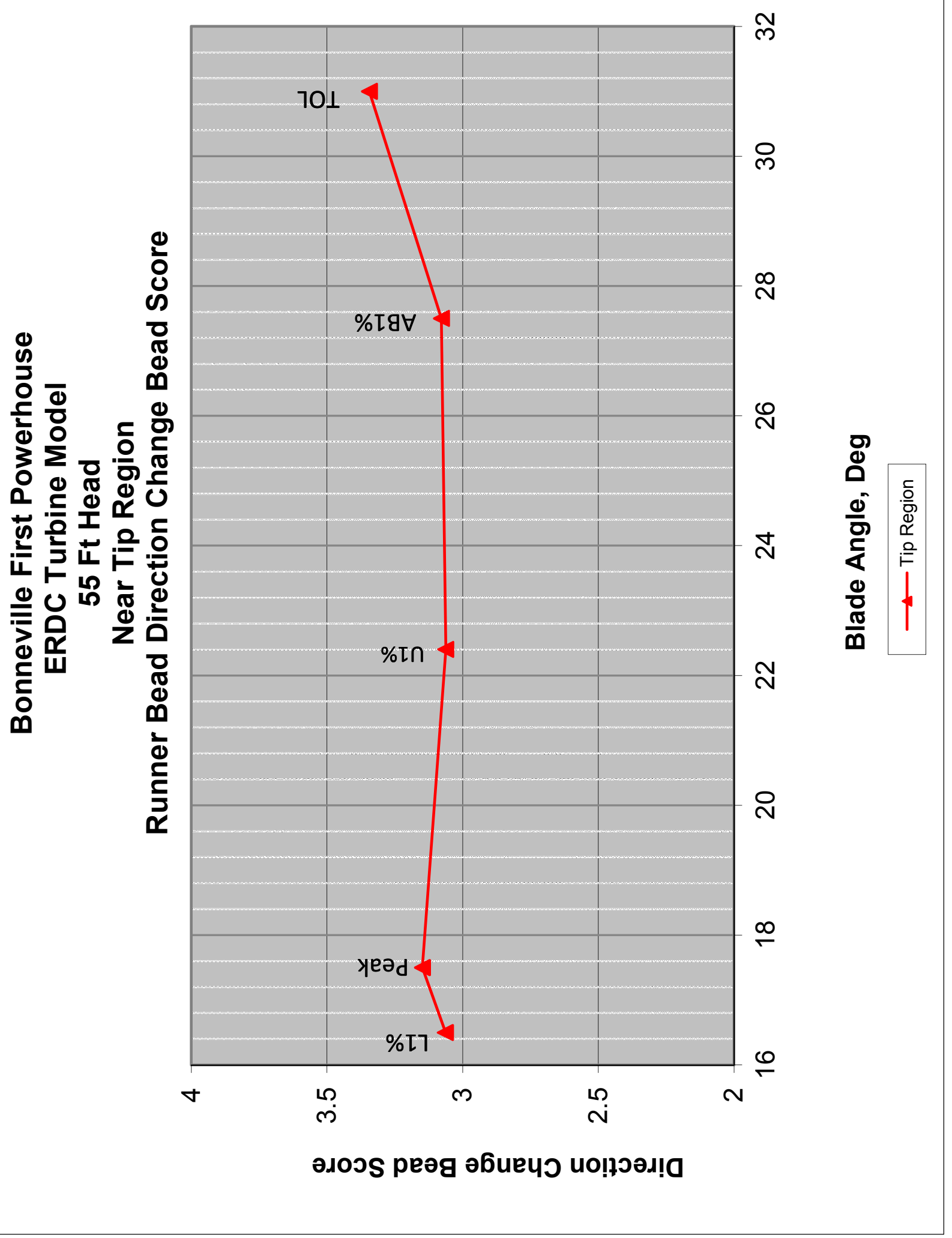

Plate 48 


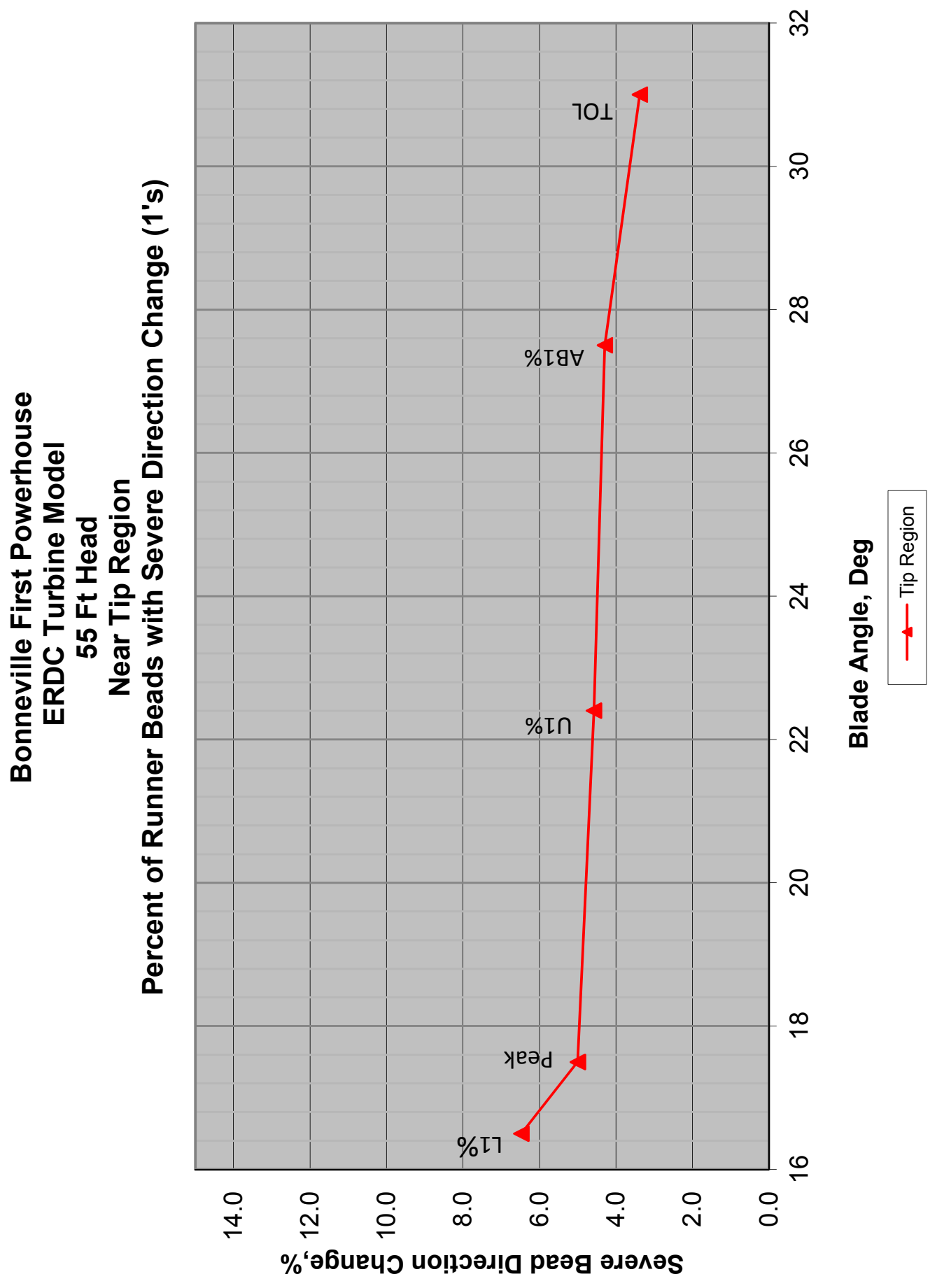

Plate 49 


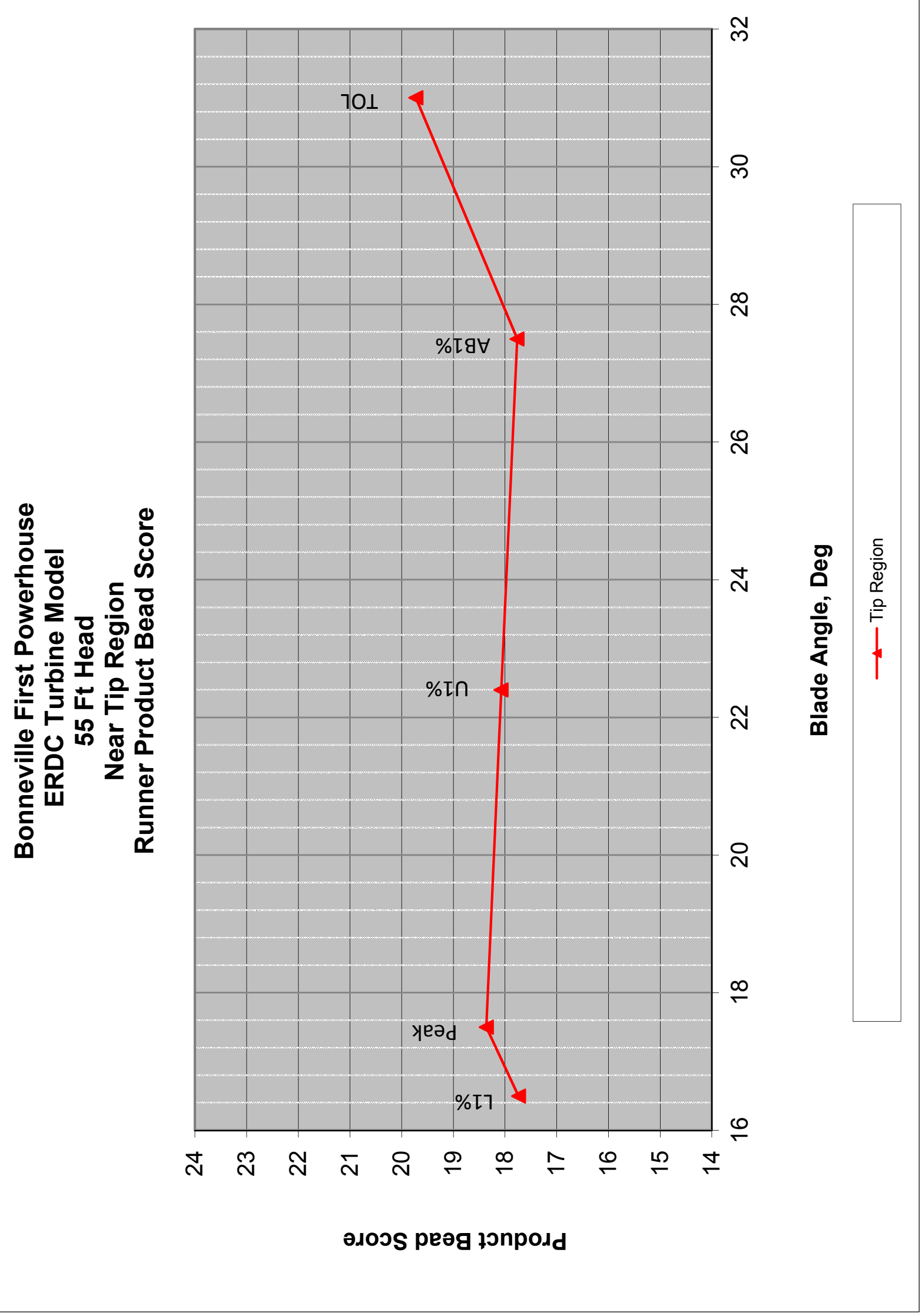


Bonneville First Powerhouse

ERDC Turbine Model

Runner Contact Bead Passage Scores

55 FT Head

All Regions Combined

\begin{tabular}{|c|c|c|c|c|c|c|c|c|c|c|c|}
\hline 1 & $\begin{array}{c}\text { Target } \\
\text { Discharge, } \\
\text { cfs }\end{array}$ & $\begin{array}{c}\text { Contact } \\
\text { score }\end{array}$ & $\begin{array}{c}\text { Contact } \\
\text { Stdev }\end{array}$ & $\begin{array}{l}\text { Contact } \\
\text { Variance }\end{array}$ & $\begin{array}{c}\% \text { severe } \\
\text { contact } \\
1 \text { 's and } 2 \text { 's }\end{array}$ & $\begin{array}{c}\text { Standard } \\
\text { error \% }\end{array}$ & $\begin{array}{c}95 \% \\
\text { Confidence } \\
\text { interval }\end{array}$ & $\begin{array}{c}\% \text { contact } \\
1 \text { 's , 2's } \\
\text { and 3's }\end{array}$ & $\begin{array}{c}\text { Standard } \\
\text { error } \%\end{array}$ & $\begin{array}{c}95 \% \\
\text { Confidence } \\
\text { interval }\end{array}$ & \# of beads \\
\hline $1324=-$ & 7266 & 5.72 & 0.75 & 0.59 & 2.1 & 0.4 & 0.7 & 2.8 & 0.4 & 0.8 & 1649 \\
\hline 17.5 & 7529 & 5.76 & 0.78 & 0.62 & 2.4 & 0.3 & 0.7 & 3.6 & 0.4 & 0.8 & 1943 \\
\hline 22.4 & 9768 & 5.83 & 0.62 & 0.39 & 1.2 & 0.2 & 0.5 & 1.5 & 0.3 & 0.5 & 1890 \\
\hline 27.5 & 11465 & 5.81 & 0.53 & 0.31 & 0.9 & 0.2 & 0.4 & 1.4 & 0.3 & 0.5 & 1875 \\
\hline 31 & 13248 & 5.86 & 0.48 & 0.24 & 0.7 & 0.2 & 0.4 & 0.9 & 0.2 & 0.5 & 1651 \\
\hline
\end{tabular}

Bonneville First Powerhouse

ERDC Turbine Model

Runner Change in Direction Bead Passage Scores

55 FT Head

All Regions Combined

\begin{tabular}{|c|c|c|c|c|c|c|c|c|c|c|c|}
\hline $\begin{array}{c}\text { Blade } \\
\text { Angle, } \\
\text { Deg }\end{array}$ & $\begin{array}{c}\text { Target } \\
\text { Discharge, } \\
\text { cfs }\end{array}$ & $\begin{array}{c}\text { Ch } \\
\text { Direction } \\
\text { score }\end{array}$ & $\begin{array}{c}\text { Ch } \\
\text { Direction } \\
\text { Stdev }\end{array}$ & $\begin{array}{c}\text { Ch } \\
\text { Direction } \\
\text { Variance }\end{array}$ & $\begin{array}{c}\% \text { severe } \\
\text { Ch } \\
\text { Direction } \\
1 \text { 's }\end{array}$ & $\begin{array}{c}\text { Standard } \\
\text { error } \%\end{array}$ & $\begin{array}{c}95 \% \\
\text { Confidence } \\
\text { interval }\end{array}$ & \begin{tabular}{|c|}
$\%$ Ch \\
Direction \\
1's and 2's
\end{tabular} & $\begin{array}{c}\text { Standard } \\
\text { error } \%\end{array}$ & $\begin{array}{c}95 \% \\
\text { Confidence } \\
\text { interval }\end{array}$ & \# of beads \\
\hline 16.5 & 7266 & 3.16 & 0.76 & 0.59 & 6.9 & 0.6 & 1.2 & 11.9 & 0.8 & 1.6 & 1649 \\
\hline 17.5 & 7529 & 3.19 & 0.74 & 0.56 & 5.9 & 0.5 & 1.0 & 9.7 & 0.7 & 1.3 & 1943 \\
\hline 22.4 & 9768 & 3.17 & 0.65 & 0.43 & 3.1 & 0.4 & 0.8 & 9.2 & 0.7 & 1.3 & 1890 \\
\hline 27.5 & 11465 & 3.25 & 0.61 & 0.38 & 2.0 & 0.3 & 0.6 & 6.1 & 0.6 & 1.1 & 1875 \\
\hline 31 & 13248 & 3.37 & 0.66 & 0.44 & 2.4 & 0.4 & 0.7 & 5.8 & 0.6 & 1.1 & 1651 \\
\hline
\end{tabular}

Bonneville First Powerhouse

ERDC Turbine Model

Runner Product Bead Passage Scores

55 FT Head

All Regions Combined

\begin{tabular}{|c|c|c|c|c|c|}
\hline $\begin{array}{c}\text { Blade } \\
\text { Angle, } \\
\text { Deg }\end{array}$ & $\begin{array}{c}\text { Discharge, } \\
\text { cfs }\end{array}$ & $\begin{array}{c}\text { Product } \\
\text { Score }\end{array}$ & $\begin{array}{c}\text { Product } \\
\text { Std Dev }\end{array}$ & $\begin{array}{c}\text { Product } \\
\text { Variance }\end{array}$ & \# of beads \\
\hline 16.5 & 7266 & 18.49 & 5.22 & 27.62 & 1649 \\
\hline 17.5 & 7529 & 18.76 & 5.09 & 26.28 & 1943 \\
\hline 22.4 & 9768 & 18.72 & 4.42 & 19.82 & 1890 \\
\hline 27.5 & 11465 & 19.08 & 4.19 & 18.06 & 1875 \\
\hline 31 & 13248 & 19.93 & 4.40 & 19.76 & 1651 \\
\hline
\end{tabular}




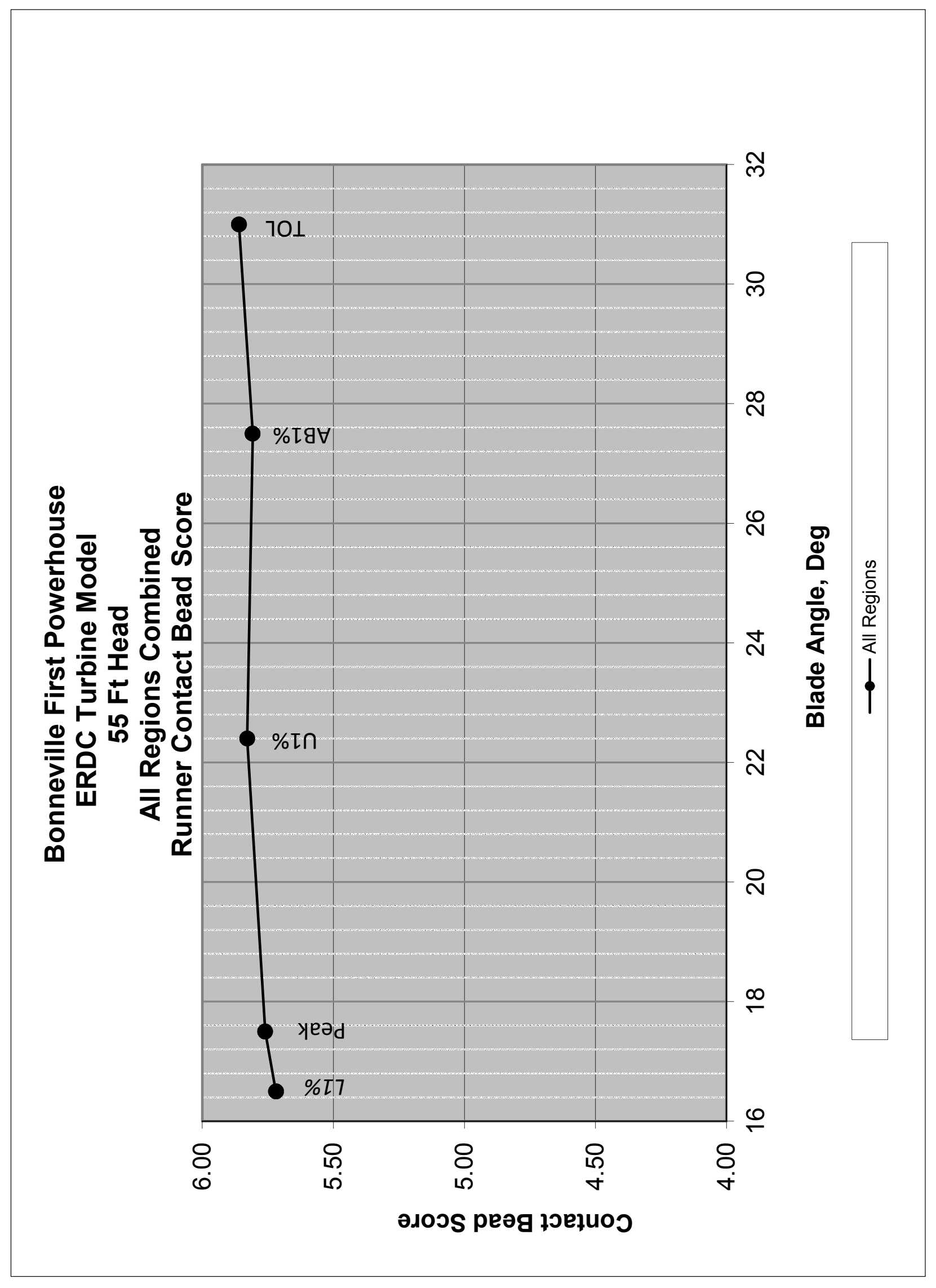




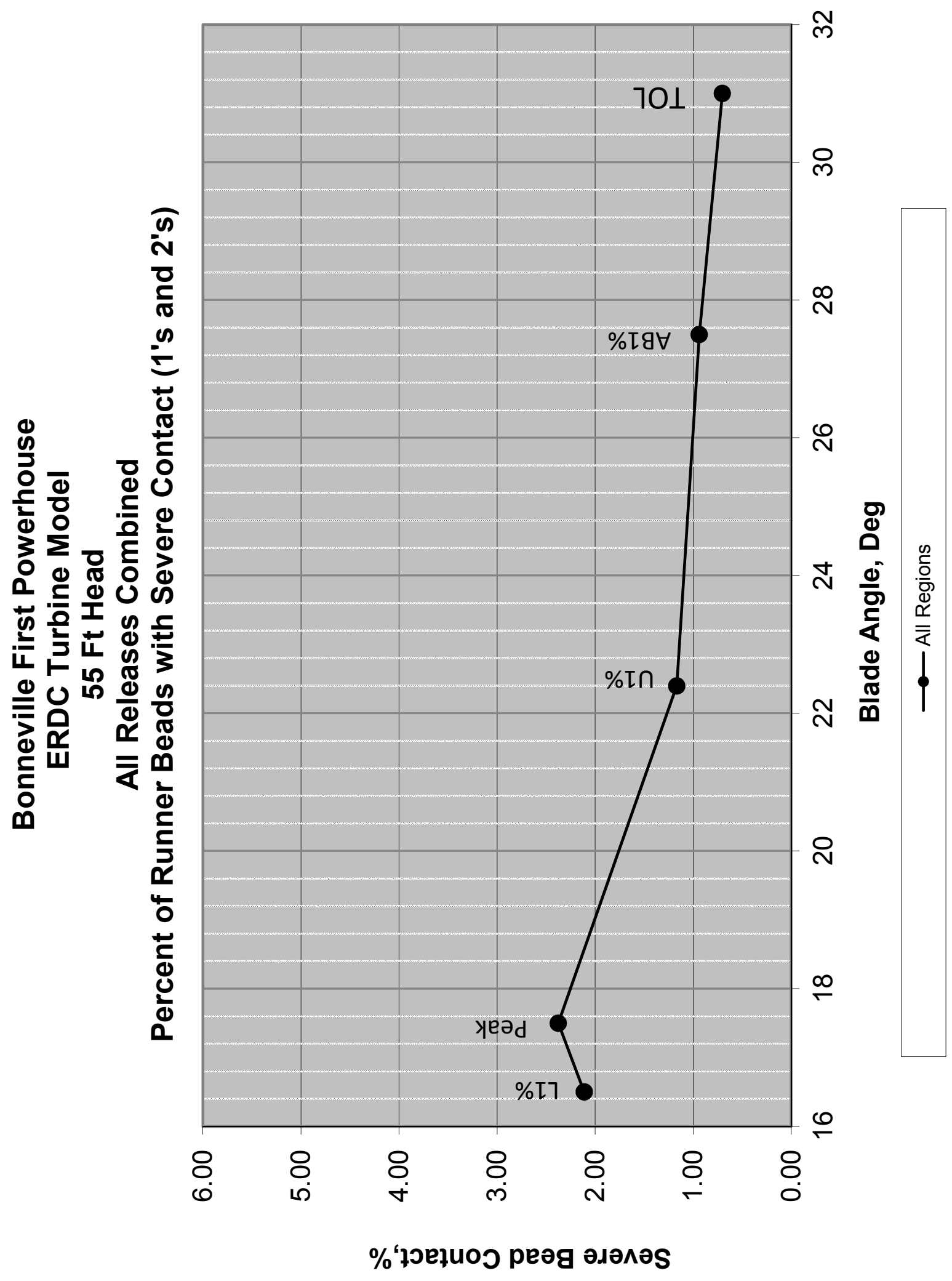




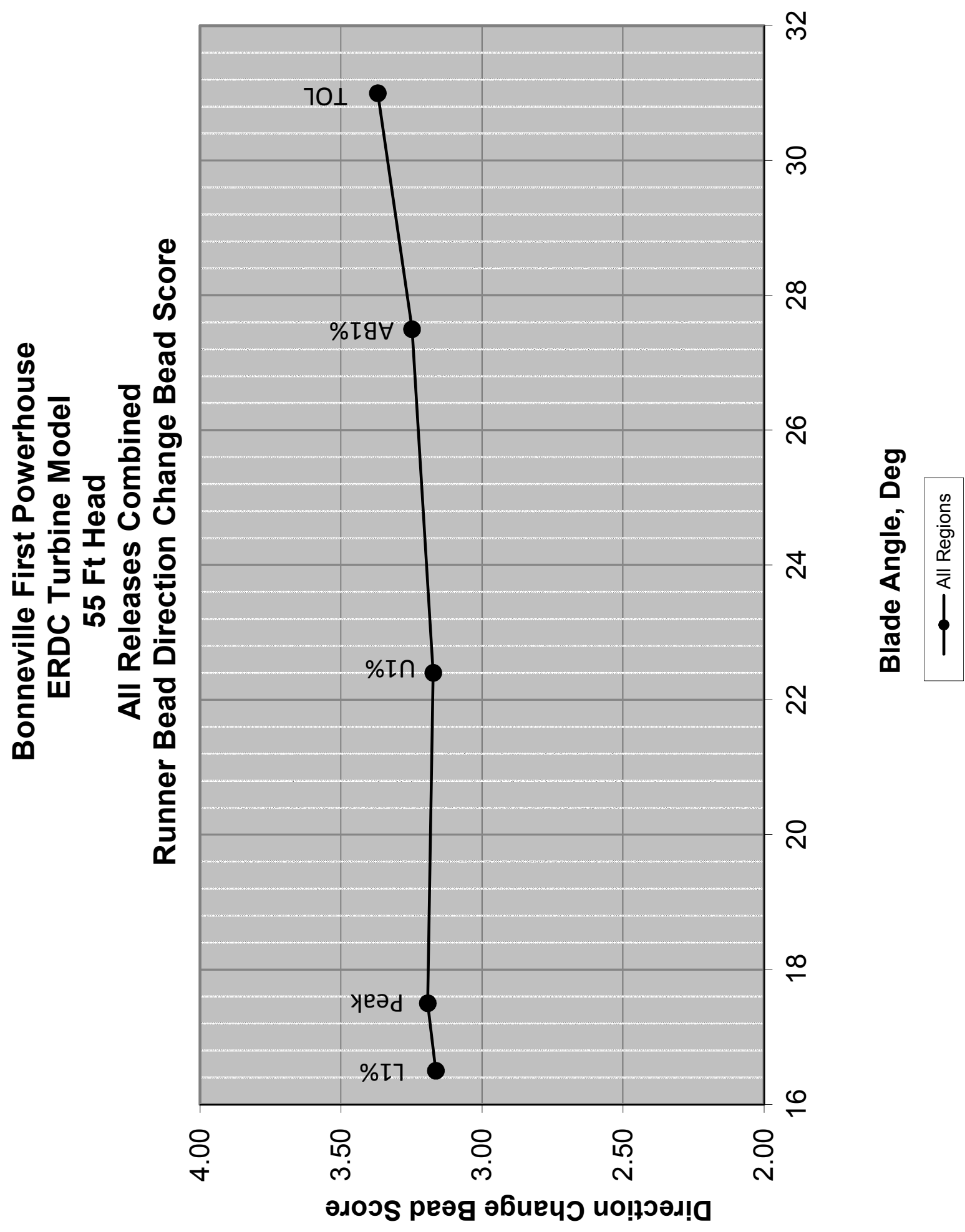

Plate 54 


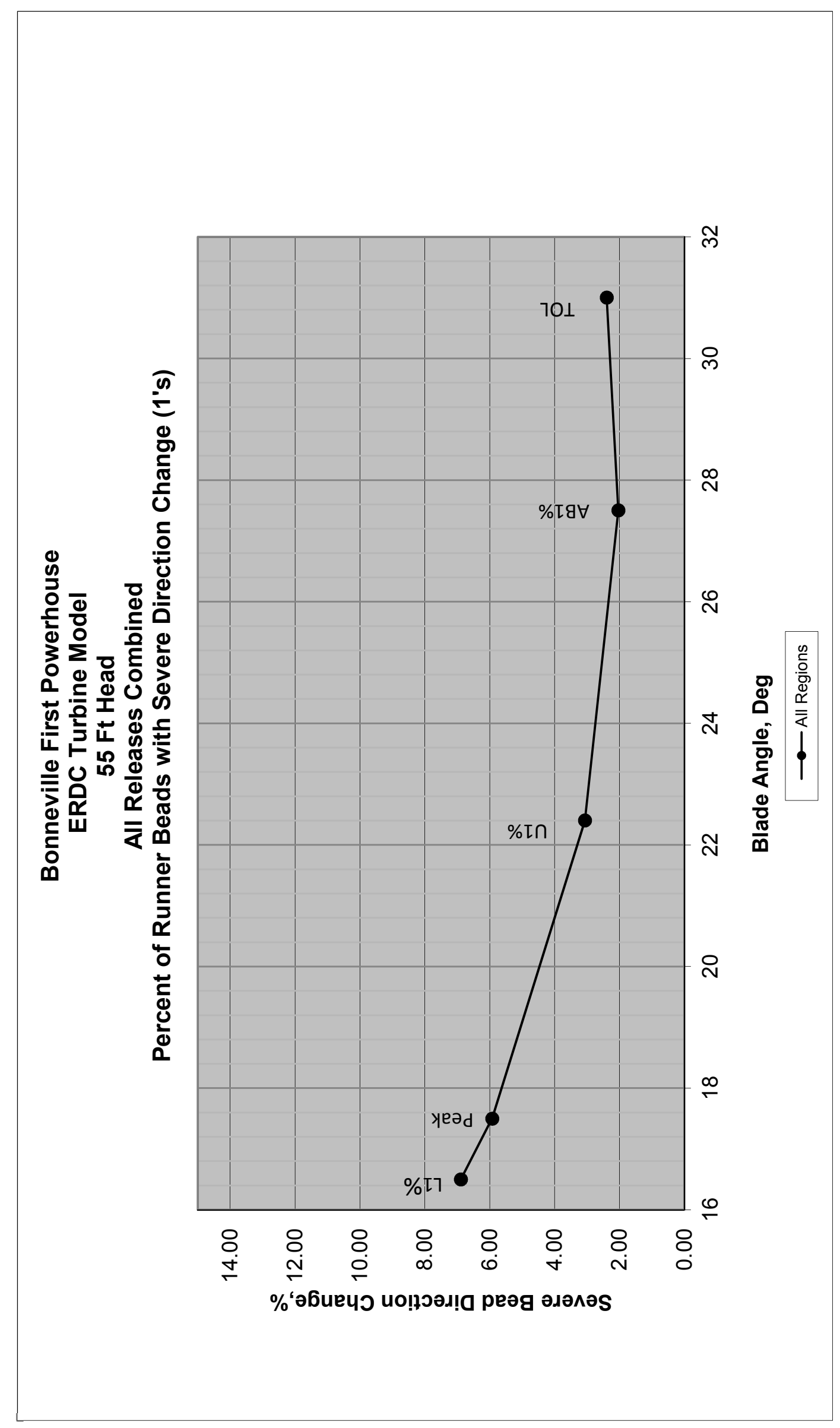

Plate 55 


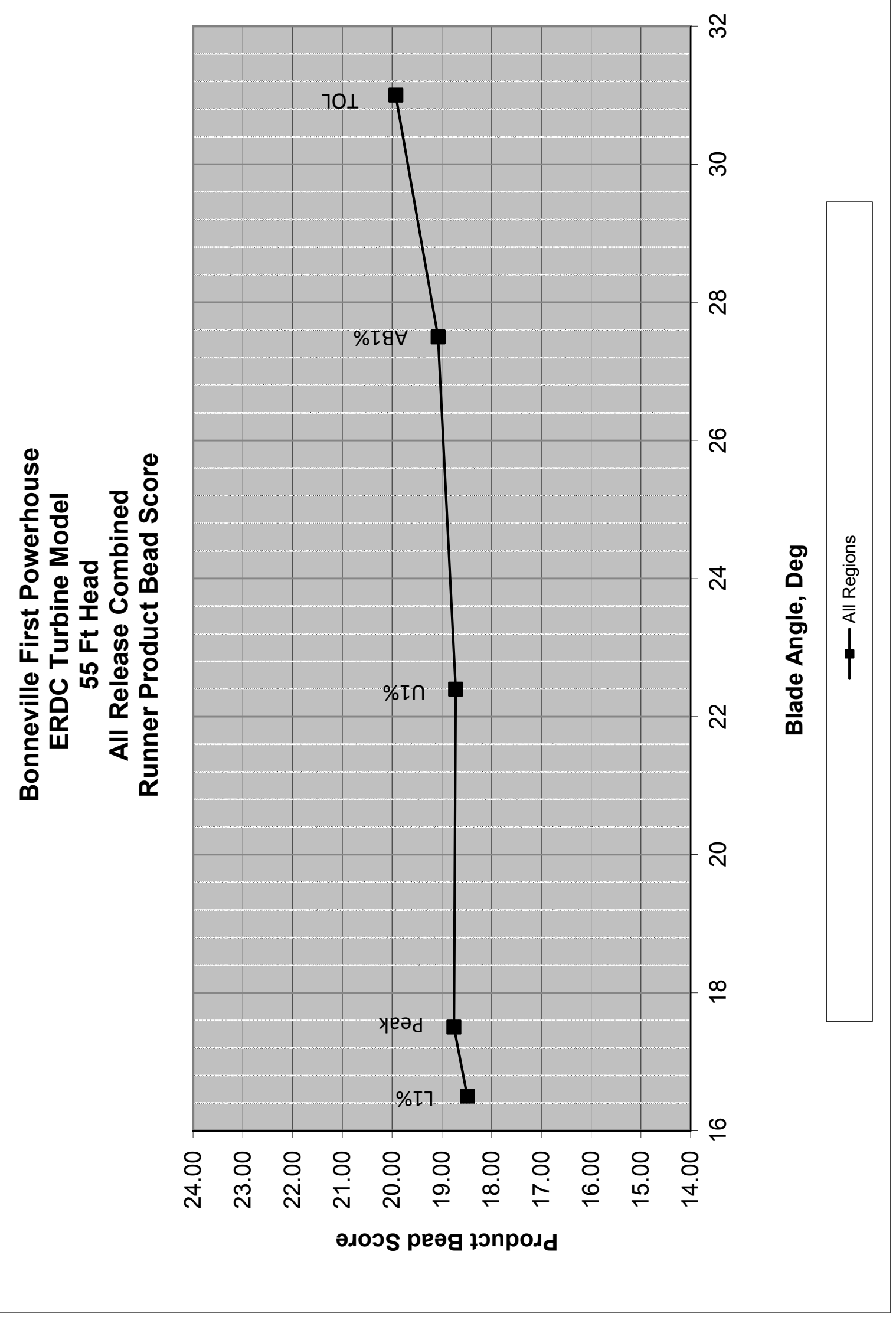


Bonneville First Powerhouse

ERDC Turbine Model

Draft Tube Elbow and Splitter Pier Bead Summary Table

Draft Tube Elbow Contact Bead Passage Scores

55 FT Head

\begin{tabular}{|c|c|c|c|c|c|c|c|c|}
\hline $\begin{array}{c}\text { Blade } \\
\text { Angle, } \\
\text { Deg }\end{array}$ & $\begin{array}{c}\text { Discharge, } \\
\text { Cfs }\end{array}$ & $\begin{array}{c}\text { Contact } \\
\text { score }\end{array}$ & $\begin{array}{c}\text { Contact } \\
\text { Stdev }\end{array}$ & $\begin{array}{c}\text { Contact } \\
\text { Variance }\end{array}$ & $\begin{array}{c}\text { \% severe } \\
\text { contact 1's } \\
\text { and 2's }\end{array}$ & $\begin{array}{c}\text { Standard } \\
\text { error \% }\end{array}$ & $\begin{array}{c}95 \% \\
\text { Confidenc } \\
\text { e interval }\end{array}$ & \# of beads \\
\hline 16.5 & 7266 & 5.68 & 0.82 & 0.68 & 2.3 & 0.6 & 1.2 & 650 \\
\hline 17.5 & 7529 & 5.63 & 0.91 & 0.82 & 2.7 & 0.7 & 1.3 & 600 \\
\hline 22.4 & 9768 & 5.76 & 0.76 & 0.58 & 2.2 & 0.6 & 1.2 & 600 \\
\hline 27.5 & 11465 & 5.76 & 0.81 & 0.65 & 2.2 & 0.5 & 1.0 & 912 \\
\hline 31 & 13248 & 5.70 & 0.84 & 0.71 & 2.4 & 0.6 & 1.2 & 668 \\
\hline
\end{tabular}

Bonneville First Powerhouse

ERDC Turbine Model

Draft Tube Elbow and Splitter Pier Bead Summary Table

Draft Tube Elbow Change in Direction Bead Passage Scores

55 FT Head

\begin{tabular}{|c|c|c|c|c|c|c|c|c|}
\hline $\begin{array}{c}\text { Blade } \\
\text { Angle, } \\
\text { Deg }\end{array}$ & $\begin{array}{c}\text { Discharge, } \\
\text { Cfs }\end{array}$ & $\begin{array}{c}\text { Ch } \\
\text { Direction } \\
\text { score }\end{array}$ & $\begin{array}{c}\text { Ch } \\
\text { Direction } \\
\text { Stdev }\end{array}$ & $\begin{array}{c}\text { Ch } \\
\text { Direction } \\
\text { Variance }\end{array}$ & $\begin{array}{c}\text { \% severe } \\
\text { 1's and } \\
\text { Moderate } \\
\text { 2's }\end{array}$ & $\begin{array}{c}95 \% \\
\text { Standard } \\
\text { error \% }\end{array}$ & $\begin{array}{c}\text { Confidenc } \\
\text { e interval }\end{array}$ & \# of beads \\
\hline 16.5 & 7266 & 3.43 & 0.72 & 0.52 & 9.00 & 1.1 & 2.2 & 650 \\
\hline 17.5 & 7529 & 3.54 & 0.75 & 0.56 & 10.0 & 1.2 & 2.4 & 600 \\
\hline 22.4 & 9768 & 3.59 & 0.69 & 0.48 & 6.0 & 1.0 & 1.9 & 600 \\
\hline 27.5 & 11465 & 3.63 & 0.66 & 0.44 & 5.7 & 0.8 & 1.5 & 912 \\
\hline 31 & 13248 & 3.45 & 0.78 & 0.60 & 8.7 & 1.1 & 2.1 & 668 \\
\hline
\end{tabular}

Bonneville First Powerhouse

ERDC Turbine Model

Draft Tube Elbow and Splitter Pier Bead Summary Table

Draft Tube Elbow Product Bead Passage Scores

55 FT Head

\begin{tabular}{|c|c|c|c|c|c|}
\hline $\begin{array}{c}\text { Blade } \\
\text { Angle, } \\
\text { Deg }\end{array}$ & $\begin{array}{c}\text { Discharge, } \\
\text { Cfs }\end{array}$ & $\begin{array}{c}\text { Product } \\
\text { Score }\end{array}$ & $\begin{array}{c}\text { Product Std } \\
\text { Dev }\end{array}$ & $\begin{array}{c}\text { Product } \\
\text { Variance }\end{array}$ & \# of beads \\
\hline 16.5 & 7266 & 19.90 & 5.35 & 28.57 & 650 \\
\hline 17.5 & 7529 & 20.50 & 5.76 & 33.18 & 600 \\
\hline 22.4 & 9768 & 21.09 & 5.05 & 25.48 & 600 \\
\hline 27.5 & 11465 & 21.37 & 4.97 & 24.72 & 912 \\
\hline 31 & 13248 & 20.08 & 5.58 & 31.10 & 668 \\
\hline
\end{tabular}




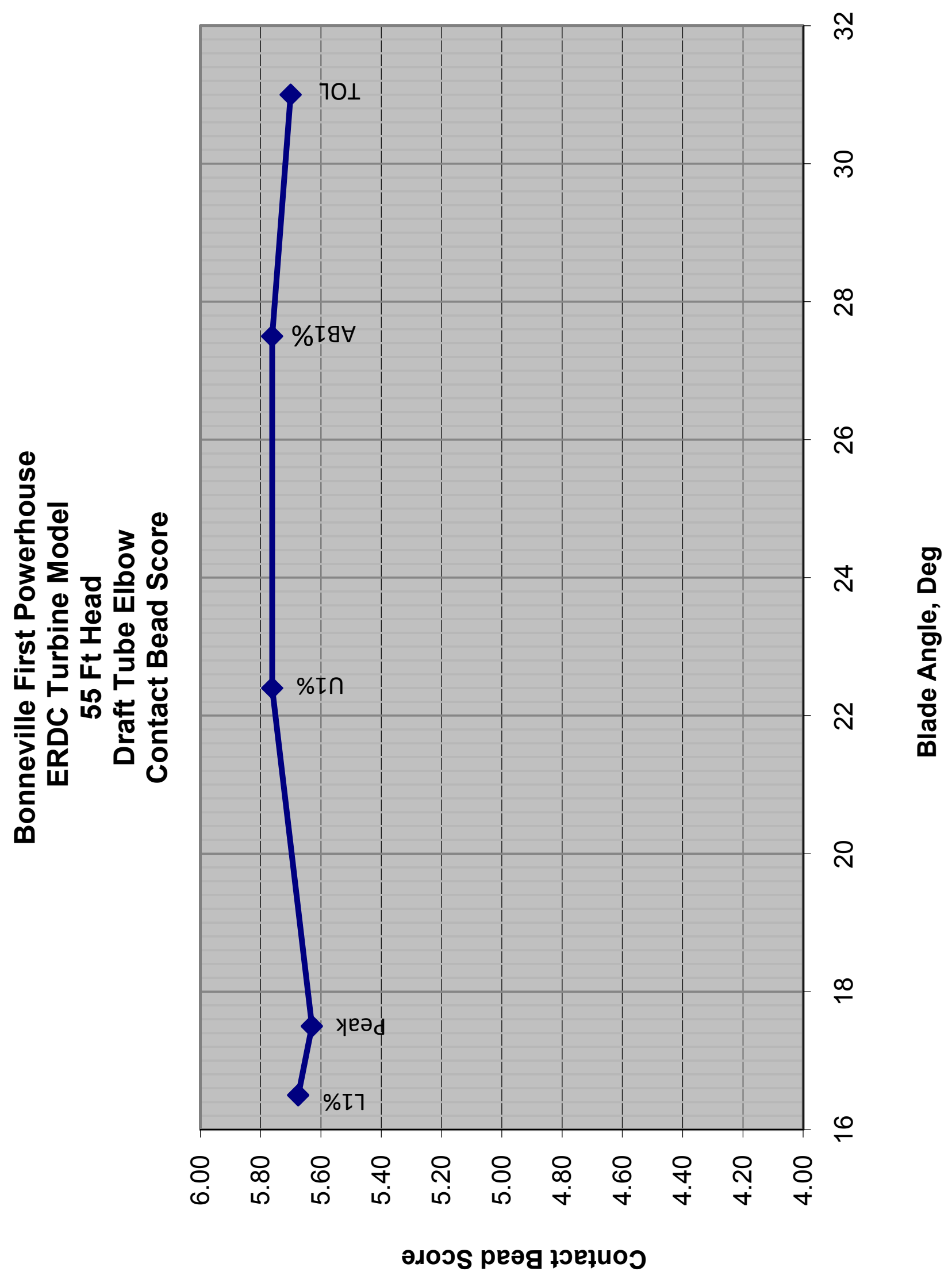

Plate 58 


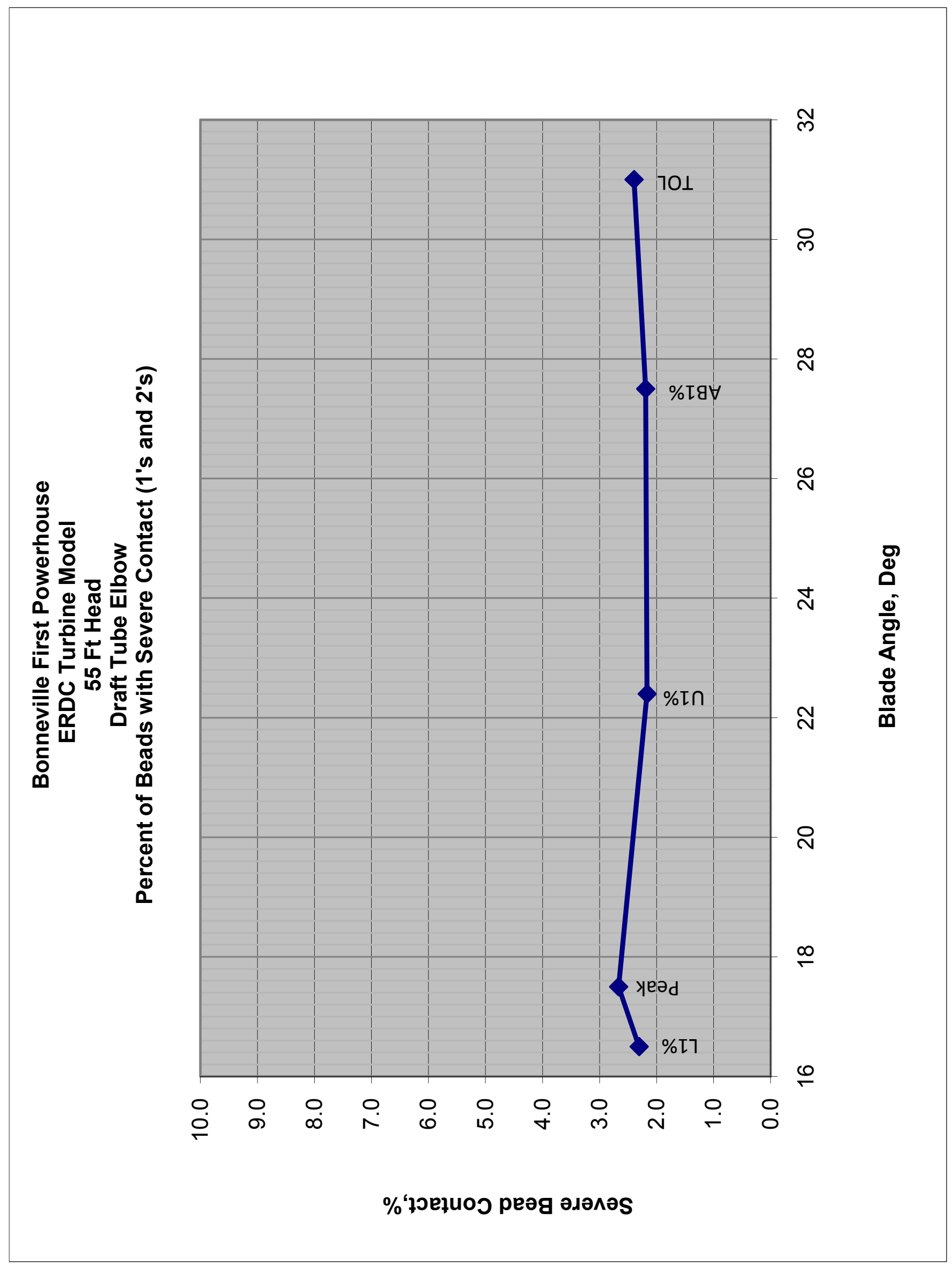

Plate 59 


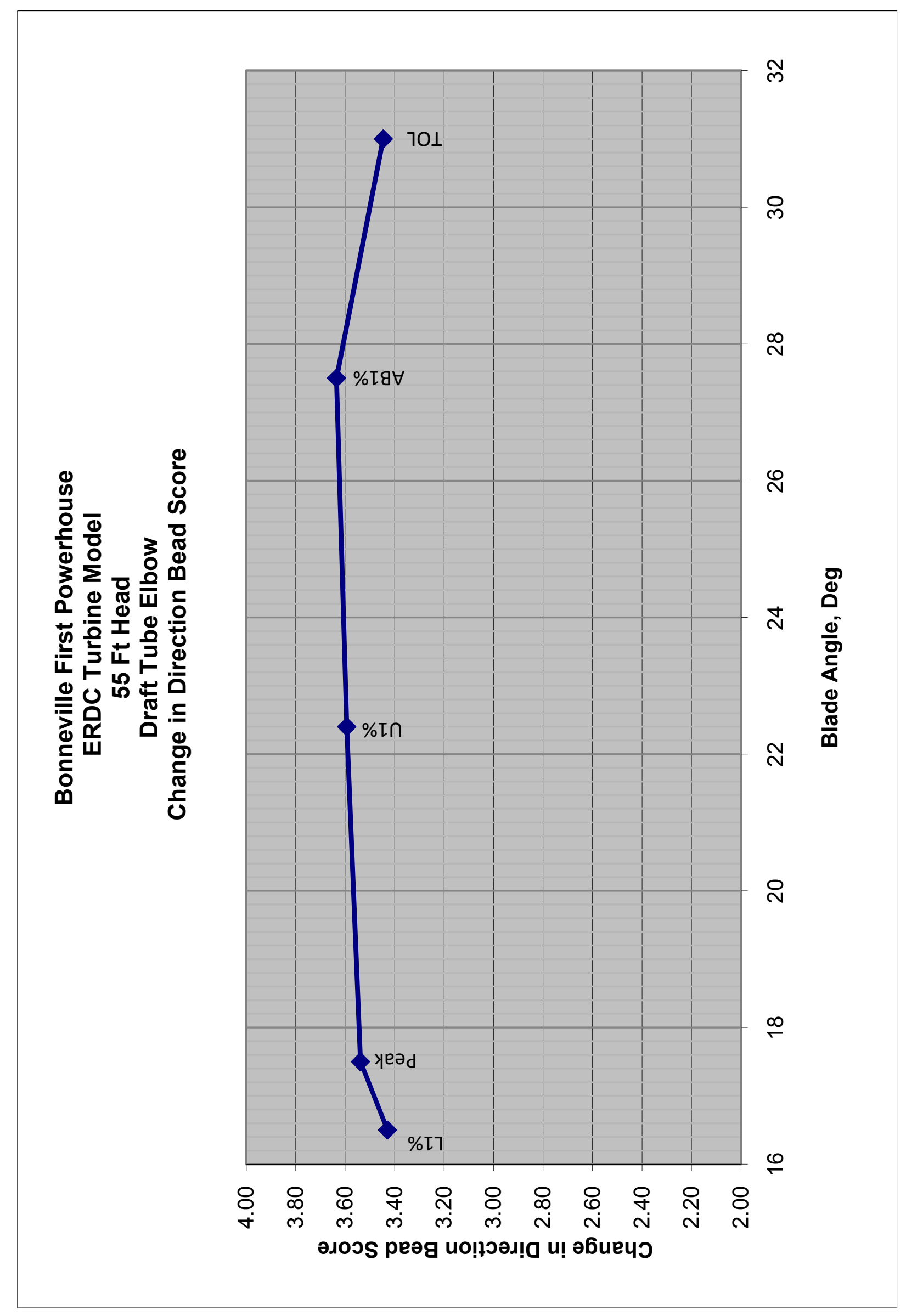

Plate 60 


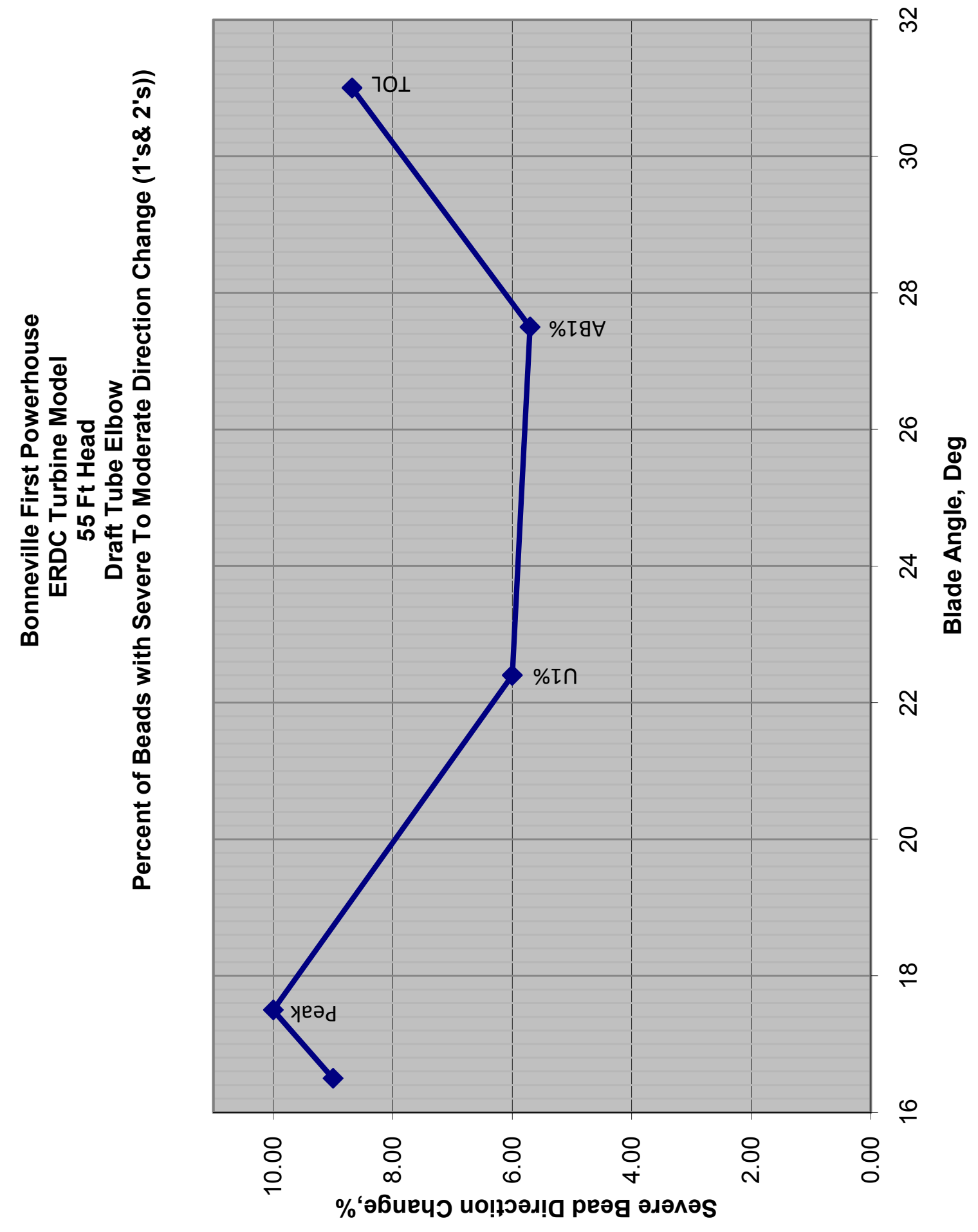



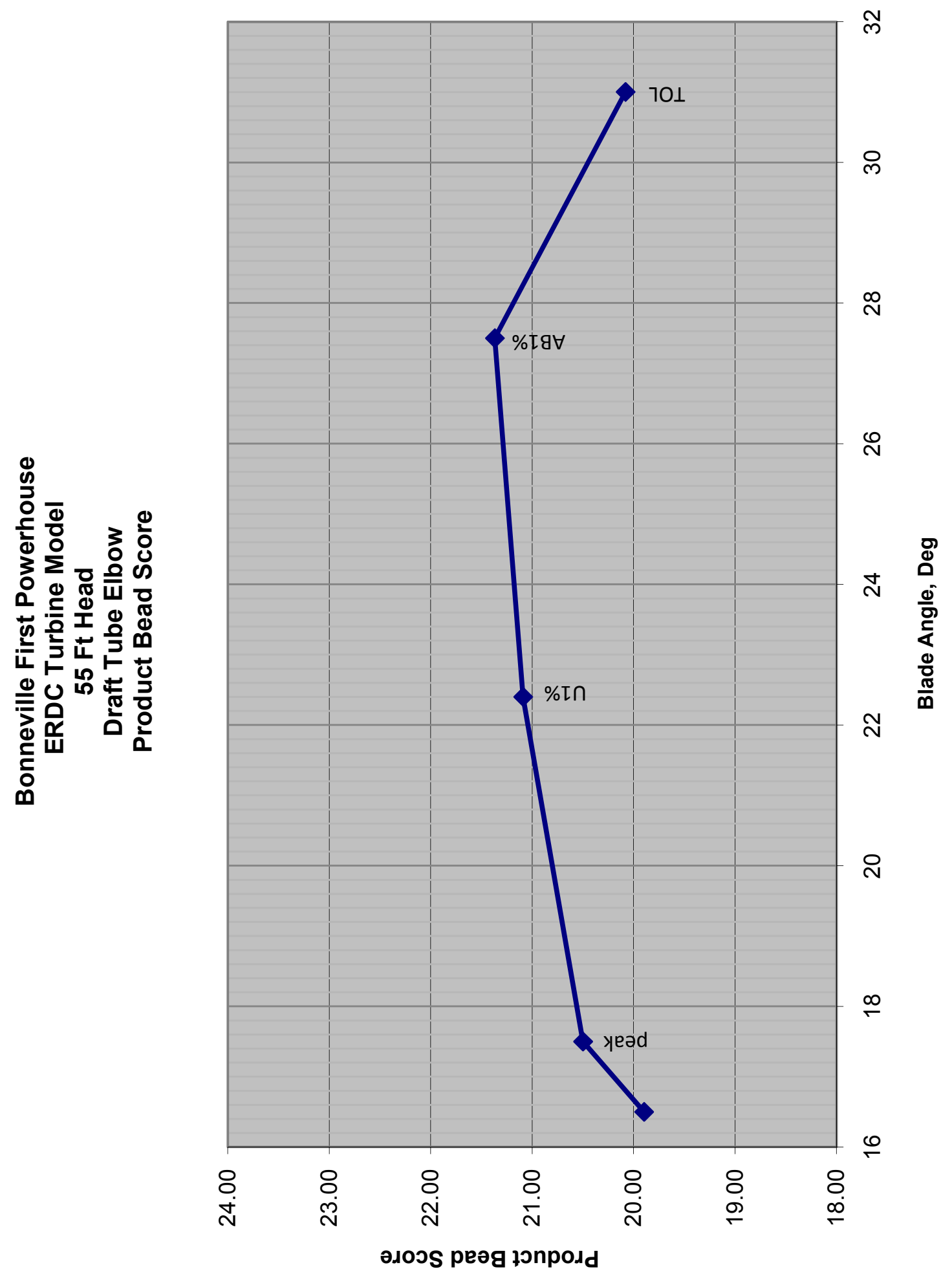

Plate 62 


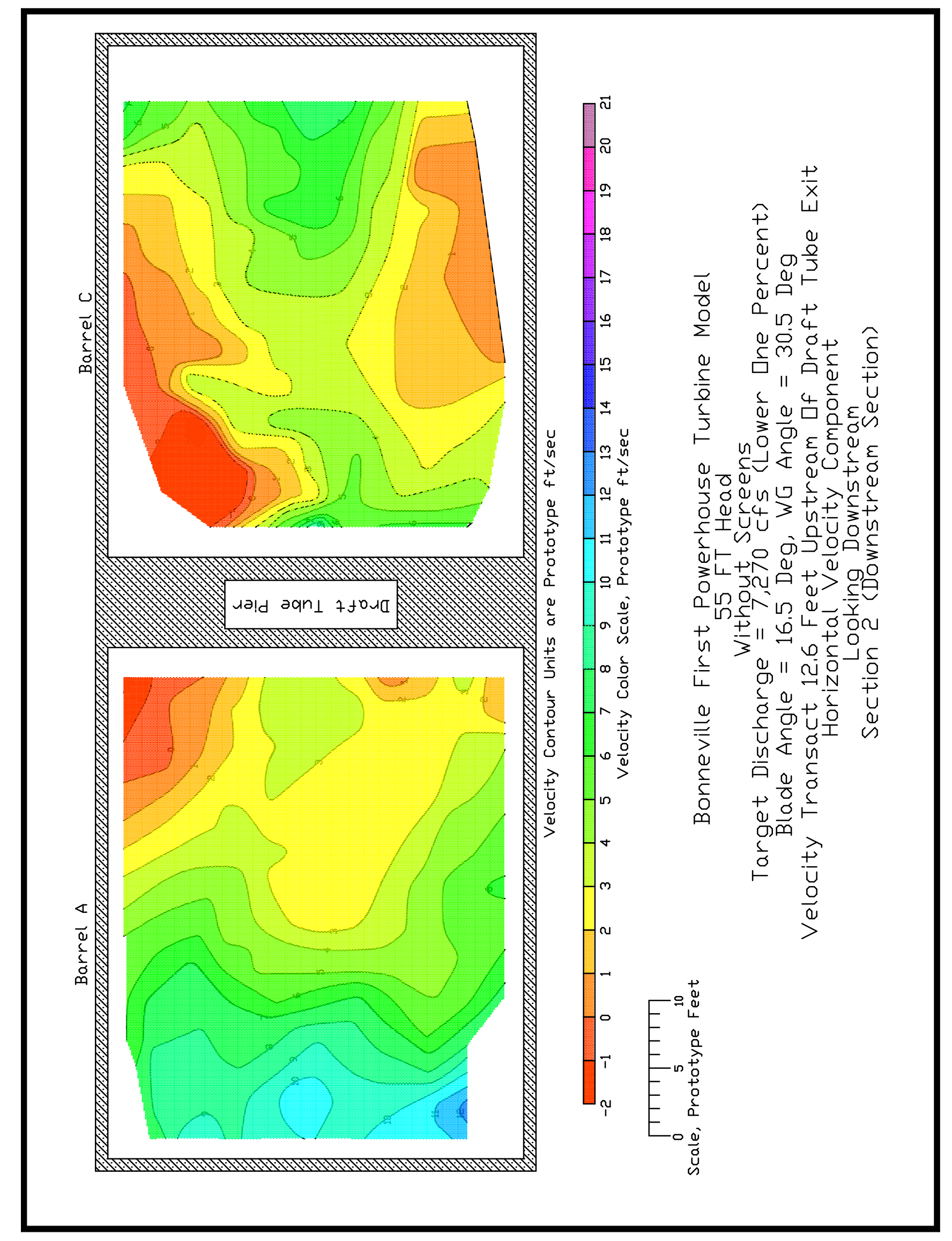

Plate 63 


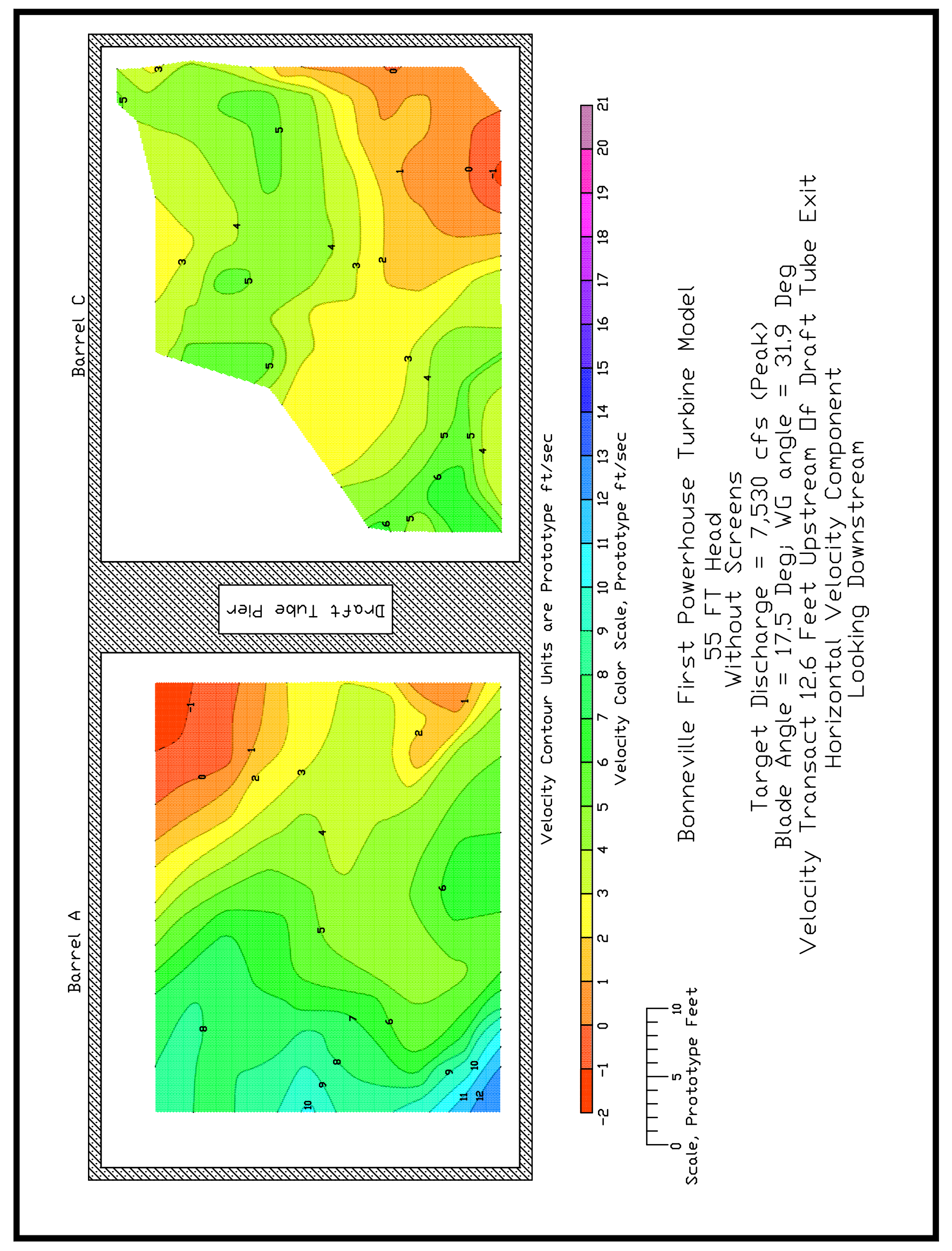



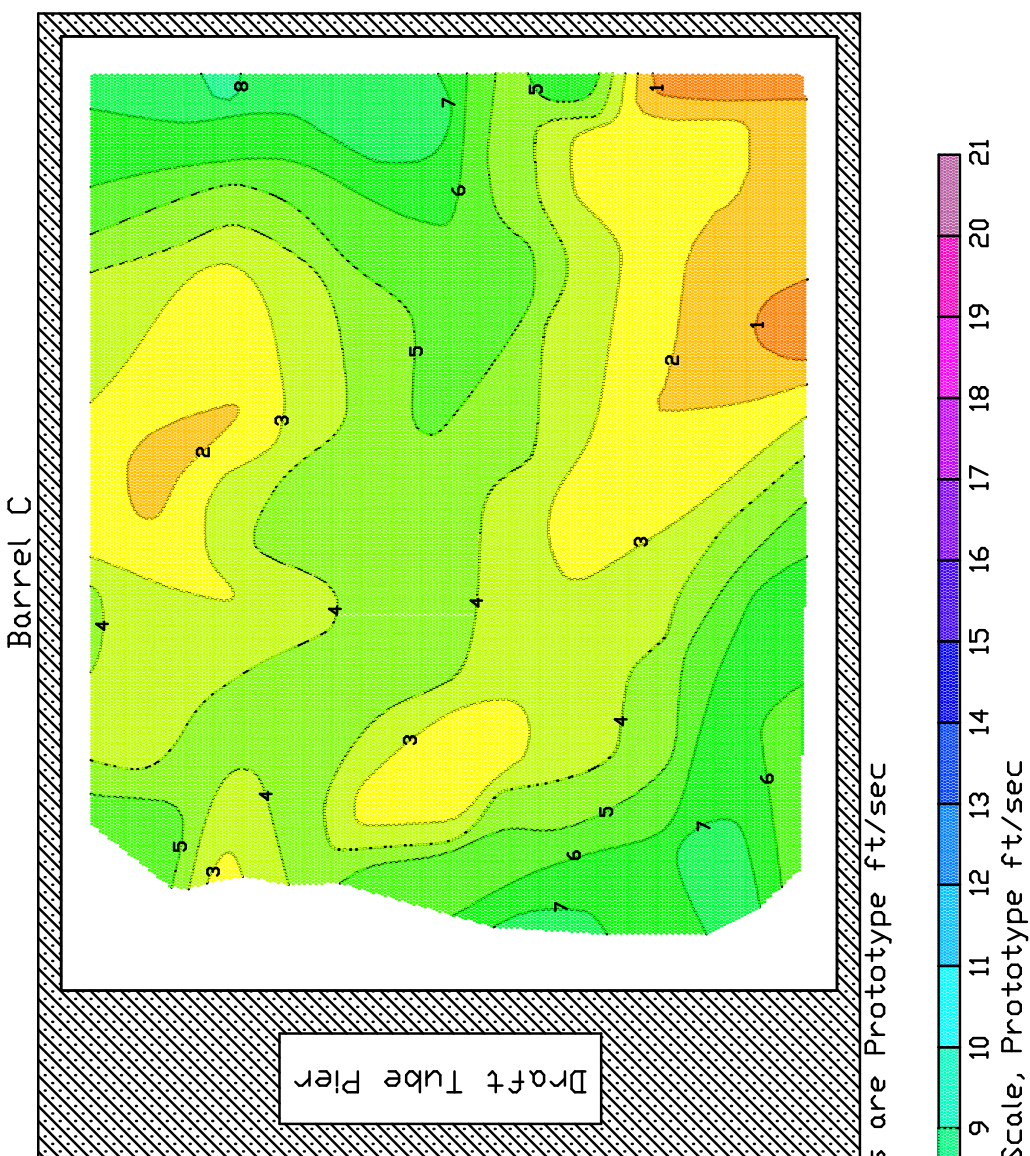

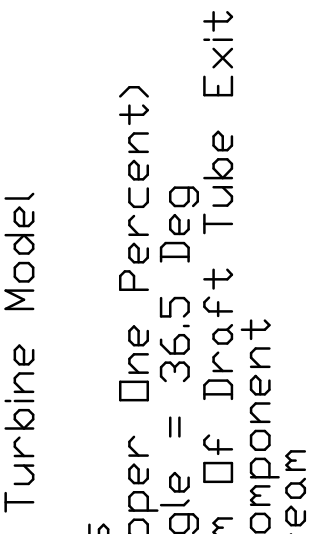

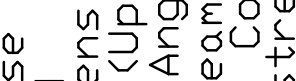

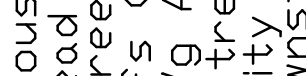

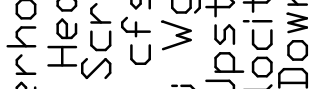

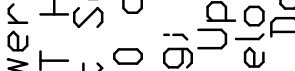
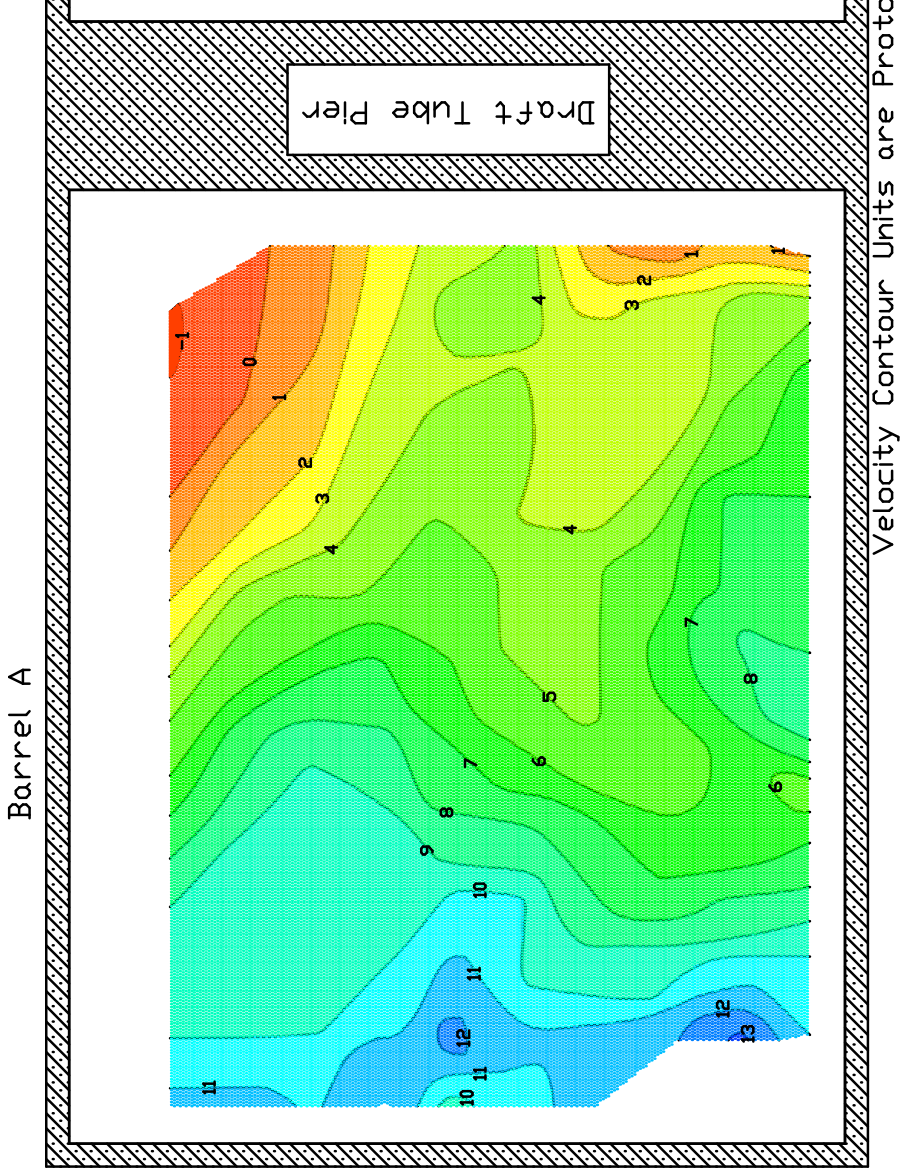

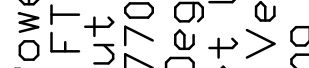
口

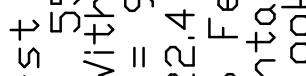
U $H^{\infty} \frac{1}{0} \frac{0}{0}$

正

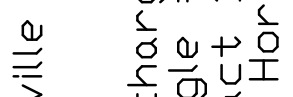
5
$\frac{1}{5}$
0
0 $\frac{7}{8}$

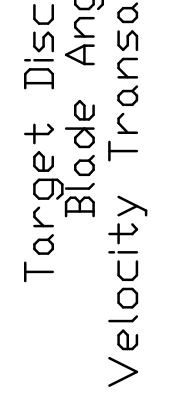




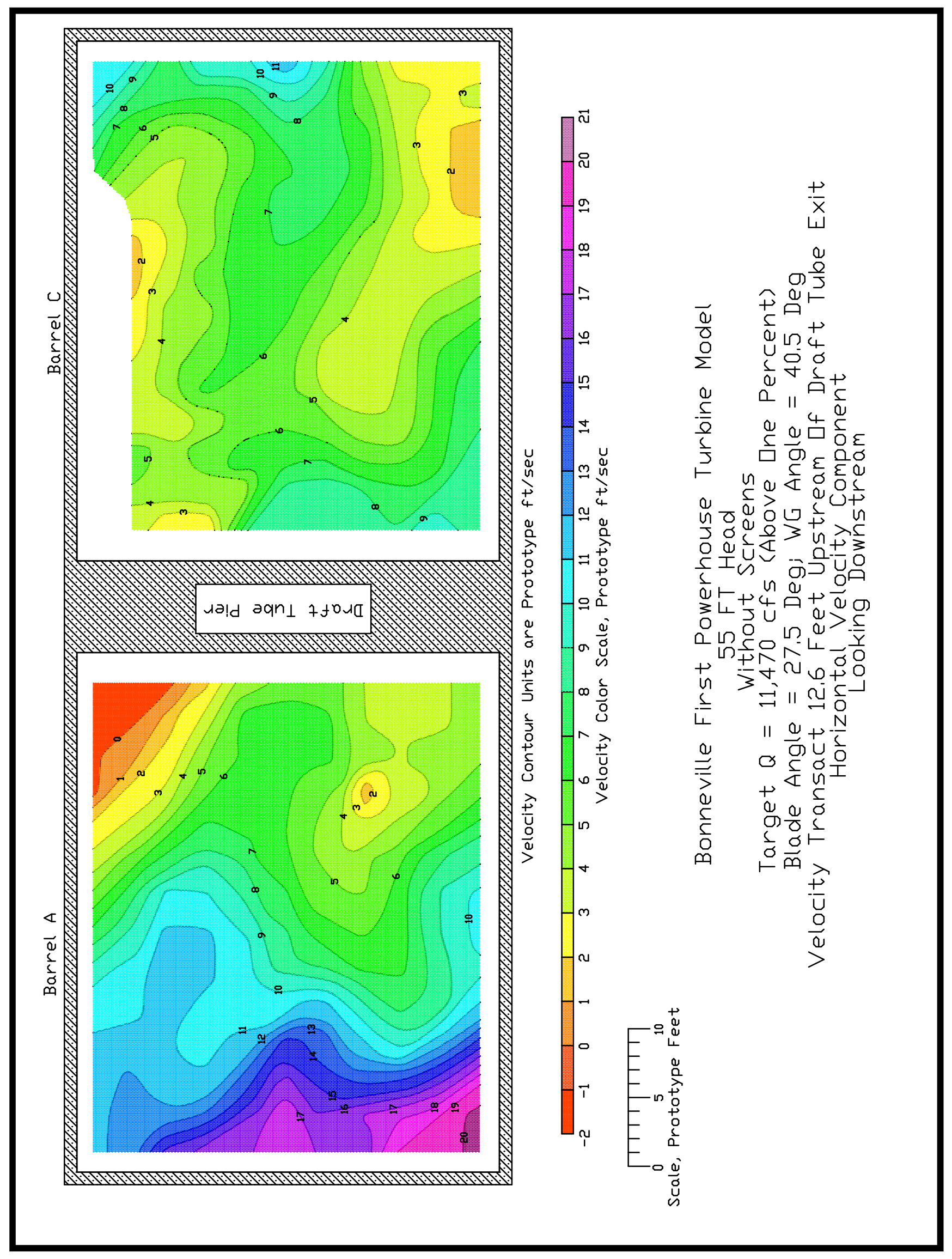




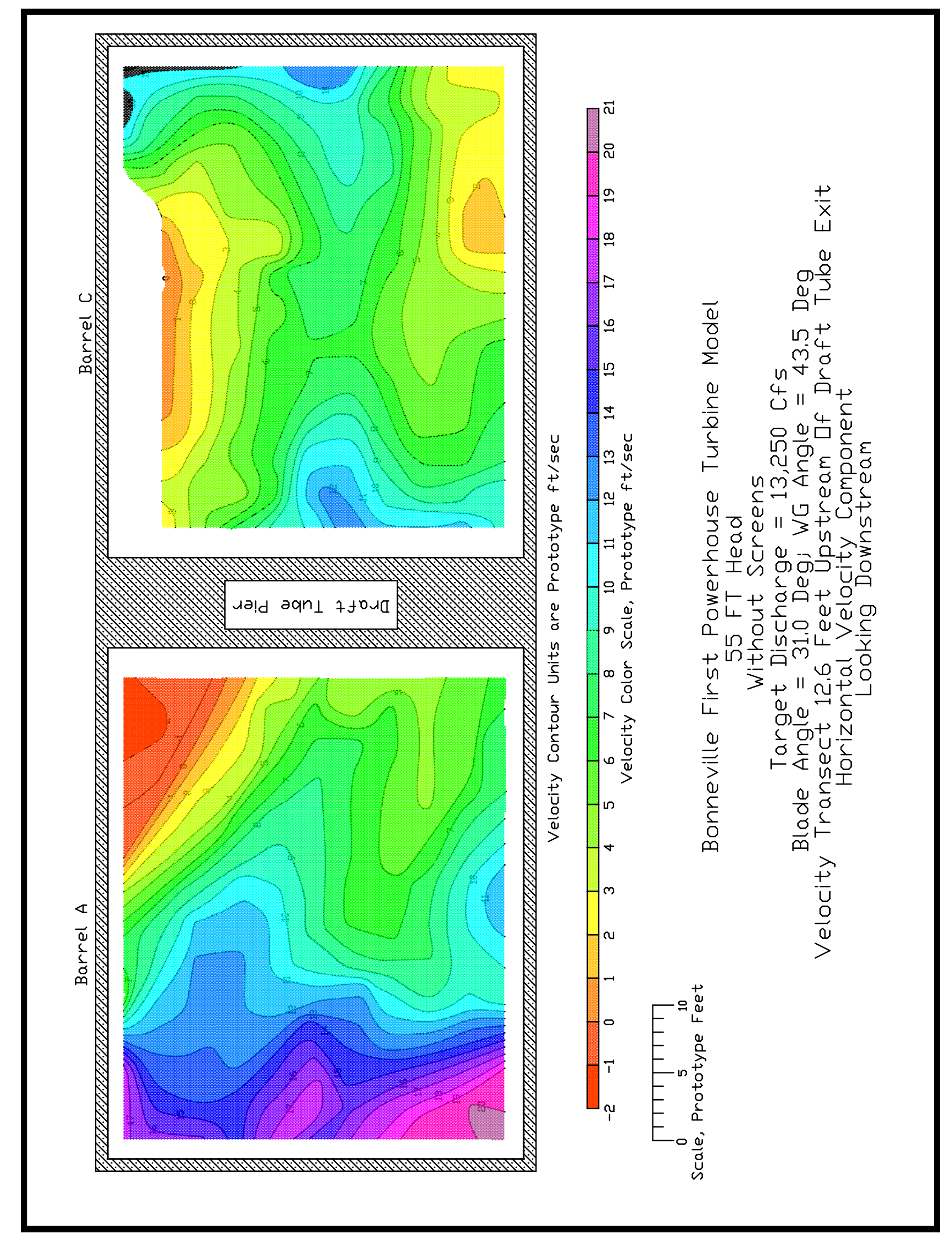




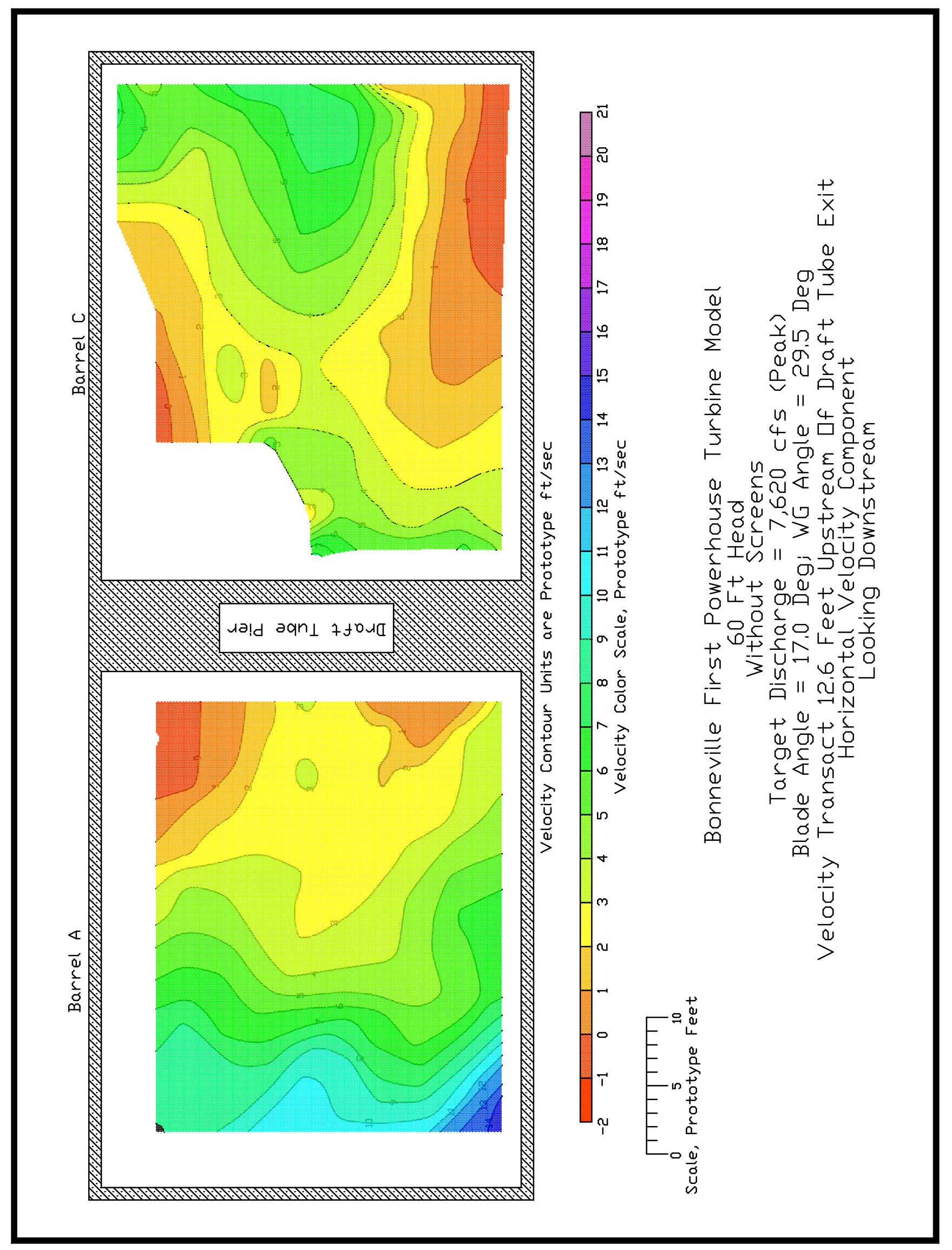




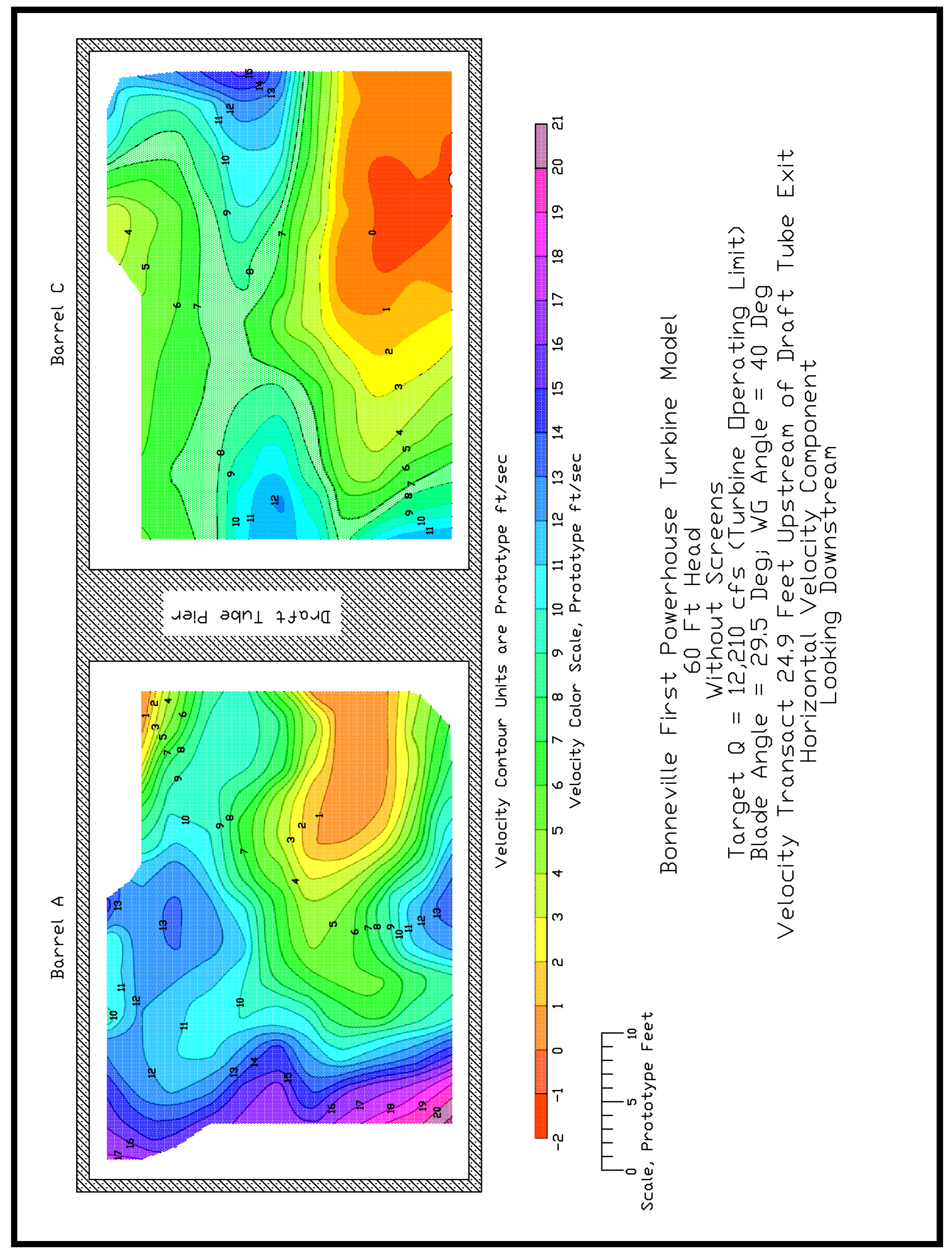



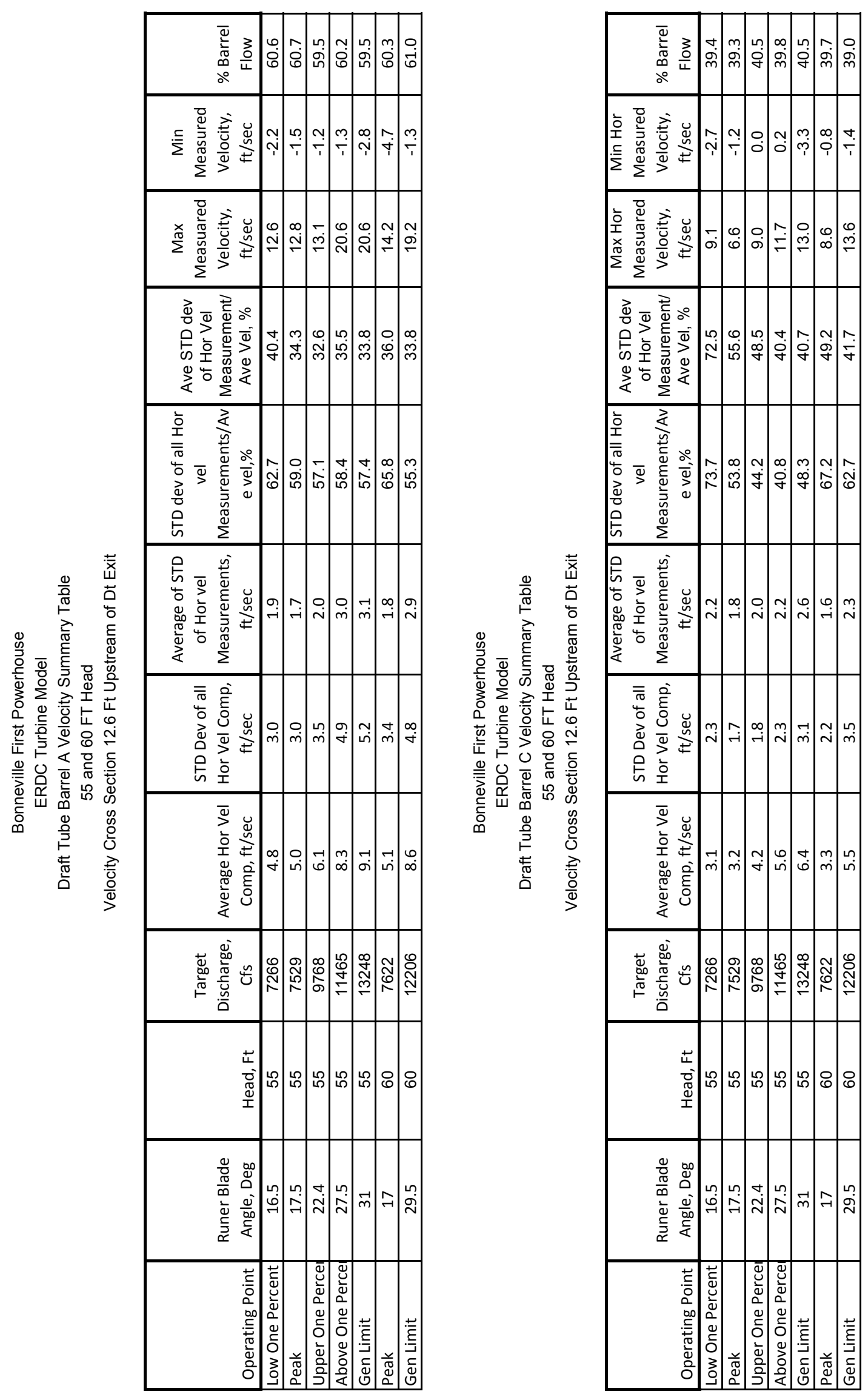

Plate 70 


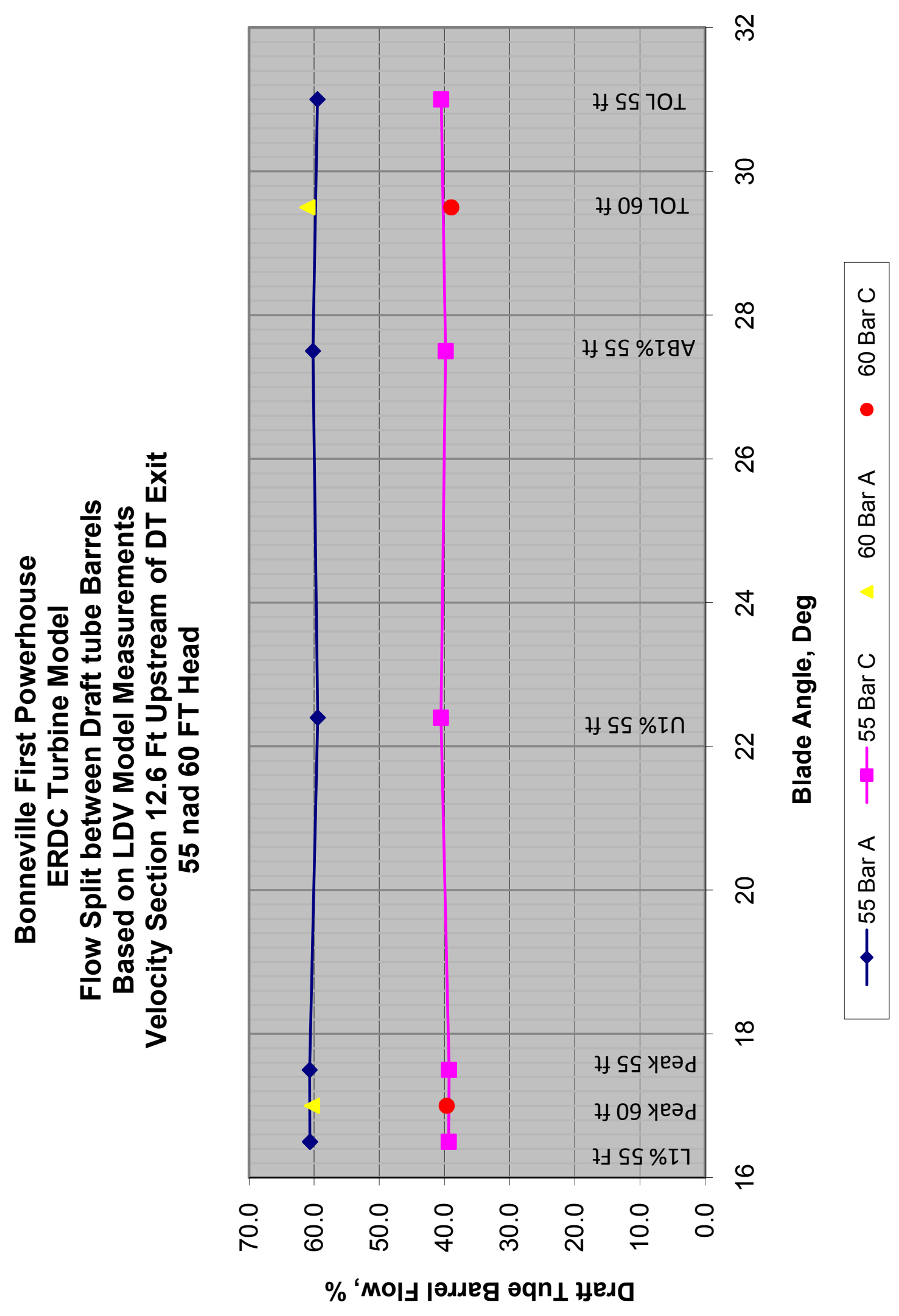

Plate 71 


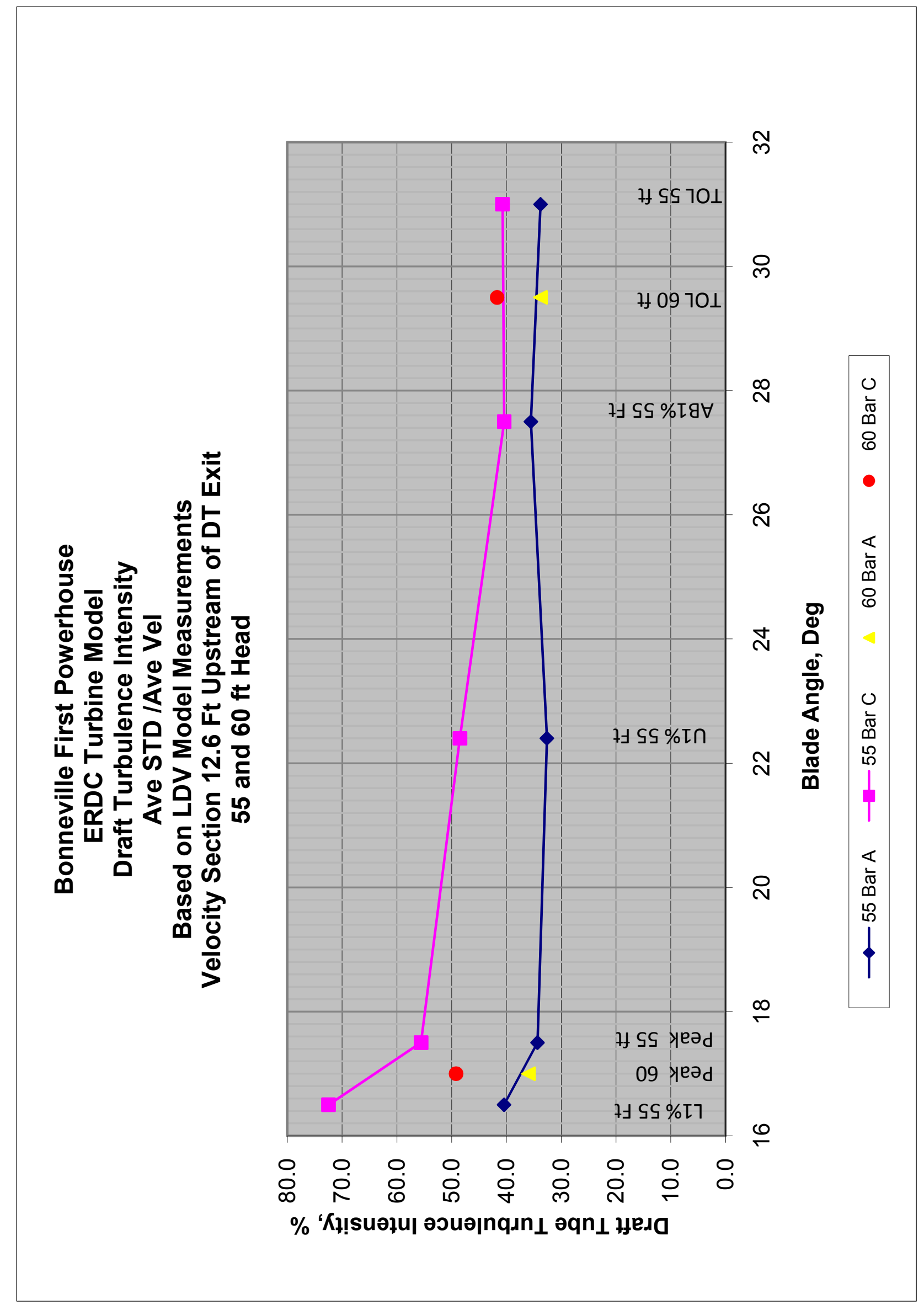

Plate 72 


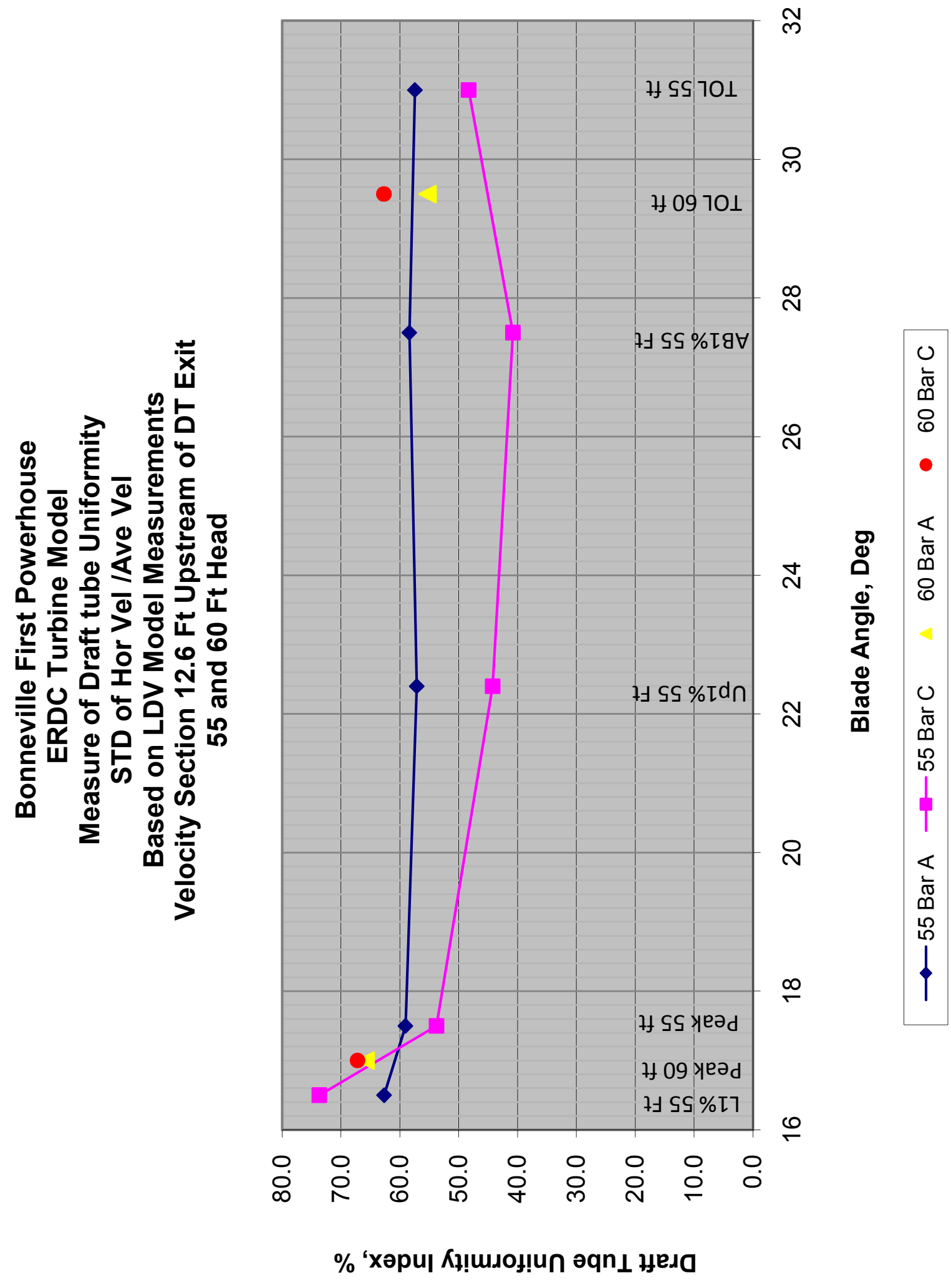

Plate 73 


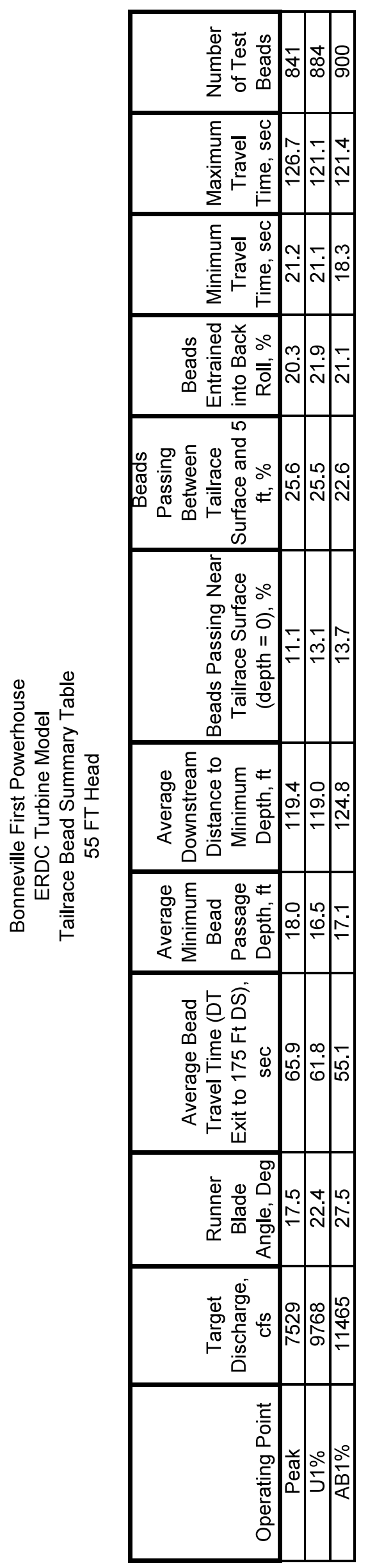




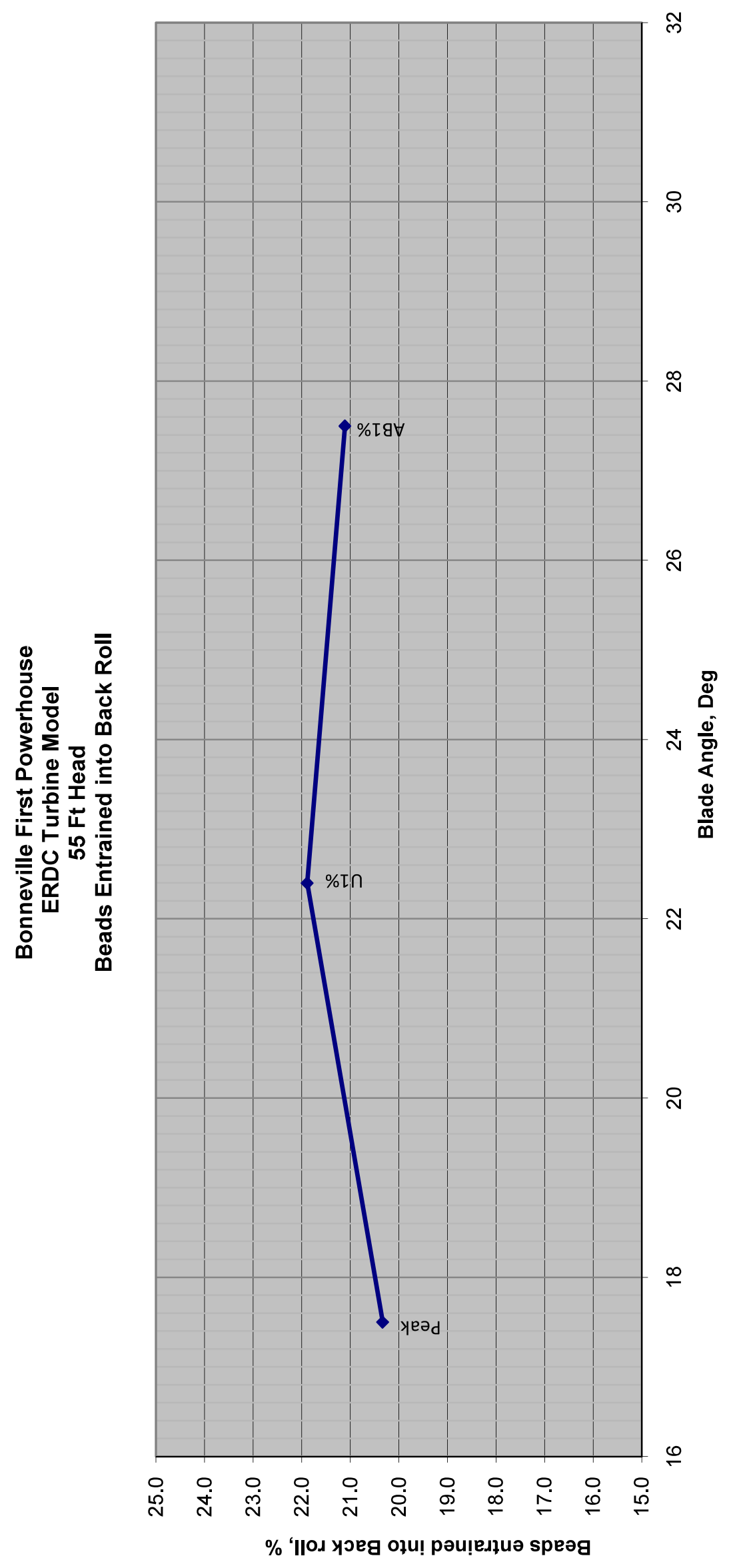

Plate 75 


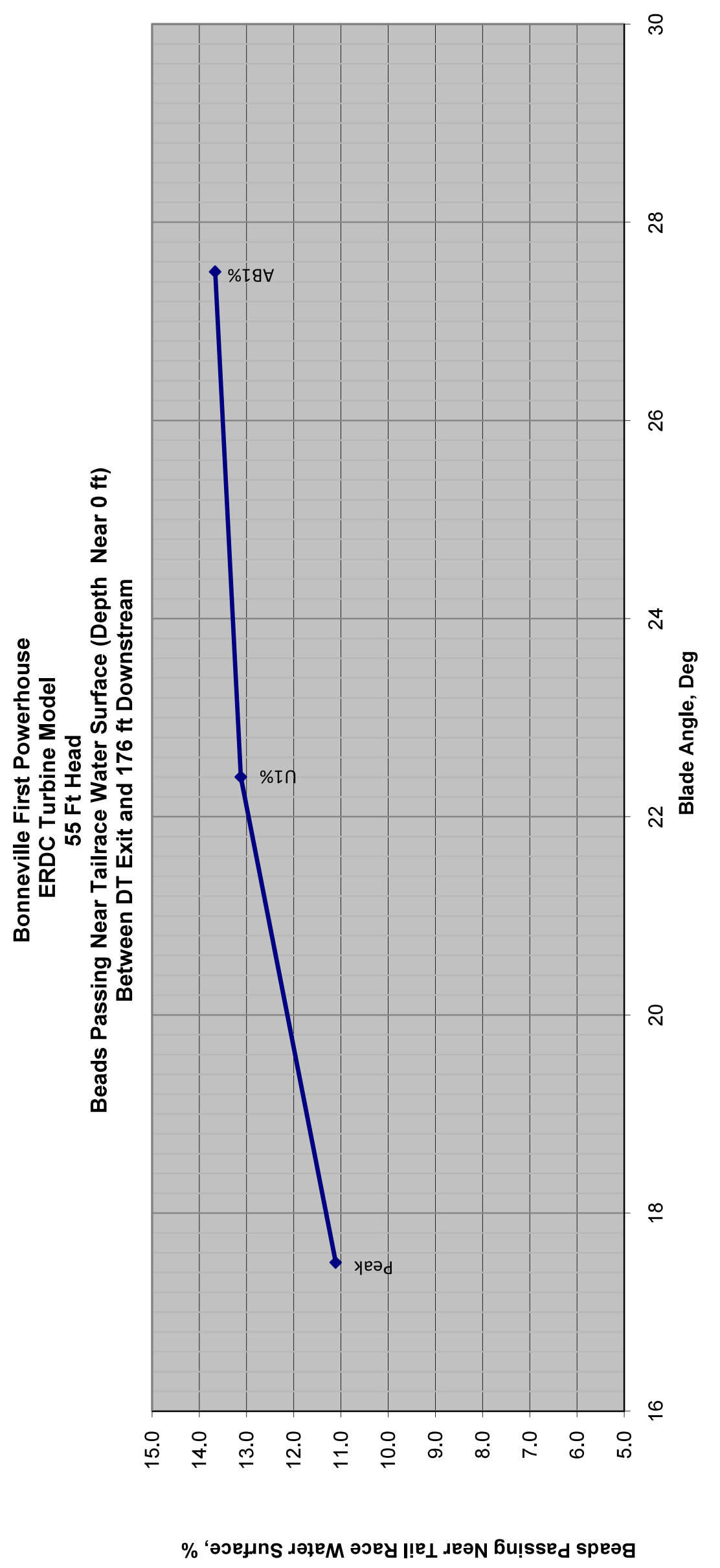

Plate 76 


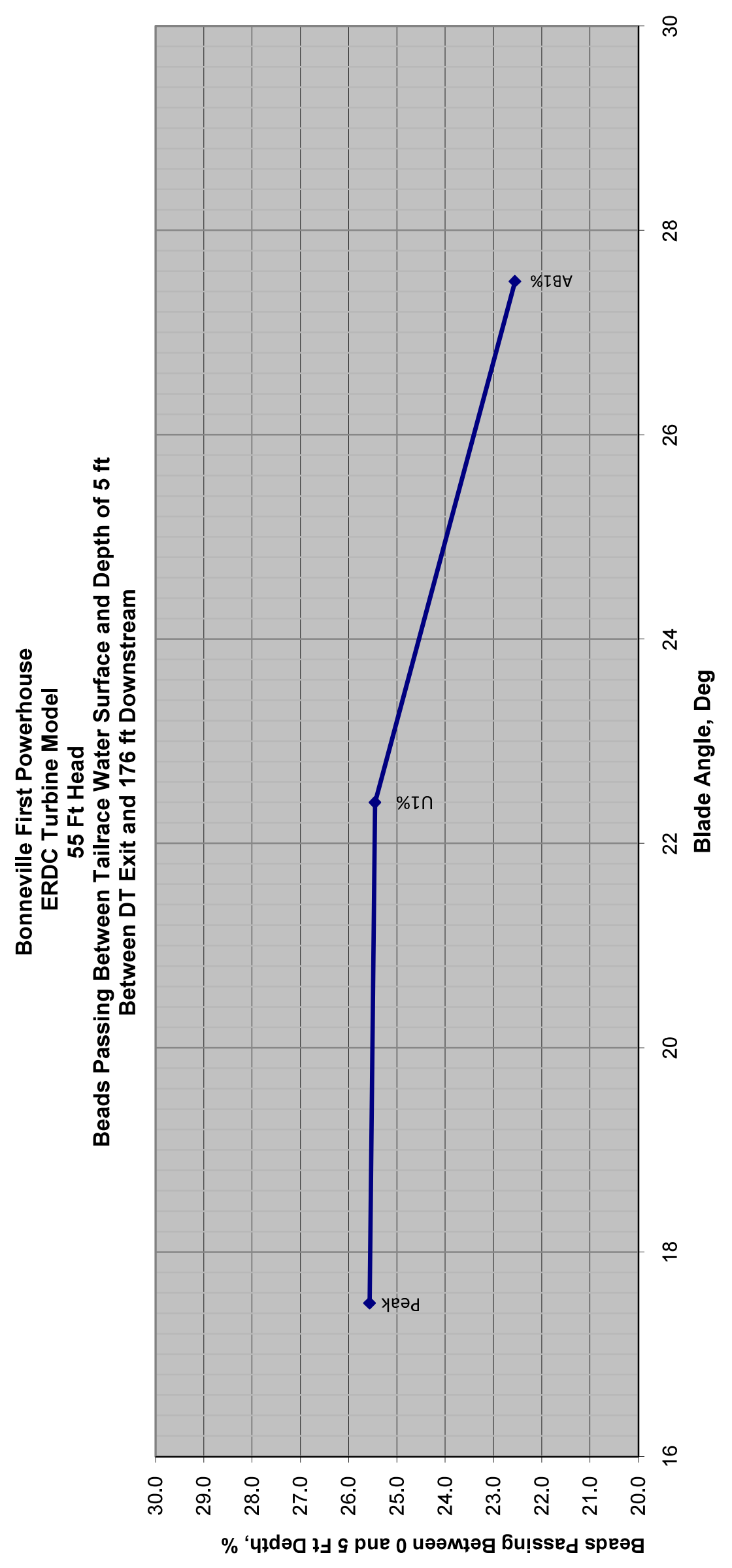

Plate 77 


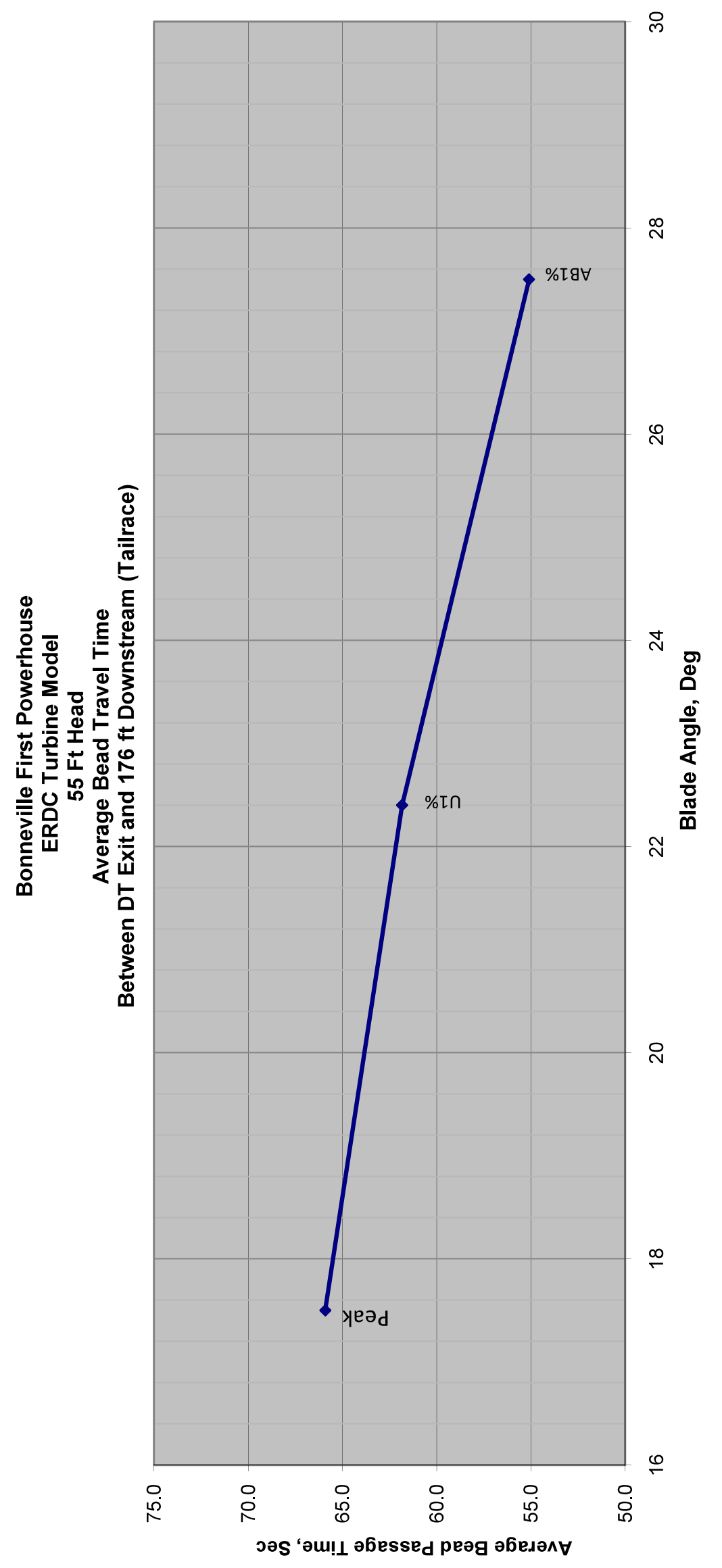

Plate 78 


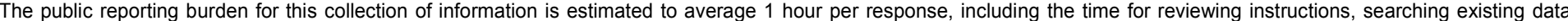

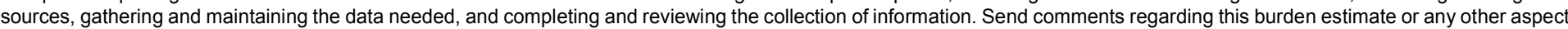

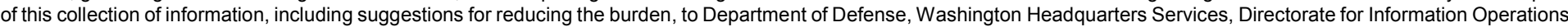

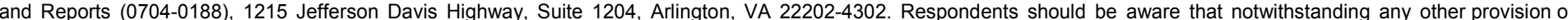
law, no person shall be subject to any penalty for failing to comply with a collection of information if it does not display a currently valid OMB control number.

PLEASE DO NOT RETURN YOUR FORM TO THE ABOVE ADDRESS.

\begin{tabular}{l|l|l}
$\begin{array}{l}\text { 1. REPORT DATE } \\
\text { May } 2017\end{array}$ & $\begin{array}{l}\text { 2. REPORT TYPE } \\
\text { Final }\end{array}$ & 3. DATES COVERED (FrOm - To)
\end{tabular}

\section{TITLE AND SUBTITLE}

Bonneville First Powerhouse ERDC Turbine Operating Range Investigation

5a. CONTRACT NUMBER

5b. GRANT NUMBER

5c. PROGRAM ELEMENT NUMBER

\section{AUTHOR(S)}

Robert A. Davidson

\section{5d. PROJECT NUMBER}

$26480 \mathrm{~A}$

5e. TASK NUMBER

5f. WORK UNIT NUMBER

\section{PERFORMING ORGANIZATION} REPORT NUMBER

U.S. Army Engineer Research and Development Center

Coastal and Hydraulics Laboratory

3909 Halls Ferry Road, Vicksburg, MS 39180-6199

\section{SPONSORING/MONITORING AGENCY NAME(S) AND ADDRESS(ES)}

U.S. Army Corps of Engineers, Portland District

333 SW First Ave.

Portland, OR 97204-3440

\section{DISTRIBUTION/AVAILABILITY STATEMENT}

Approved for public release; distribution is unlimited.

\section{SUPPLEMENTARY NOTES}

\section{ABSTRACT}

As part of the Turbine Survival Program implemented by U.S. Army Corps of Engineers, Portland and Walla Walla Districts in the Northwestern Division, this study investigates all potential fish passage routes through the Bonneville First Powerhouse (B1), minimum gap runner (MGR), and draft tube using a 1:25 physical turbine model. Fish passage at on-cam turbine operations is investigated throughout the complete operating range of the B1 MGR to help determine the target operating range for minimizing turbine effects on fish passing through the B1 powerhouse. Relative effects of blade contact, shear, stay vane and wicket passage, draft tube conditions, and effects on egress were determined across the entire turbine operational range at $55 \mathrm{ft}$ head. This includes operation within and beyond the current $1 \%$ operating zone. Results from these model investigations indicate that that steeper blade angles (BAs) (if operated at peak efficiency for that subject blade angle) provide for better passage conditions for fish. Fewer severe contacts with the turbine runner and less severe change in direction occur at steeper BAs. The draft tube elbow performs better at steeper BAs, and the quality of flow exiting the draft tube is better at steeper BAs. In addition, there are indications that egress conditions may be better at steeper BAs.

\section{SUBJECT TERMS}

Bonneville Dam (Or. And Wash.), Columbia River, Fishes_-Effect of dams on, Fishes_-Migration, Fish populations, Fishways_-Design and construction, Hydraulic turbines - Models, Turbines-Blades-Design and construction

\section{SECURITY CLASSIFICATION OF:}

a. REPORT

Unlimited b. ABSTRACT c. Unlimited
17. LIMITATION OF ABSTRACT

SAR
18. NUMBER OF PAGES

128 19a. NAME OF RESPONSIBLE PERSON Robert A. Davidson

19b. TELEPHONE NUMBER (Include area code) 601-634-3052 